Giovana Jeremias Andrade

\title{
A influência da Corrente de Contorno Oeste \\ Profunda na Circulação de Revolvimento Meridional do Atlântico Sul
}

Dissertação apresentada ao Instituto Oceanográfico da Universidade de São Paulo, como parte dos requisitos para obtenção do título de Mestre em Ciências, Programa de Oceanografia, área de Oceanografia Física.

Orientadora:

Profa. Dra. Olga Tiemi Sato

São Paulo

2019 


\section{UNIVERSIDADE DE SÃO PAULO \\ INSTITUTO OCEANOGRÁFICO}

\section{A influência da Corrente de Contorno Oeste Profunda na Circulação de Revolvimento Meridional do Atlântico Sul}

Giovana Jeremias Andrade

Dissertação apresentada ao Instituto Oceanográfico da Universidade de São Paulo, como parte dos requisitos para obtenção do título de Mestre em Ciências, área de Oceanografia Física.

\section{Versão Corrigida}

Julgada em

Conceito

$\operatorname{Prof}(a) . \operatorname{Dr}(a)$.

Conceito

$\operatorname{Prof(a).~Dr(a).~}$

$\operatorname{Prof(a).~Dr(a).~}$

Conceito 


\section{Agradecimentos}

Em primeiro lugar gostaria de agradecer ao meu marido, Fernando por toda a paciência, compreensão e amor que você teve comigo nesses anos em que realizei o mestrado, não só nesses últimos anos, mas nos 10 anos em que estamos juntos. Você mais do que ninguém sabe o quanto foi árduo e desafiador. Além disso, seus intermináveis conhecimentos matemáticos e ajudas no Latex foram de extrema importância na execução do trabalho. Você é minha inspiração.

Gostaria também de fazer uma agradecimento especial à minha mãe, Zuleide, por todo o carinho e apoio emocional que você me deu, não só nos últimos anos mas durante toda a vida. Você sempre me incentivou e não mediu esforços para que eu sempre pudesse continuar estudando. Sem você eu não conseguiria ter chegado até aqui.

Alba, obrigada por me fazer companhia nesses meses finais. A elaboração da dissertação foi um processo solitário e ter você comigo todos os dias me fazia lembrar o que realmente é importante na vida. Anseio pela hora de te conhecer. Você é meu tudo.

Muito obrigada à minha grande amiga Carolina, sua parceria e companheirismo foram essenciais durante estes últimos anos. Obrigada por sempre acreditar em mim e nunca me deixar desistir. Seu bom humor fez diferença em meus dias. O mundo é pequeno pra gente minha "Luz".

Um muitíssimo obrigada à uma pessoa que eu pude ter o prazer de conhecer durante o mestrado, minha amiga Thaís. Só pelo fato de ter conhecido você e sua família já valeu a pena. Foi um grande prazer dividir o Lab, almoçar no RU e passar raiva com o Latex junto com você. Valeu dupla!

Obrigada aos colegas do LOS pelos cafés, brincadeiras, festinhas e todo o apoio durante esses anos do mestrado. Vocês são incríveis.

Além disso, gostaria de agradecer à minha orientadora, a Profa. Dra. Olga Tiemi Sato, muito obrigada por todos os seus ensinamentos e sua paciência. Você se dedica muito ao seu trabalho e está sempre disposta a tirar o melhor de cada um dos seus alunos. Os seus esforços me fizeram crescer como aluna. Obrigada.

À Fundação de Amparo à Pesquisa do Estado de São Paulo (FAPESP), processo ${ }^{\circ}$ 2017/09859-5 pelo financiamento do projeto de pesquisa, tornando possível a concepção deste trabalho. 


\section{Lista de Figuras}

1 Representação da circulação de revolvimento meridional global (MOC) que inclui o ramo mais quente (vermelho) relacionado à circulação mais superficial, enquanto que os ramos mais frios (azul) são referentes à circulação de camadas inferiores. Adaptado de Rahmstorf 2002. . . . . . . . . . . . . . . . . . . . . . . . . . . . . . . . . . 14

2 Representação esquemática da circulação do Atlântico Sul. As principais correntes do Atlântico Sudoeste são: Corrente das Malvinas (CM), Corrente do Brasil (CB), Corrente do Atlântico Sul (CAS), Corrente Sul Equatorial (CSE), Corrente Norte do Brasil (CNB). Adaptado de Stramma and England (1999). . . . . . . . . . . . . . . 17

3 Seção meridional oceano Atlântico em que as setas representam a MOC. O sombreado colorido mostra um perfil de densidade zonal média, derivado de dados observacionais de Levitus, Burgett, and Boyer (1994) (Adaptado de Kuhlbrodt et al. 2007). . . . . . . . 23

4 Esquema da altura dinâmica em 2500 dbar (linhas em preto), ajustado para estimar a circulação geostrófica absoluta e do percurso da CCOP pelo oceano Atlântico (linhas em vermelho). As recirculações são mostradas pelas linhas hachuradas em vermelho. Adaptado de (Reid 1994). . . . . . . . . . . . . . . . . . . . . . . . . . . . . 25

5 Representação da temperatura da superfície do mar (TSM) no Atlântico Sul obtida através do HYCOM utilizando a média de TSM entre 2005 e 2012, em torno de 2000 m de profundidade. São mostradas as 7 latitudes do Atlântico Sul que foram efetuadas as análises $\left(10^{\circ} \mathrm{S}, 14^{\circ} \mathrm{S}, 18^{\circ} \mathrm{S}, 22^{\circ} \mathrm{S}, 26^{\circ} \mathrm{S}, 30 \mathrm{~s}^{\circ} \mathrm{S}\right.$ e $\left.34.5^{\circ} \mathrm{S}\right)$. Em torno de $21^{\circ} \mathrm{S}$ temos a região da Cadeia Vitória Trindade (CVT). A Bifurcação de Santos acontece em torno de $27^{\circ} \mathrm{S}$, na região da Bacia de Santos $(\mathrm{BS})$, que está localizada entre $23^{\circ} \mathrm{S}$ e $28^{\circ} \mathrm{S}$ e $44^{\circ} \mathrm{We} 48^{\circ} \mathrm{W} \ldots \ldots \ldots \ldots \ldots$

6 Localização de instalação dos instrumentos CPIES (AA e BB) fundeados pelo programa SAMOC no Atlântico Sul entre o período de 2012 e 2014. . . . . . . . . . . . . 32

7 Modelo de ecossonda invertida acoplada com o sensor de pressão (PIES) e correntômetro (CPIES). Figura adaptada de Kennelly, Tracey and Watts (2007). . . . . . . . . 33 
$8 \quad$ Perfis das médias de temperatura para as latitudes de $10^{\circ} \mathrm{S}$ (Painel a), $22^{\circ} \mathrm{S}$ (Painel b) e $34.5^{\circ} \mathrm{S}$ (Painel c), entre as longitudes de $55^{\circ} \mathrm{W}$ e $32^{\circ} \mathrm{W}$ ). As linhas representam o WOA18 (em preto), HYCOM (em azul) e ECCO (em vermelho). A média usada pelo WOA18 é a média decadal total e para ambos os modelos foi usado a média entre agosto de 1992 a julho de 2015 . . . . . . . . . . . . . . . . . . . . . . 43

$9 \quad$ Figura análoga à 8 porém referente aos dados de salinidade. . . . . . . . . . . . . . 44

10 Diferença da média de temperatura nas latitudes $10^{\circ} \mathrm{S}$ (Painéis a,b), $22^{\circ} \mathrm{S}$ (Painéis c,d) e $34.5^{\circ} \mathrm{S}$ (Painéis e,f), entre as longitudes de $55^{\circ} \mathrm{W}$ e $32^{\circ} \mathrm{W}$ ) para o período de 1992 a 2015. Os painéis da esquerda (a,c,e) são referentes ao HYCOM e os painéis da direita $(b, d, f)$ aо ECCO . . . . . . . . . . . . . . . . . . . . . . . 45

11 Figura análoga à 10 porém referente aos dados de salinidade. . . . . . . . . . . . . 46

12 Diferença das temperaturas médias (WOA18-HYCOM) para as latitudes de $10^{\circ} \mathrm{S}, 22^{\circ} \mathrm{S}$ e $34.5^{\circ}$ S para a bacia do Atlântico Sul. . . . . . . . . . . . . . . . . . . . . . . . 48

13 Análogo à Figura 12 porém referente aos dados de salinidade. . . . . . . . . . . . . 49

14 Diferença das temperaturas médias (WOA18-HYCOM) para as latitudes de $10^{\circ} \mathrm{S}, 22^{\circ} \mathrm{S}$ e $34.5^{\circ} \mathrm{S}$ até $32^{\circ} \mathrm{W}$, abaixo da profundidade de $1000 \mathrm{~m}$, isto é, na região da CCOP. . . . 50

15 Análogo à Figura 14 porém referente aos dados de salinidade. . . . . . . . . . . . . 51

16 Seção zonal da média de salinidade do HYCOM nas latitudes $10^{\circ} \mathrm{S}$ (Painel a), $22^{\circ} \mathrm{S}$ (Painel b) e $34.5^{\circ} \mathrm{S}$ (Painel c) entre 1992 e 2015. Contornos em preto indicam os valores de salinidade e os contornos em vermelhos mostram os níveis densidade neutra entre $27,9 \mathrm{~kg} \cdot \mathrm{m}^{-3}$ e $28,10 \mathrm{~kg} \cdot \mathrm{m}^{-3}$, que são correspondentes as características da APAN. 52

17 Velocidade meridional dos CPIES (AA e BB) fundeados pelo programa SAMOC no Atlântico Sul em $34.5^{\circ}$ S. . . . . . . . . . . . . . . . . . . . . . . 54

18 Seções verticais da velocidade meridional $\left(\mathrm{m}^{\mathrm{s}} \mathrm{s}^{-1}\right)$ da CCOP obtidas através do HYCOM nas latitudes de $10^{\circ} \mathrm{S}, 14^{\circ} \mathrm{S}, 18^{\circ} \mathrm{S}$ e $22^{\circ} \mathrm{S}$ do Atlântico sul, no período entre 1992 a 2015. O tracejado (linhas brancas) representa velocidade igual a zero. . . . . . . . . 56

19 Seções verticais da velocidade meridional $\left(\mathrm{m}^{\mathrm{s}} \mathrm{s}^{-1}\right)$ da CCOP obtidas através do HYCOM nas latitudes de $26^{\circ} \mathrm{S}, 30^{\circ} \mathrm{S}$ e $34.5^{\circ} \mathrm{S}$ do Atlântico sul, no período entre 1992 a 2015. O tracejado (linhas brancas) representa velocidade igual a zero. . . . . . . . . 57 
20 Média de velocidade no período de 2005 a 2012 para a profundidade de $2200 \mathrm{~m}$, oriundo da simulação global do modelo HYCOM. A magnitude da corrente é representada pelos vetores de velocidade. . . . . . . . . . . . . . . . . . . 58

21 Velocidade máxima do HYCOM (linha preta) e do ECCO (linha vermelha) em função da latitude $\left(10^{\circ} S, 14^{\circ} S, 22^{\circ} S, 26^{\circ} S, 30^{\circ} S\right.$ e $\left.34.5^{\circ} S\right)$. . . . . . . . . . . . . . . 59

22 Profundidade do centro da CCOP no HYCOM (linha preta) e no ECCO (linha vermelha) em função da latitude $\left(10^{\circ} S, 14^{\circ} S, 22^{\circ} S, 26^{\circ} S, 30^{\circ} S\right.$ e $\left.34.5^{\circ} S\right)$. . . . . . . . . 60

23 Seções verticais da velocidade meridional $\left(\mathrm{m} \cdot \mathrm{s}^{-1}\right)$ da CCOP obtidas através do ECCO nas latitudes de $10^{\circ} \mathrm{S}, 14^{\circ} \mathrm{S}, 18^{\circ} \mathrm{S}$ e $22^{\circ} \mathrm{S}$ do Atlântico sul, no período entre 1992 a 2015. O tracejado (linhas brancas) representa velocidade igual a zero. . . . . . . . . 61

24 Seções verticais da velocidade meridional $\left(\mathrm{m} \cdot \mathrm{s}^{-1}\right)$ da CCOP obtidas através do ECCO nas latitudes de $26^{\circ} S, 30^{\circ} \mathrm{S}$ e $34.5^{\circ} \mathrm{S}$ do Atlântico sul, no período entre 1992 a 2015 . $\mathrm{O}$ tracejado (linhas brancas) representa velocidade igual a zero. . . . . . . . . . . . . . 62

25 Média do transporte de volume da CCOP no período de 1992 a 2006 nas latitudes de $10^{\circ} \mathrm{S}, 14^{\circ} \mathrm{S}, 18^{\circ} \mathrm{S}, 22^{\circ} \mathrm{S}, 26^{\circ} \mathrm{S}, 30^{\circ} \mathrm{S}$ e $34.5^{\circ} \mathrm{S}$ do HYCOM (azul), do ECCO (vermelho) para o período de 1992 a 2006 e por Garzoli et al. (2015) nas latitudes $10^{\circ} \mathrm{S}, 15^{\circ} \mathrm{S}, 20^{\circ} \mathrm{S}$, $25^{\circ} S, 30^{\circ} S$ e $34.5^{\circ} S$ para o período de 1980 a 2006 . . . . . . . . . . . . . . . 67

26 Séries temporais dos valores de transporte de volume da CCOP obtidos através do modelo HYCOM no período de 1992 a 2015 nas latitudes de $10^{\circ} \mathrm{S}$ (Painel a), $14^{\circ} \mathrm{S}$ (Painel b), $18^{\circ} S$ (Painel c) e $22^{\circ} S$ (Painel d) do Atlântico sul. . . . . . . . . . . . . . 70

27 Análogo à Figura 26 , porém referente às latitudes $26^{\circ} \mathrm{S}$ (Painel e), $30^{\circ} \mathrm{S}$ (Painel $\mathrm{f}$ ) e $34.5^{\circ}$ S (Painel g) do Atlântico sul. . . . . . . . . . . . . . . . . . . . . . . . . . . 71

28 Séries temporais dos valores de transporte de volume da CCOP obtidos através do modelo ECCO no período de 1992 a 2015 nas latitudes de $10^{\circ} \mathrm{S}, 14^{\circ} \mathrm{S}, 18^{\circ} \mathrm{S}$ e $22^{\circ} \mathrm{S}$ do Atlântico sul. . . . . . . . . . . . . . . . . . . . . . . 72

29 Análogo à Figura| 28 , porém referente às latitudes $26^{\circ} \mathrm{S}, 30^{\circ} \mathrm{S}$ e $34.5^{\circ} \mathrm{S}$ do Atlântico sul. 73

30 Ciclo anual da CCOP nas latitudes $10^{\circ} \mathrm{S}, 22^{\circ} \mathrm{S}$ e $34.5^{\circ} \mathrm{S}$ obtido pelo HYCOM (Painéis a esquerda) e ECCO (Painéis a direita) no período entre 1992 e 2015. . . . . . . . . . 74 
31 Anomalia do transporte de volume (linhas em vermelho) nas latitudes $10^{\circ} \mathrm{S}$ (Painel a) e $22^{\circ} \mathrm{S}$ (Painel b) e $34.5^{\circ} \mathrm{S}$ (Painel c) entre 1992 e 2015 obtida pelo HYCOM. As linhas em preto representam a anomalia do transporte após a passagem do filtro Hamming de 25 meses. . . . . . . . . . . . . . . . . . . . . . 75

32 Anomalia do transporte de volume (linhas em verde) nas latitudes $10^{\circ} \mathrm{S}$ (Painel a) e $22^{\circ} \mathrm{S}$ (Painel b) e $34.5^{\circ} \mathrm{S}$ (Painel c) entre 1992 e 2015 obtida pelo ECCO. As linhas em preto representam a anomalia do transporte após a passagem do filtro Hamming de 25 meses. . . . . . . . . . . . . . . . . . . . . 76

33 Análise espectral da variância da série temporal de volume integrado da CCOP nas latitudes $10^{\circ} \mathrm{S}$ (Painel a), $22^{\circ} \mathrm{S}$ (Painel b) e $34.5^{\circ} \mathrm{S}$ (Painel c) calculado a partir do HYCOM usando um comprimento de janela de 2 anos com 50\% de sobreposição. . . . 78

$34 \quad$ Anomalia do transporte de volume nas latitudes $10^{\circ} \mathrm{S}$ (Painel a) e $22^{\circ} \mathrm{S}$ (Painel b) e $34.5^{\circ} \mathrm{S}$ (Painel c) entre 1992 e 2015. As linhas em preto são referentes ao HYCOM e as linhas em vermelho da AMOC. . . . . . . . . . . . . . . . . . . . 80

35 Anomalia do transporte de volume nas latitudes $10^{\circ} \mathrm{S}$ (Painel a) e $22^{\circ} \mathrm{S}$ (Painel b) e $34.5^{\circ} \mathrm{S}$ (Painel c) entre 1992 e 2015. As linhas em preto são referentes ao ECCO e as linhas em azul da AMOC. . . . . . . . . . . . . . . . . . . . . . . . . . 81 


\section{Lista de Tabelas}

1 Tabela com os locais, profundidades e datas iniciais de implementação dos instrumentos PIES e CPIES. . . . . . . . . . . . . . . . . . . 32

2 Tabela com os dados utilizados nas estimativas do modelo ECCO. . . . . . . . 36

3 Tabela com as médias e desvios padrão de transporte de volume da CCOP através do HYCOM e ECCO. . . . . . . . . . . . . . . . . . . . . . . . . . . . 63

4 Tabela com as médias e desvios padrões de transporte de volume da CCOP com os resultados obtidos pelo HYCOM, ECCO e por Garzoli et al. (2015), que foi usado como parâmetro para comparação. . . . . . . . . . . . . . . . . 65

$5 \quad$ Valores médios de transporte de volume da CCOP obtidos pelo HYCOM . . . 66

$6 \quad$ Valores médios de transporte de volume da CCOP obtidos pelo ECCO . . . . . 67

7 Variância do transporte de volume da CCOP em faixas de períodos obtidas através do HYCOM para as latitudes $10^{\circ} \mathrm{S}$ (Painel a), $22^{\circ} \mathrm{S}$ (Painel b) e $34.5^{\circ} \mathrm{S}$ (Painel c). . . . . . . . . . . . . . . . . . . 77

8 Variância do transporte de volume da CCOP em faixas de períodos obtidas através do ECCO para as latitudes $10^{\circ} \mathrm{S}$ (Painel a), $22^{\circ} \mathrm{S}$ (Painel b) e $34.5^{\circ} \mathrm{S}$ (Painel c). . . . . . . . . . . . . . . . . . . . 79 


\section{Lista de Siglas}

ASA - Água de Superfície Antártica

ACAS - Água Central do Atlântico Sul

ACI - Água Circumpolar Inferior

ACS - Água Circumpolar Superior

ADCP - Acoustic Doppler Current Profiler

AAF - Água Antártida de Fundo

AIA - Água Intermediaria Antártica

AML - Água do mar de Labrador

AMN - Água dos mares Nódicos

AMOC - Atlantic Meridional Overturning Circulation

APAN - Agua Profunda do Atlântico Norte

APC - Águas Profundas Circumpolares

APCI - Água Profunda Circumpolar Inferior

APCS - Água Profunda Circumpolar Superior

AT - Água Tropical

CA - Corrente das Agulhas

CAS - Corrente do Atlântico Sul

$\mathrm{CB}$ - Corrente do Brasil

$\mathrm{CBg}$ - Corrente de Benguela

CBM - Confluência Brasil-Malvinas

CCA - Corrente Circumpolar Antártica

CCOP - Corrente de Contorno Oeste Profunda

$\mathrm{CM}$ - Corrente das Malvinas

CNB - Corrente Norte do Brasil

CPIES - Current-Pressure Inverted Echo-Sounders

CSE - Corrente Sul Equatorial

CTD - Conductivity, Temperature, and Depth

CVT - Cadeia Vitória-Trindade

ECCO - Estimating the Circulation Climate of the Ocean

ENSO - 1 Niño-Oscilação Sul

FLAME - Family of Linked Atlantic Model Experiments

FOE - Empirical Orthogonal Function

HYCOM - HYbrid Coordinate Ocean Model

LADCP - Lowered Acoustic Doppler Current Profiler

MICOM - Miami Isopycnic-Coordinate Ocean Model

MIT GCM - Massachusetts Institute of Technology's General Circulation Mode

MOC - Meridional Overturning Circulation

OFES - Ocean General Circulation Model For the Earth Simulator

PIES - Pressure Inverted Echo-Sounders

SAMOC - Southwest Atlantic MOC

SEaOS - Southern Elephant Seals as Oceanographic Samplers

TSM - Temperatura da Superfície do Mar

XBT - Batitermógrafo descartável

WOA18 - World Ocean Atlas 2018

WOCE - World Ocean Circulation Experiment 


\section{Sumário}

\begin{tabular}{lll}
\hline 1 & Introdução & 13
\end{tabular}

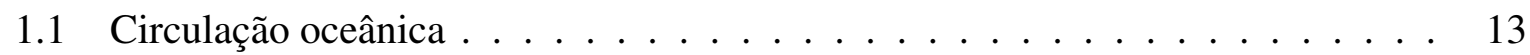

1.2 Circulação no oceano Atlântico Sul $\ldots \ldots$. . . . . . . . . . . . . . . . 16

1.3 Circulação de Revolvimento Meridional no Atlântico . . . . . . . . . . . . . . 20

1.4 Corrente de Contorno Oeste profunda no Atlântico . . . . . . . . . . . . . . . 24

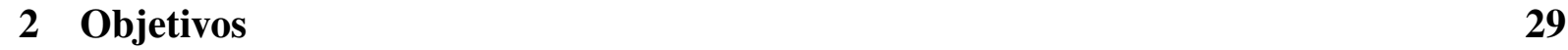

$2.1 \quad$ Objetivos Específicos $\ldots \ldots \ldots$. . . . . . . . . . . . . . . . . . . 29

3 Dados e metodologia 30

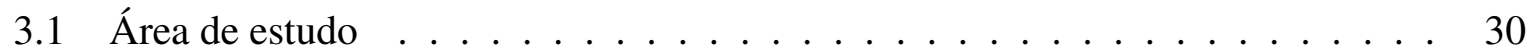

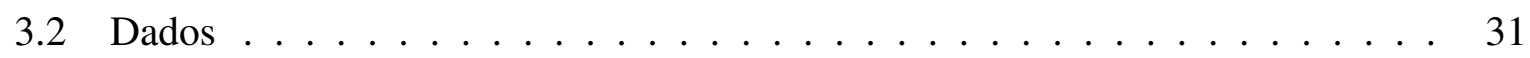

3.3 Dados observacionais $\ldots \ldots \ldots \ldots \ldots$. . . . . . . . . . . . . . 31

3.4 Simulações de Modelos Numéricos . . . . . . . . . . . . . . . . . . . . 33

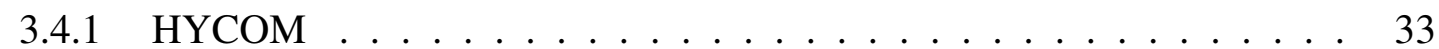

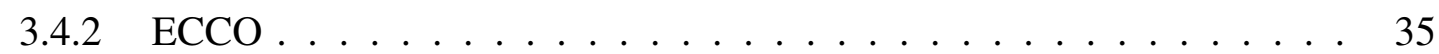

3.5 Temperatura e salinidade climatológica $\ldots \ldots \ldots$. . . . . . . . . 37

3.6 Análise de erro . . . . . . . . . . . . . . . . . . . 37

$3.6 .1 \quad$ Skill Score $\ldots \ldots \ldots$. . . . . . . . . . . . . . . . . 37

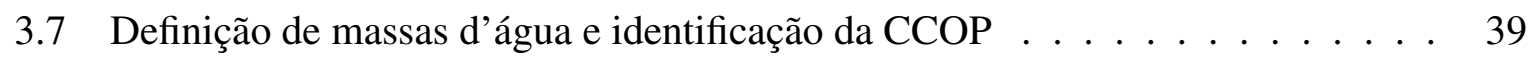

3.8 Cálculo do Transporte de Volume $\ldots \ldots \ldots$. . . . . . . . . . . . . . . . . . . . . . 39

3.9 Variabilidade da CCOP e Análise Espectral $\ldots \ldots \ldots$. . . . . . . . . . . 41

3.10 Correlação da CCOP com a AMOC . . . . . . . . . . . . . . . . . . 41

\begin{tabular}{|lll}
\hline 4 & Resultados e Discussão & 42
\end{tabular}

4.1 Validação dos modelos oceânicos HYCOM e ECCO . . . . . . . . . . . . . . 42 
4.2 Identificação e localização da CCOP . . . . . . . . . . . . . . . . . 52

$4.3 \quad$ Velocidades meridionais obtidas pelos CPIES $\ldots \ldots \ldots \ldots$

4.3 .1 Seções Verticais de velocidade meridional obtidas pelo HYCOM . . . . 53

4.3.2 Seções Verticais de velocidade meridional obtidas pelo ECCO . . . . . 58

4.4 Transporte de Volume $(\mathrm{Sv})$. . . . . . . . . . . . . . . . . . . . . . 63

4.5 Variabilidade da CCOP $\ldots \ldots \ldots \ldots \ldots \ldots$

4.6 Distribuição espectral de energia . . . . . . . . . . . . . . . . . . . . 77

$4.7 \quad$ Correlação entre a CCOP e a AMOC $\ldots \ldots \ldots$. . . . . . . . . . . . . . . 79

\begin{tabular}{|lrl}
\hline 5 & Conclusão & 82
\end{tabular} 


\section{Resumo}

A Corrente de Contorno Oeste Profunda (CCOP) é a corrente responsável em transportar uma porção significativa do volume profundo do Atlântico como parte da Circulação de Revolvimento Meridional (MOC). O objetivo deste trabalho é investigar quais são as escalas dominantes da variabilidade da CCOP, como sua intensidade varia ao longo do contorno oeste do Atlântico Sul e qual é a sua contribuição efetiva na MOC. Foram usados dados de velocidade meridional obtidos pelos correntômetros CPIES que coletaram dados entre 2012 e 2014. Além disso, foram utilizadas as saídas do modelo HYbrid Coordinate Ocean Models (HYCOM) e do Estimating the Circulation \& Climate of the Ocean (ECCO). As análises de ambos os modelos foram no período entre 1992 e 2015 , nas latitudes $10^{\circ} \mathrm{S}, 14^{\circ} \mathrm{S}, 18^{\circ} \mathrm{S}, 22^{\circ} \mathrm{S}, 26^{\circ} \mathrm{S}, 30^{\circ} \mathrm{S}$ e $34.5^{\circ} \mathrm{S}$ entre as longitudes de $55^{\circ} \mathrm{W}$ e $32^{\circ} \mathrm{W}$. O método estatístico SkillScore forneceu os resultados de 0,90 e 0,81 (HYCOM) e 0.93 e 0,92 (ECCO) para temperatura e salinidade, respectivamente. A velocidade média obtida pelo CPIES-AA foi de $2,83 \pm 2,9 \mathrm{~cm} \cdot \mathrm{s}^{-1}$ e $1,48 \pm 1,8 \mathrm{~cm} . \mathrm{s}^{-1}$ pelo CPIES-BB. As velocidades médias obtidas pelo HYCOM no mesmo local foram de $-2,48 \pm 3,5$ $\mathrm{cm} . \mathrm{s}^{-1} \mathrm{e}-1,43 \pm 2,7 \mathrm{~cm} . \mathrm{s}^{-1}$ e pelo ECCO foram de $-1,78 \pm 1,5 \mathrm{~cm} . \mathrm{s}^{-1} \mathrm{e}-0,85 \pm 0,4 \mathrm{~cm} . \mathrm{s}^{-1}$, respectivamente. As médias de transporte de volume integrado da CCOP vão decrescendo ao longo do percurso pelo Atlântico Sul com a CCOP centrada entre 2000 e 2500 m. Através das séries temporais ao longo dos 22 anos de dados, o HYCOM mostrou que somente nas latitudes $10^{\circ} \mathrm{S}$ e $18^{\circ} \mathrm{S}$ existe uma tendência de aumento de transporte de volume de $-0,054 \mathrm{~Sv} /$ ano e $-0,083$ Sv/ano, respectivamente. Quando analisamos o ECCO, observamos em todas as latitudes uma tendência de aumento de transporte, exceto em $30^{\circ} \mathrm{S}$, onde há uma tendência de diminuição do transporte de volume 0,014 Sv/ano. Após as análises, foi identificado um ciclo anual da CCOP. Esse sinal anual foi removido, resultando na anomalia do transporte. Para eliminar os sinais de alta frequência foi aplicado um filtro Hamming de 25 meses nos dados. Os resultados do HYCOM mostraram que as latitudes $10^{\circ} \mathrm{S}$ e $22^{\circ} \mathrm{S}$ apresentaram um padrão de aumento de transporte entre 1995-1998, 2004-2007 e 2009-2012. Em 34.5 $\mathrm{S}$ houve um aumento de transporte entre 1995-1997, 1999-2001, 2003-2004, 2007-2009, e 2011 2014. Pelo ECCO vimos que na latitude $10^{\circ} \mathrm{S}$ houve um aumento de transporte após o ano de 2003 . Em $22^{\circ} \mathrm{S}$ e $34.5^{\circ} \mathrm{S}$ foi visto um aumento de transporte entre 1995 e 1999 e após 2005. A porcentagem da variância explicada pelo período anual ou semestral é aproximadamente 19\% (HYCOM) e 18\% (ECCO) cada. O período de maior concentração de energia foi o mesmo para as 3 latitudes, ou seja, entre 50 e 160 dias para ambos os modelos. A análise espectral da variância do transporte de volume mostrou um pico de energia centrado em torno de 120-160 dias (HYCOM) e 130-160 dias (ECCO) nas 3 latitudes. As análises do HYCOM mostraram que nas latitudes $10^{\circ} \mathrm{S}, 22^{\circ} \mathrm{S}$ e $34.5^{\circ} \mathrm{S}$ a correlação da CCOP com a AMOC foi de $\mathrm{r}=0,7, \mathrm{r}=0,5 \mathrm{e} \mathrm{r}=0,4$, respectivamente. $\mathrm{O}$ ECCO apresentou resultados similares ao HYCOM, no qual a correlação em $10^{\circ} \mathrm{S}$ foi de $\mathrm{r}=-0,7$ e em $22^{\circ} \mathrm{S}$ e $34.5^{\circ} \mathrm{S}$ foi de $\mathrm{r}=-0,4$ (fraca), respectivamente. Deste modo, podemos supor que em $10^{\circ} \mathrm{S}$, quando ocorre um aumento de transporte da CCOP, acontece também um aumento de transporte da AMOC.

Palavras-chave: Corrente de Contorno Oeste Profunda, Circulação de Revolvimento Meridional, Atlântico Sul, CPIES. 


\begin{abstract}
The Deep Western Boundary Current (DWBC) is the oceanic current responsible for the transport of a significant portion of the deep volume of the Atlantic as part of the Meridional Overturning Circulation (MOC). The main objective of this work is to investigate what are the dominant scales of DWBC variability, how its intensity varies along the western boundary of the South Atlantic and what is its effective contribution is to the MOC. Meridional velocity data obtained between 2012-2014 by CPIES current meters were used. In addition, the outputs of the model HYbrid Coordinate Ocean Models (HYCOM) and the Estimating the Circulation \& Climate of the Ocean (ECCO) have been used. The analyzes of both models have been made in the period between $1992-2015$, at latitudes $10^{\circ} \mathrm{S}, 14^{\circ} \mathrm{S}, 18^{\circ} \mathrm{S}, 22^{\circ} \mathrm{S}, 26^{\circ} \mathrm{S}, 30^{\circ} \mathrm{S}$ and $34.5^{\circ} \mathrm{S}$ and between the longitudes of $55^{\circ} \mathrm{W}$ and $32^{\circ} \mathrm{W}$. The results obtained by the statistic model SkillScore were from 0,90 and 0,81 (HYCOM) and 0,93 and 0,92 (ECCO) for temperature and salinity, respectively. The mean velocity obtained from CPIES-AA was $2,83 \pm 2,9 \mathrm{~cm} \cdot \mathrm{s}^{-1}$ and $1,48 \pm 1,8 \mathrm{~cm} \cdot \mathrm{s}^{-1}$ by CPIES-BB. The mean velocity obtained by HYCOM at the same points were $-2,48 \pm 3,5$ $\mathrm{cm} \cdot \mathrm{s}^{-1}$ and $-1,43 \pm 2,7 \mathrm{~cm} \cdot \mathrm{s}^{-1}$ and by ECCO were $-1,78 \pm 1,5 \mathrm{~cm} \cdot \mathrm{s}^{-1}$ and $-0,85 \pm 0,4 \mathrm{~cm} \cdot \mathrm{s}^{-1}$, respectively. The DWBC volume transport integrated average decreases along the course of the South Atlantic with the DWBC centered between 2000 and $2500 \mathrm{~m}$. Over the 22 years of temporal series data, HYCOM showed that only in the latitudes of $10^{\circ} \mathrm{S}$ and $18^{\circ} \mathrm{S}$ there is a tendency of volume transport increase of $-0,054 \mathrm{~Sv} /$ year and $-0,083 \mathrm{~Sv} / y e a r$, respectively, and the other latitudes indicate a tendency of transport reduction. We have seen that as the DWBC moves along the South Atlantic, it loses intensity, variability, as well as its transportation volume. When analyzing the ECCO, we have observed at all latitudes a tendency to transport increase, except at $30^{\circ} \mathrm{S}$, where there is a tendency to volume transport reduction -0,014 Sv/year. After analysis, it was identified a annual cycle of DWBC. The annual signal was removed, resulting in transport anomaly. To eliminate the high frequency signals, a 25 month Hamming filter was applied to the data. The results of HYCOM at the latitudes $10^{\circ} \mathrm{S}$ and $22^{\circ} \mathrm{S}$ showed a pattern of increased transport between 1995-1998, 2004-2007 and 2009-2012. At $34.5^{\circ} \mathrm{S}$ there was an increase in transport between 1995-1997, 1999-2001, 2003-2004, 2007-2009 and 2011-2014. From the ECCO we have seen that at the latitude of $10^{\circ} \mathrm{S}$ there has been an increase in transport after the year 2003. At $22^{\circ} \mathrm{S}$ and $34.5^{\circ} \mathrm{S}$ there was an increase between 1995-1999 and after 2005. The variation percentage explained by the annual or semi-annual period is less than $19 \%$ (HYCOM) and 19\% (ECCO) each. The period of the highest energy concentration was the same for the 3 latitudes, that is, between 50-160 days for both models. The spectral analysis of the variance from the integrated transport volume of DWBC indicates a peak energy centered around 120-160 days (HYCOM) and 130-160 days (ECCO) at 3 latitudes. HYCOM analysis showed that at latitudes $10^{\circ} \mathrm{S}, 22^{\circ} \mathrm{S}$ and $34.5^{\circ} \mathrm{S}$ the correlation between CCOP and AMOC was $\mathrm{r}=0,7, \mathrm{r}=0,5$ and $\mathrm{r}=0,4$, correspondingly. ECCO presented similar results to HYCOM, in which the correlation at $10^{\circ} \mathrm{S}$ was $\mathrm{r}=-0,7,22^{\circ} \mathrm{S}$ and $34.5^{\circ} \mathrm{S}$ was $\mathrm{r}=-0,4$, respectively. We can assume that at $10^{\circ} \mathrm{S}$, when a transport increase of CCOP occurs, a transport increase of the AMOC occurs at the same time.
\end{abstract}

Key Words: Deep Western Boundary Current, Meridional Overturning Circulation, South Atlantic, CPIES. 


\section{Introdução}

\subsection{Circulação oceânica}

A circulação oceânica de larga escala pode ser dividida em duas partes. A primeira é a circulação confinada nos primeiros $500 \mathrm{~m}$ forçada principalmente pelo vento que sopra sobre a superfície do oceano, enquanto a outra é a circulação profunda é governada pelas variações da densidade da água do mar. Esses mecanismos interagem entre si, a qual é de forma nãolinear, uma vez que as correntes são capazes de alterar a distribuição de calor e sal. Entretanto, é importante diferenciar estes mecanismos entre si, principalmente pelos efeitos das mudanças no vento ou dos fluxos de água doce e calor da superfície na circulação (Rahmstorf 2002).

O fluxo meridional de calor nos oceanos é uma variável crucial para entendermos como as trocas entre o oceano e a atmosfera determinam os padrões e governam a variabilidade do sistema climático. A principal fonte de energia que alimenta esse sistema é a radiação solar incidente na superfície. A máxima incidência dessa radiação ocorre na região equatorial, porém em decorrência da esfericidade do planeta, a distribuição dessa energia decresce em direção aos polos. Nos oceanos, as correntes são responsáveis pela distribuição meridional do calor, removendo o excesso de calor do equador e transportando-o em direção aos polos (Sato 2005). Por esse motivo, o gradiente meridional de calor observado nos oceanos se torna mais suave quando comparado com o gradiente esperado devido à incidência da radiação solar. Ou seja, os oceanos transportam e armazenam o calor no seu interior e, portanto, agem como um modulador de uma grande parte de energia disponível no planeta.

Os oceanos são caraterizados como um fluido geofísico de espessura muito fina em relação ao raio da Terra (casca esférica fina) e em rotação e, como tal, os movimentos sobre esse fluido são sujeitos à conservação de vorticidade potencial. Como consequência à vorticidade relativa introduzida pela ação dos ventos na superfície e ao efeito da força de Coriolis, as correntes no lado oeste do oceano são mais intensas do que as do lado leste. As correntes de borda oeste são as responsáveis pela redistribuição de calor em cada bacia oceânica. Essa circulação pode ser observada nas camadas superiores do oceano e constituem a parte da circulação governada pelos ventos (Stommel, Arons, and Faller 1958).

Abaixo da circulação regida pelos ventos existe outra circulação que é controlada por fluxos de densidade. A densidade da água é dependente da temperatura e salinidade. Segundo Rahmstorf (2002), as anomalias anuais da temperatura da superfície do mar (TSM) são indica- 
dores da conexão do efeito do transporte de calor do oceano, com anomalias quentes nas três principais regiões de formação de águas profundas do oceano: o norte do Atlântico (mar de Labrador e mares Nórdicos), o mar de Ross e o mar de Weddell (em amarelo) (Figura 1). As águas próximas da superfície (em vermelho) fluem para essas três regiões principais de formação de águas de fundo e recirculam em profundidade. A combinação das duas circulações é conhecida como a circulação de revolvimento meridional (MOC, sigla do inglês Meridional Overturning Circulation).

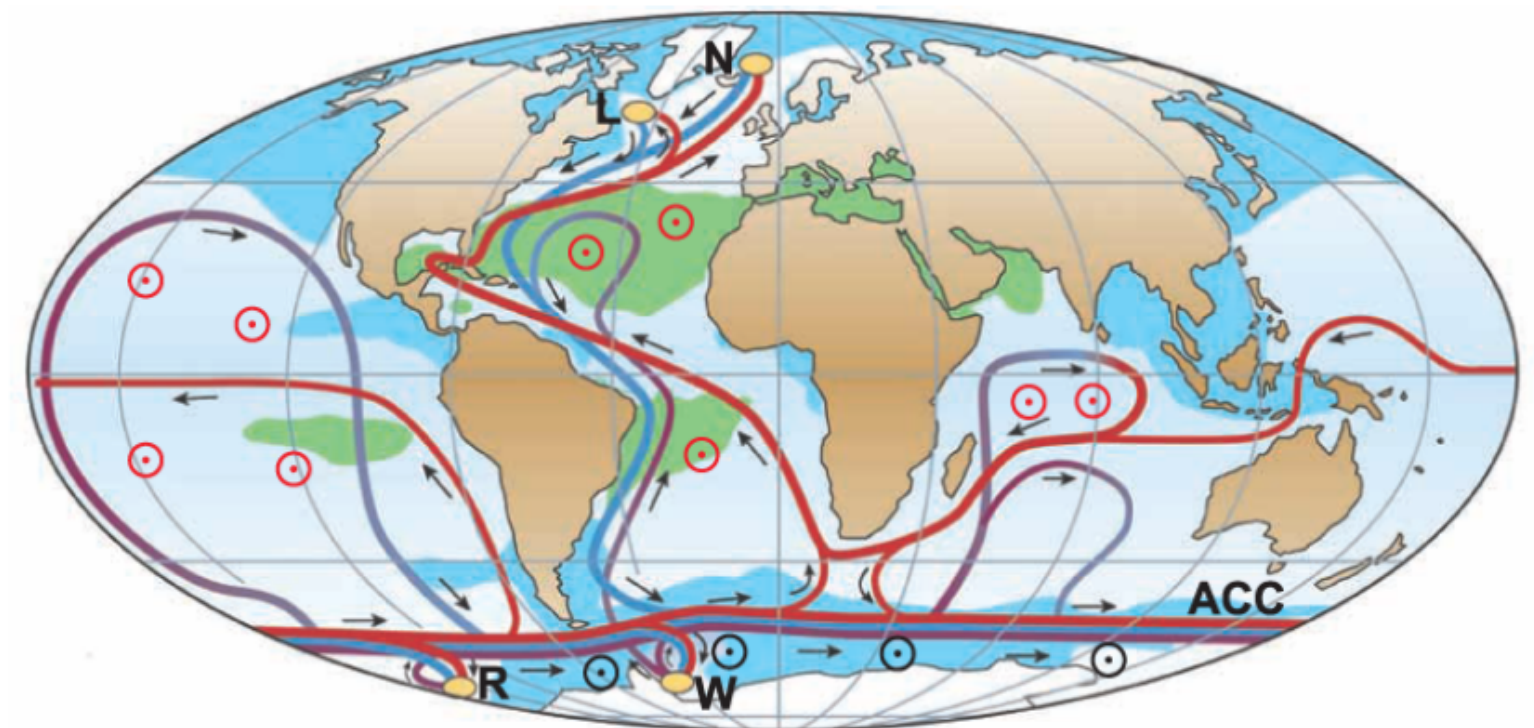

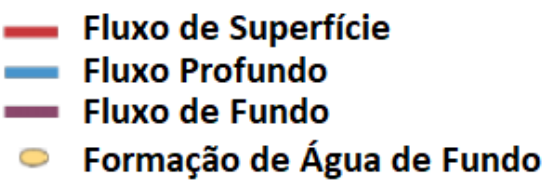

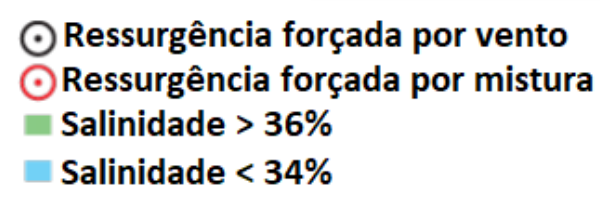

\section{Mar de Labrador \\ N Mares Nórdicos \\ W Mar de Weddell \\ R Mar de Ross}

Figura 1. Representação da circulação de revolvimento meridional global (MOC) que inclui o ramo mais quente (vermelho) relacionado à circulação mais superficial, enquanto que os ramos mais frios (azul) são referentes à circulação de camadas inferiores. Adaptado de Rahmstorf 2002.

As alterações das médias zonais de TSM não estão relacionadas somente com a circulação. A magnitude da anomalia quente do norte do Atlântico Norte $\left(\sim 10^{\circ} \mathrm{C}\right)$ está de acordo com estimativas (Rahmstorf 1994) e simulações de modelos climáticos (Manabe and Stouffer 1988; Vellinga and Wood 2002) do efeito de transporte de calor oceânico. Os fluxos de superfície de calor, água doce e momento, assim como a gravidade e as marés impulsionam as águas oceânicas, diretamente ou através de processos intermediários, como ondas por exemplo (Kuhlbrodt et al. 2007).

A dinâmica do oceano profundo foi inicialmente explicada através de conceitos de conservação de vorticidade potencial (Stommel et al.1958; Stommel and Arons 1960a,b). O modelo 
conceitual propunha que o mar da Groenlândia seria uma região de formação de água profunda e que portanto, deveria existir um escoamento profundo em direção ao sul, bordeando a margem oeste do Atlântico. Esse volume de água preencheria a camada inferior do oceano, e causaria o soerguimento da interface entre essa camada e a camada superior, se não houver difusão turbulenta descendente. Este soerguimento causaria o estiramento das colunas de água no oceano profundo que, por consequência, requereria um deslocamento das colunas de água em direção aos polos, para conservar a vorticidade potencial.

Usando um modelo do padrão de circulação em bacias oceânicas, Stommel and Arons (1960) consideraram a existência de duas regiões de formação de massas de água abissais, uma no Atlântico Norte e outra no mar de Weddel. Além disso, deveria existir um fluxo de compensação de águas das zonas profundas em direção às camadas de superfície.

No Atlântico, ainda segundo a Figura 1, águas mais quentes e mais salinas fluem ao longo de todo o oceano Austral em direção ao mar de Labrador e mares Nórdicos. Por outro lado, não há formação de águas profundas no Pacífico Norte, uma vez que suas águas superficiais são menos salinas, e para que haja o afundamento das águas, é necessário que ocorra uma aumento de densidade, seja por resfriamento ou por um aumento em salinidade. As águas profundas formadas no oceano Austral se tornam mais densas e, portanto, espalham-se em níveis mais profundos do que do Atlântico Norte (Tomczak 2000).

As regiões polares e sub-polares são muito importantes para circulação termoalina dos oceanos, pois é observada na superfície águas mais frias e mais salinas. Devido à perda de calor do oceano para a atmosfera, ocorrem processos de mistura convectiva profunda e, com isso, as águas de superfície ficam mais frias e, portanto, mais densas, sendo capazes de afundar (Tomczak 2000). Deste modo, o oceano Atlântico desempenha um papel fundamental na formação da água que preenche o fundo dos oceanos e na sua recirculação em direção às outras bacias oceânicas. No Atlântico Sul, além da formação de água de fundo, o fluxo de água segue em direção ao Índico e Pacífico, e também recebe o fluxo de retorno das águas aquecidas pela superfície (Talley et al. 2011).

Ainda é necessário que haja mais estudos para a compreensão de como a variabilidade natural da circulação afeta variabilidade da superfície oceânica. Variações da circulação termohalina no Atlântico em escalas de tempo decadais são observadas em diversos modelos climáticos acoplados, com uma amplitude típica de poucos Sverdrups, sendo que elas são provavelmente oscilações amortecidas impulsionadas por variações estocásticas nos fluxos de 
superfície (isto é, variabilidade climática) (Delworth, Manabe, and Stouffer 1993).

A região do continente Antártico é diferenciada pois é isolada de outras regiões da Terra pelo oceano Austral e a Corrente Circumpolar Antártica, ao passo que a estrutura oceânica nas regiões do norte é determinada pelas interações entre as águas do Atlântico Norte e as de origem Ártica. As massas de águas profundas formadas em altas latitudes são sujeitas a uma forte influência de outras massas de água (Água Profunda Circumpolar Superior, Água Profunda Circumpolar Inferior, Água Intermediária Antártica) e intensa mistura com a Água Mediterrânea, que é da mesma densidade, resultando na formação do principal indicador diferencial desta água identificado como máxima salinidade (Morozov et al. 2010).

As condições de formação das águas no oceano Ártico são semelhantes às da região Antártica, entretanto, as águas densas que ocupam a camada inferior do Oceano Ártico ocupam regiões intermediárias devido à profundidade da região ser inferior a $1000 \mathrm{~m}$. Isto significa que apenas águas intermediárias do oceano Ártico são capazes de circular pelo Atlântico e, portanto, todas as águas da camada inferior do Atlântico têm uma componente de origem Antártica (Talley et al. 2011). A massa de água recém formada se propaga para sul a profundidades maiores que 1500 m, e no oceano Austral, é advectada por correntes para todos os oceanos. Deste modo, por causa dessa propagação de águas profundas mais frias, é necessário que haja um transporte compensador com águas mais quentes nas camadas superiores dos oceanos Pacífico e Índico de volta para Atlântico (Morozov et al. 2010).

\subsection{Circulação no oceano Atlântico Sul}

No Atlântico Sul, a circulação de grande escala nos primeiros 1000 m é um giro anticiclônico conhecido como giro subtropical do Atlântico Sul. Segundo Stramma and England (1999), o giro é delimitado ao sul pela Corrente do Atlântico Sul (CAS), que flui para leste em direção à África, onde parte do fluxo contribui para a Corrente de Benguela (CBg), que escoa para norte. A Corrente Sul Equatorial (CSE), que forma o limite norte do giro subtropical, é uma extensa corrente que escoa desde o sul do continente africano, a partir da $\mathrm{CBg}$, até a costa brasileira. Ao atingir a margem continental, por volta de $10^{\circ} \mathrm{S}$, a CSE divide-se em Corrente do Brasil (CB) e Corrente Norte do Brasil (Talley 2003).

A CB flui para sul como uma corrente rasa e quente e torna-se mais profunda em latitudes mais altas ao longo da costa do Brasil, em aproximadamente $28^{\circ} \mathrm{S}$ (Silveira et al. 2000). $\mathrm{A} C B$ se separa da costa próximo à latitude em que se encontra a Corrente das Malvinas (CM), 
em $38^{\circ}$ S, região conhecida como Confluência Brasil-Malvinas (CBM) (Peterson and Stramma 1991). O giro também é influenciado pela Corrente Circumpolar Antártica (CCA) e Corrente das Agulhas (CA), que introduz águas do oceano Índico no Atlântico, porém parte desse fluxo retorna devido à retroflexão da corrente (Peterson and Stramma 1991) (Figura2).

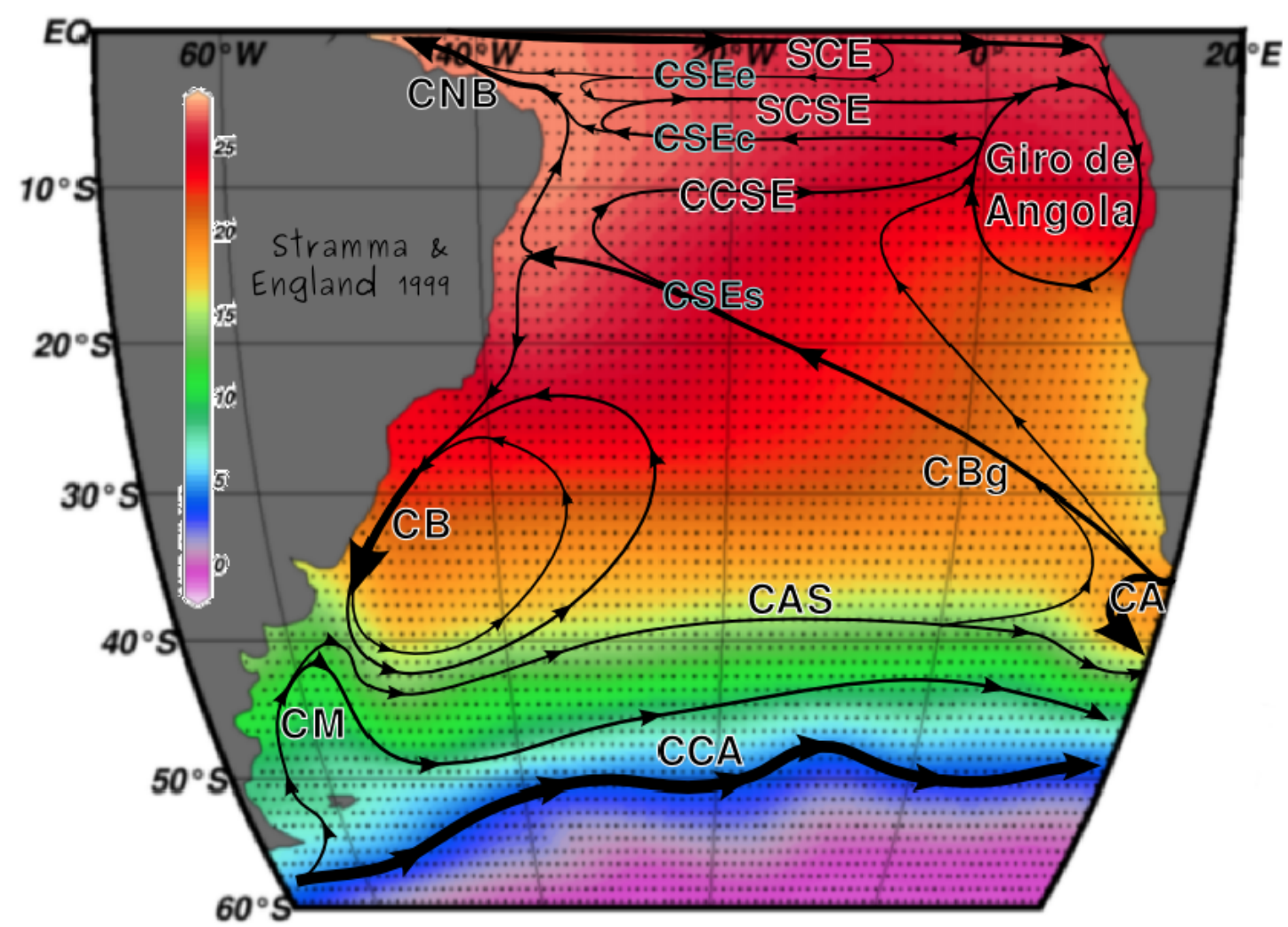

Figura 2. Representação esquemática da circulação do Atlântico Sul. As principais correntes do Atlântico Sudoeste são: Corrente das Malvinas (CM), Corrente do Brasil (CB), Corrente do Atlântico Sul (CAS), Corrente Sul Equatorial (CSE), Corrente Norte do Brasil (CNB). Adaptado de Stramma and England (1999).

Conforme Stramma and England (1999), a circulação do Atlântico Sul está associada ao transporte de determinadas massas de água: a Água Tropical (AT) na superfície, a Água Central do Atlântico Sul (ACAS) na camada da picnoclina, a Água Intermediaria Antártica (AIA) e Água Circumpolar Superior (ACS) na camada intermediária e Água Profunda do Atlântico Norte (APAN) e a Água Circumpolar Inferior (ACI) na camada profunda.

A AT é caracterizada como uma massa superficial e de água quente e salina presente nas camadas superiores do Atlântico Sul, cuja a formação está relacionada com a intensa radiação e ao excesso de evaporação em relação à precipitação, característicos do Atlântico Sul tropical. Essa massa de água flui para o sul sendo transportada pela CB e se mistura com águas de origem costeira mais frias e de baixa salinidade (Cirano et al. 2006). Ela é composta por temperaturas maiores que $20^{\circ} \mathrm{C}$ e salinidade acima de 36 (Silveira et al. 2000). 
Abaixo da camada de AT, observa-se a ACAS, que é encontrada fluindo na região da picnoclina, com temperaturas entre $5^{\circ} \mathrm{C}$ e $8{ }^{\circ} \mathrm{C}$ e salinidades entre 34,3 e 35,8 (Emery 2001). Segundo Silveira et al. (2000), a ACAS se incorpora no giro subtropical, circula com as correntes CAS e CBg e atinge a costa da América do Sul transportada pela CSE. A ACAS sofre uma bifurcação em torno de $22^{\circ} \mathrm{S}$ (Reid 1989; Stramma and England 1999) em que parte flui em direção ao equador como a CNB em superfície e Subcorrente Norte do Brasil em subsuperfície, enquanto outra porção vai para sul como a CB (Silveira et al. 2000).

Subjacente à ACAS, encontra-se a AIA, que é uma massa d'água bem definida em níveis de subpicnoclina que flui em direção do equador em torno de $25^{\circ} \mathrm{S}$ e para sul em $28^{\circ} \mathrm{S}$ (Muller, Zangenberg, and Nonato 1998). Entre latitudes $25^{\circ} \mathrm{S}$ e $40^{\circ} \mathrm{S}$ a AIA faz parte do giro subtropical (Silveira et al. 2000). Além disso, ela é caracterizada pelos limites termohalinos de $2{ }^{\circ} \mathrm{C}$ e $6{ }^{\circ} \mathrm{C}$ para temperatura e 33,8 e 34,8 para salinidade (Emery 2001). A AIA também possui contribuições da Água Modal Subantártica, que se origina da convecção profunda de inverno ao longo do Zona Subantártica (Piola and Matano 2001).

Abaixo da AIA, encontra-se as massas de águas pertencentes às camadas profundas do oceano. A Água Profunda do Atlântico Norte (APAN) têm origem nas altas latitudes do oceano Atlântico Norte, de onde se espalham para o sul ao longo do continente americano, sendo a principal fonte de ventilação abaixo da termoclina principal (Piola and Matano 2001). Ela é caracterizada por valores de densidade neutra entre $27,90 \mathrm{~kg} \cdot \mathrm{m}^{-3}$ e $28,10 \mathrm{~kg} \cdot \mathrm{m}^{-3}$ e salinidade abaixo de 34,8 entre 34,6 e 35, ocupando níveis entre 2000 e 3500 m Atlântico Sul (Preu et al. 2013). De modo geral, as águas profundas do Atlântico Norte são quentes, salinas, ricas em oxigênio e nutrientes, enquanto as do Atlântico Sul são mais frias, menores em salinidade e oxigênio e maiores em nutrientes (Giresse 2007).

A APAN se desloca através de um escoamento organizado conhecido como a Corrente de Contorno Oeste Profunda (CCOP), que transporta massas de águas frias recém ventiladas do norte do Atlântico Norte para o Atlântico Sul através do contorno oeste da bacia (Bower and Hunt 2000). Deste modo, a CCOP é a principal corrente que transporta uma porção considerável de águas mais frias pela MOC e, portanto, um componente importante no balanço de calor global (Meinen et al. 2017). Ela flui em direção ao sul como uma corrente de borda oeste ao longo do lado leste da margem continental americana, cruza o equador e eventualmente se incorpora à CCA no oceano Austral. A partir dessa região, a água profunda escorre em direção ao oceano Índico e Pacífico e eventualmente retorna à superfície (Garzoli et al. 2015). 
As Águas Profundas Circumpolares (APC) são encontradas entre $800 \mathrm{~m}$ e $1000 \mathrm{~m} \mathrm{e}$ como são oriundas da APAN, são ricas em nutrientes. Entretanto, ao longo do seu percurso pela região da Antártica, ela sofre diversas misturas e suas concentrações de salinidade e oxigênio são reduzidas. Sendo assim, a APC possui um máximo relativo de salinidade, e no núcleo, sua salinidade é menor que a da APAN (Piola and Matano 2001). É por este motivo que no Atlântico Sul, a APAN divide a APC em duas camadas: a APC superior, que também é conhecida como Água Profunda Circumpolar Superior (APCS) e a APC inferior, denominada Água Profunda Circumpolar Inferior (APCI). Segundo Preu et al. (2013), a APCS pode ser classificada como a massa d'água que possui densidade neutra entre $27,75 \mathrm{~kg} \cdot \mathrm{m}^{-3}$ e $27,90 \mathrm{~kg} \cdot \mathrm{m}^{-3}$ e oxigênio dissolvido abaixo de 4,5 mL. $\mathrm{L}^{-1}$ e a APCI entre $28,06 \mathrm{~kg} \cdot \mathrm{m}^{-3}$ e $28,20 \mathrm{~kg} \cdot \mathrm{m}^{-3}$ e salinidade abaixo de 34,8 .

As águas abissais dos oceanos no hemisfério sul são derivadas das altas latitudes do sul e são geralmente chamadas de Água Antártida de Fundo (AAF). No Atlântico Sul, a AFA é caracterizada com temperatura potencial $(\theta)$ menor que $0{ }^{\circ} \mathrm{C}$ (Preu et al. 2013). A AFA é mais densa e fria do que as águas próximas à região da Passagem de Drake e essa massa de água forma-se no mar de Weddell como o produto da água muito fria, densa e menos salina. Ela segue pela plataforma continental e, por suas características, ela afunda e encontra a APAN que aflora e acrescenta um pouco de salinidade a água fria e menos salina, tornando-a ainda mais densa (Morozov et al. 2010). A característica de temperatura mínima da AFA vem do fato de que na formação dessa massa de água na plataforma continental Antártica, ocorre o congelamento de parte das águas (Tomczak and Large 1989).

Incorporado ao giro subtropical, as águas mais superficiais circulam pela região sudeste da Bacia do Brasil e fluem para oeste (Stramma and England 1999) enquanto que, em maiores profundidades, as massas de água profundas APAN e AFA, têm uma dinâmica mais complexa, uma vez que elas se bifurcam e recirculam em diversas latitudes do Atlântico sul (Reid 1989). O giro subtropical do Atlântico Sul leva as águas das camadas superiores em direção ao Atlântico Norte, e na região do mar de Labrador e mares Nórdicos, essas águas sofrem processos de mistura e se tornam mais densas, e por consequência afundam e se tornam parte da MOC. Este fluxo que entra no Atlântico Sul para se incorporar ao giro subtropical é originário tanto do oceano Índico, via a corrente das Agulhas, assim como, através da Passagem de Drake, advindo ao oceano Pacífico (Talley et al. 2011). 


\subsection{Circulação de Revolvimento Meridional no Atlântico}

A circulação de revolvimento meridional do Atlântico (AMOC, sigla do inglês Atlantic Meridional Overturning Circulation) possui papel fundamental no clima da Terra, uma vez que, exerce um forte controle sobre a estratificação e distribuição de massas de água, quantidade de calor que é transportada pelo oceano e o ciclo e armazenamento de espécies químicas como o dióxido de carbono no mar profundo (Diz and Barker 2015). No Atlântico Norte, o transporte máximo de calor para o norte é de cerca de 1015 W (Trenberth and Caron 2001), contribuindo para o clima predominante no noroeste da Europa.

Timmermann et al. (2005) investigaram o impacto de uma redução da MOC no Atlântico Norte induzida por água doce na profundidade da termoclina do Pacífico e sua possível consequência na variabilidade do El Niño-Oscilação Sul (ENSO), usando um modelo global acoplado oceano-atmosfera-gelo (ECBILT-CLIO) e o modelo ENSO intermediário, respectivamente. Os autores verificaram que uma redução na AMOC implica em uma redução da variabilidade do ENSO devido a um aprofundamento da termoclina do Pacífico tropical. Além disso, o fluxo de calor da AMOC interfere na posição atual da Zona de Convergência Intertropical ao norte do equador (Donohoe et al. 2013).

Schmittner (2005) usou um modelo acoplado ecossistema-clima e verificou que a produtividade oceânica global é sensível às mudanças da AMOC, pois uma perturbação pode levar à um colapso dos estoques de plâncton no Atlântico Norte para menos da metade de sua biomassa inicial, devido ao rápido acúmulo das camadas de mistura do inverno e sua separação associada aos nutrientes presentes no oceano profundo. Levermann et al. (2005) usaram o modelo CLIMBER-3 $\alpha$ para investigar mudanças no nível do mar devido ao enfraquecimento da MOC e mostraram que a magnitude deste efeito dinâmico pode alcançar localmente até $\sim 1 \mathrm{~m}$, dependendo da força inicial da MOC. Estudos recentes forneceram evidências paleo-oceanográficas de que a convecção profunda do Mar de Labrador e a AMOC têm sido anomalamente fracos nos últimos 150 anos em comparação com os 1.500 precedentes anos (Thornalley et al. 2018; Caesar et al. 2018).

Caesar et al. (2018) analisaram os dados do modelo climático e TSM e forneceram evidências de um enfraquecimento da AMOC em cerca de $3 \pm 1 \mathrm{~Sv}$ (cerca de 15\%) desde meados do século XX. O padrão de TSM encontrado pode ser explicado por uma desaceleração na AMOC e redução do transporte de calor para o norte, bem como um desvio associado ao norte 
da corrente do Golfo. Thornalley et al. (2018) pressupõe que quando o Atlântico Norte começou a aquecer perto do final do século XIX, a água doce interferiu no sistema da AMOC. As geleiras do mar Ártico e seus arredores começaram a derreter, formando uma enorme torneira natural de água doce que adentrou no Atlântico Norte. Esse enorme influxo de água doce diluiu a água do mar da superfície, tornando-a mais leve e menos capaz de afundar, desacelerando o sistema AMOC. É interessante notar que o fator comum entre esses dois períodos de enfraquecimento da AMOC (final do século XIX e nas últimas décadas) é que ambos foram tempos de aquecimento e derretimento. Thornalley et al. (2018) prevêem que o aquecimento e o derretimento continuem no futuro devido às contínuas emissões de dióxido de carbono.

A AMOC é considerada como um elemento chave no entendimento do clima em função de seu fluxo de calor meridional. As águas superficiais que fluem para o norte são quentes e salgadas, e no Atlântico Norte liberam calor para a atmosfera. Enquanto isso, as as águas mais frias afundam a grandes profundidades e seguem até a Antártida (Lynch-Stieglitz et al. 2007). Devido à sua relevância para o clima global, a AMOC tem sido um importante foco de pesquisa há muitos anos. No entanto, o entendimento de como e quais os mecanismos físicos impulsionam o sistema da AMOC ainda não foi totalmente compreendido (Kuhlbrodt et al. 2007).

A CCOP é a corrente responsável em transportar uma porção significativa do volume profundo do Atlântico como parte da MOC, uma vez que o fluxo na porção profunda do Atlântico em direção ao sul é compensado por um fluxo mais superficial em direção ao norte e juntos integram a MOC do Atlântico (Molinari et al. 1998). Por este motivo, a variabilidade observada na CCOP tem um impacto importante no fluxo meridional de calor, água doce e volume através do Atlântico, que por sua vez será notável em escalas regionais e global na forma de mudanças climáticas.

As variações da AMOC e da CCOP e suas conexões já vem sendo estudadas a um certo tempo, principalmente no Atlântico Norte (Meinen et al. 2013; Frajka-Williams et al. 2016). Entretanto, Garzoli et al. (2013) ressaltaram que trabalhos teóricos e modelos numéricos sugeriram que variações no Atlântico Sul são de extrema importância para a estabilidade e fluxo da AMOC. Weijer et al. (2002) com o uso de modelos numéricos, sugeriram que as trocas inter-oceânicas no Atlântico Sul podem alterar significativamente a resposta da MOC a longo prazo.

Com o intuito de compreender a variabilidade do transporte de calor meridional do 
Atlântico Sul, Garzoli and Baringer (2007) utilizaram transectos com batitermógrafos descartáveis (XBT) na camada superior do oceano, afim de obter perfis de temperatura e salinidade. Foi observado que o fluxo total de calor apresenta significativa variabilidade interanual com apenas um pequeno ciclo anual. No trabalho de Hummels et al. (2015), através medições in situ contínuas em $11^{\circ} \mathrm{S}$, foi observado que o desaparecimento dos vórtices da CCOP ocorrem com uma AMOC mais fraca, conforme já era previsto. Neste mesmo estudo também foi verificado que ocorreram mudanças na camada superior de salinidade e oxigênio, referente à década passada, fato que corrobora com o aumento do vazamento das Agulhas, enquanto que nas maiores profundidades, as mudanças na massa da água provavelmente estão relacionadas à mudanças no Atlântico Norte, bem como a mudanças na circulação tropical. Bryden, King, and McCarthy (2011) utilizaram seções hidrográficas de toda a coluna d'água e verificaram que ocorre um transporte de água doce na direção sul em $24^{\circ} \mathrm{S}$ e isto implica que a atual circulação do Atlântico tem múltiplos estados de equilíbrio, podendo ser instável a um evento de água doce suficientemente grande.

A AMOC pode ser dividida em quatro ramos principais: processos de ressurgência que transportam do fundo até próximo da superfície do oceano, correntes de superfície que carregam água menos densa em direção à altas latitudes, regiões de formação de águas profundas onde as águas se tornam mais densas e afundam e correntes profundas (Kuhlbrodt et al. 2007). Esses mecanismos estão presentes em todo o oceano Atlântico e dentro desse complexo, existe um sistema de circulação composto por uma circulação profunda (APAN) e uma abissal (AFA), que são vistos como um membro inferior da AMOC. Existem 2 processos concomitantes e inseparáveis responsáveis pela condução da MOC. Um deles é o mecanismo termohalino gerado por diferenças de temperatura e salinidade no Atlântico Norte, isto é, a mistura das águas transportam o calor de superfície para as massas de águas profundas, descendo através de superfícies de mesma densidade (Marshall and Speer 2012). Enquanto isso, as águas superficiais e intermediárias resultantes são levadas para o norte do Atlântico, e devido ao resfriamento atmosférico e perda de sal durante o aumento do gelo marinho, elas afundam e, portanto, um gradiente de densidade meridional entre altas e baixas latitudes são estabelecidas (Figura 3).

A Figura 3 exibe uma seção meridional idealizada que representa a os processos presentes na MOC. No local onde o gradiente de temperatura é maior (termoclina), podemos observar as águas de superfície que são mais leves separadas das águas profundas mais densas. No continente Antártico, águas quentes e salinas se propagam junto com a CCA para sul, ao longo das 


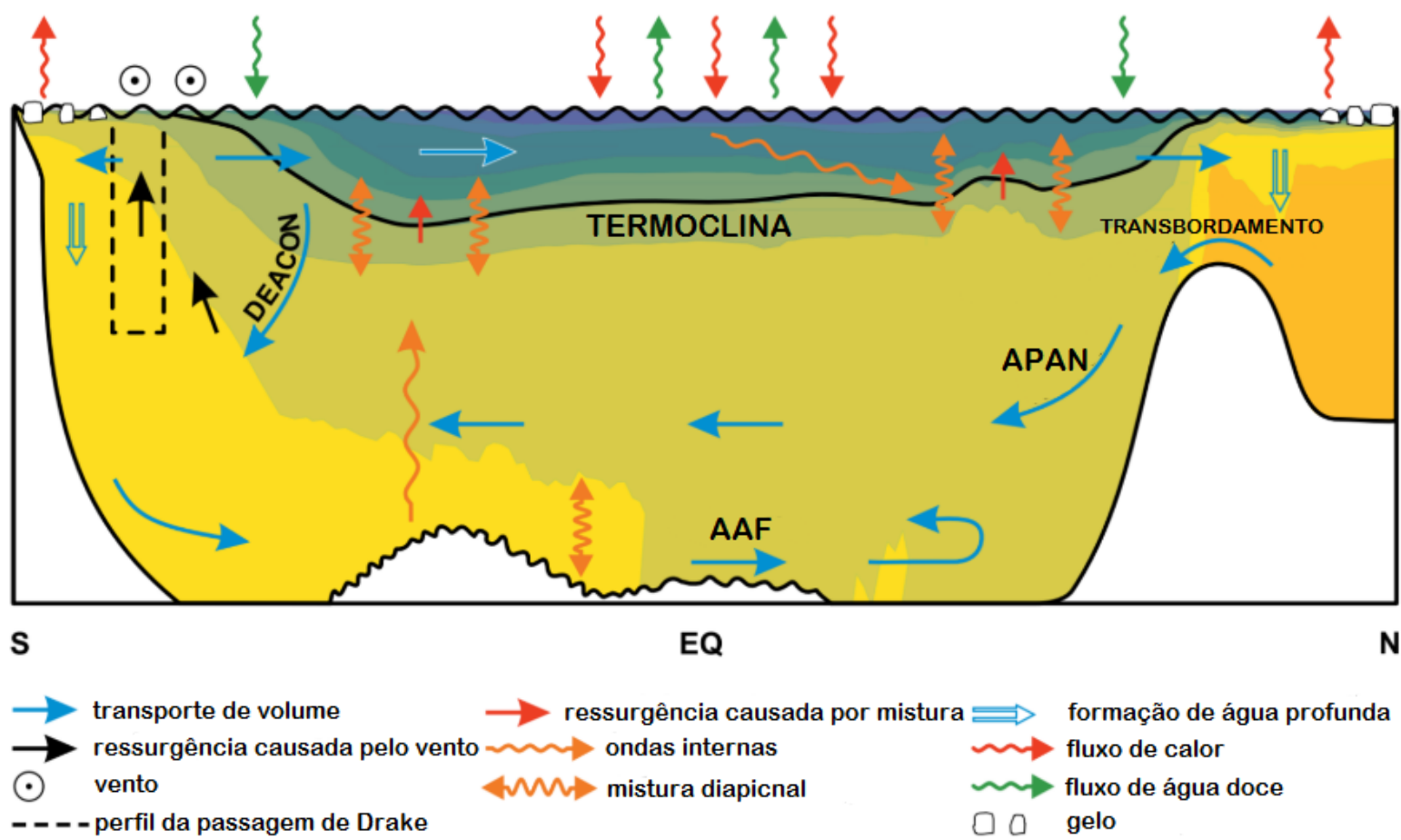

Figura 3. Seção meridional oceano Atlântico em que as setas representam a MOC. O sombreado colorido mostra um perfil de densidade zonal média, derivado de dados observacionais de Levitus, Burgett, and Boyer (1994) (Adaptado de Kuhlbrodt et al. 2007).

isopicnais e sobem das camadas mais profundas para a superfície oceânica ao sul da Frente Polar Sul. Além disso, o aumento de oxigênio resulta na formação da Água de Superfície Antártica (AASW) e águas de fundo e durante esses processos, as Águas Circumpolares são renovadas (Orsi, Johnson, and Bullister 1999).

No oceano Austral, ocorre outro mecanismo responsável pela condução da MOC. Em torno da região de $45^{\circ} \mathrm{S}$, devido à tensão de cisalhamento dos ventos de oeste e à força de Coriolis, ocorre o bombeamento das águas do fundo em direção à superfície, que resulta em uma circulação resultante para o norte a partir da CCA (Marshall and Speer 2012). Segundo Kuhlbrodt et al. (2007), os ventos de oeste são responsáveis pela ressurgência, uma vez que, eles impulsionam o transporte de Ekman, que causa um fluxo para o norte das águas superficiais no oceano Austral. Como o transporte de Ekman causa divergência nessa região, isso implica no impulsionamento das águas em direção à superfície. Deste modo, ocorre mistura ao longo do gradiente de densidade, sendo este processo conhecido como mistura diapicnal. Toggweiler and Samuels (1998) usaram dados observacionais de radiocarbono e sugeriram que que a maior parte da ressurgência oceânica é movida pelo vento e ocorre no oceano Austral. Portanto, é válido ressaltar o fato de que é imprescindível a entrada de energia mecânica no sistema para sustentar a turbulência necessária para que haja mistura de calor afim de manter os gradientes 
de pressão além dos fluxos de superfície.

\subsection{Corrente de Contorno Oeste profunda no Atlântico}

De modo geral, as massas de água profundas formadas no Atlântico Norte possuem fluxo para sul, enquanto que as formadas no oceano Austral, tem normalmente, fluxo para norte. Além disso, a topografia da região influencia os fluxos profundos e abissais (Talley et al. 2011). A CCOP foi observada por Swallow and Worthington (1961), que investigaram e mediram esse fluxo profundo que segue em direção ao sul, abaixo da corrente do Golfo .

A partir da década de 1960, se iniciaram os estudos relacionados às CCOPs em todos os oceanos (Warren 1981), com o intuito de entender a variabilidade dessa corrente, suas alterações a longo prazo e como se dá sua interação com o sistema de circulação oceânica. Entretanto, foi no início da década dos anos 1990 que foram desenvolvidos os primeiros estudos com interesse em verificar a variabilidade temporal do transporte, ciclo anual do transporte e estrutura espacial da CCOP no Atlântico norte (Lee et al. 1990; Meinen et al. 2004).

As CCOPs não necessariamente possuem fluxo associado unicamente com fontes de águas profundas, exceto no oceano Atlântico (Talley et al. 2011). Além de ser importante para que haja trocas de massas de águas entre os hemisférios e conexão de águas profundas com fluxos no interior do oceano, a CCOP também é interfere no fluxo de calor meridional relevante para o clima (Rhein et al. 1996).

A CCOP pode ser identificada através da análise de oxigênio e clorofluorcarbonetos (CFCs) pois essas águas contém concentrações consistentemente mais altas de CFCs do que o interior. Isto é corroborado com o fato da CCOP estar interligada às regiões de alta latitude, onde a convecção profunda é capaz carregar os CFCs até uma profundidade maior (Doney and Jenkins 1994). A CCOP carrega a APAN recém formada, que é composta pela Água do mar de Labrador (AML) e Água dos mares Nódicos (AMN) para sul. Essa corrente está centrada em torno de $2000 \mathrm{~m}$, porém, ela se estende até 1500 m no Atlântico Norte e trópicos e até o fundo no Atlântico Norte (Talley et al. 2011).

Na figura 4 observamos o caminho percorrido pela CCOP pelo oceano Atlântico e seguindo em direção ao oceano Índico. Essa corrente abissal tem origem quando a parte mais densa da APAN transborda pelo cume da Groenlândia-Escócia-Islândia (Smethie et al. 2000). 
Em seguida, ela contorna a Groenlândia e se une a AML no mar do Labrador e segue em direção à corrente do Atlântico Norte (CAN). Neste ponto, a CCOP possui dois caminhos, um que parte do fluxo acompanha a CAN fluindo através da Zona de Fratura Charlie-Gibbs, enquanto outra parte continua para sul ao longo do contorno oeste (Talley et al. 2011).

A CCOP carregando a APAN segue em direção ao equador, onde parte do fluxo vira para leste e acompanha o equador (Talley et al. 2011). Nos trópicos, entre $20^{\circ} \mathrm{S}$ e $5^{\circ} \mathrm{N}$ existe um desmembramento que ocorre próximo do equador, todo como parte do giro abissal da Guiana (Kanzow, Send, and McCartney 2008).

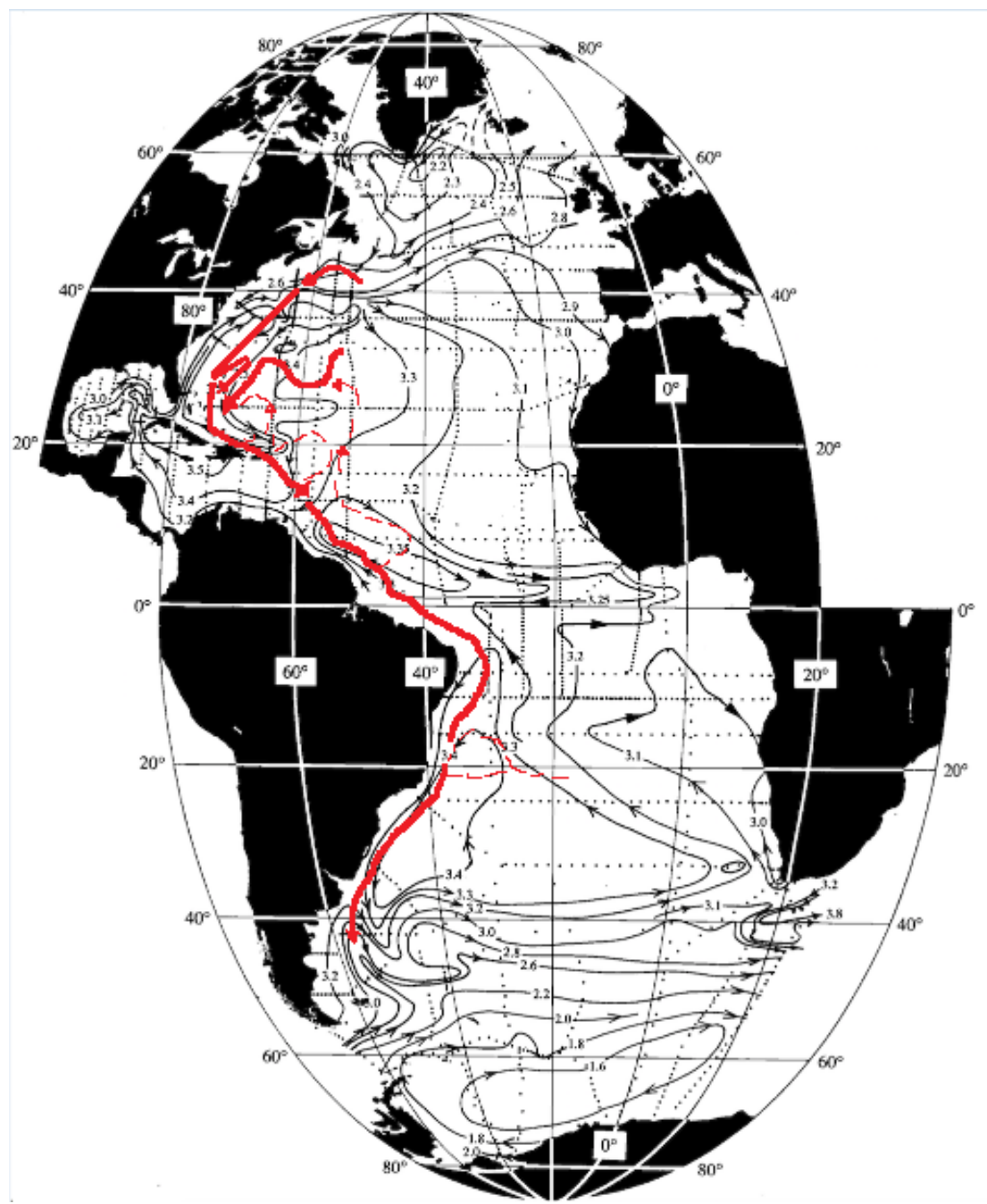

Figura 4. Esquema da altura dinâmica em 2500 dbar (linhas em preto), ajustado para estimar a circulação geostrófica absoluta e do percurso da CCOP pelo oceano Atlântico (linhas em vermelho). As recirculações são mostradas pelas linhas hachuradas em vermelho. Adaptado de (Reid 1994).

A taxa de formação de APAN foi estimada utilizando datação de radiocarbono por Broecker (1979) com valores superiores a $20 \mathrm{~Sv}\left(1 \mathrm{~Sv}=10^{6} \mathrm{~m}^{3} \cdot \mathrm{s}^{-1}\right)$. Os dois locais de formação do Atlântico Norte são responsáveis por mais de 90\% do volume de APAN (Gordon 1986). O 
transporte da CCOP foi estimado em 24 Sv na região próxima ao cabo Hatteras no Atlântico Norte entre 1200 e $2400 \mathrm{~m}$ de profundidade (Richardson 1977).

Schott et al. (1993) utilizaram dados de fundeio e encontraram um transporte médio para a CCOP de $17 \mathrm{~Sv}$, ao cruzar o equador, em $44^{\circ} \mathrm{W}$. Além disso, eles identificaram que a variabilidade da CCOP está associada a modificações na magnitude do jato. Deste modo, devido ao seu meandramento, ocorre a presença de picos de variabilidade com períodos de 60 e 20-30 dias. Utilizando os mesmos dados de fundeio, o método das funções ortogonais empíricas (FOE) foi aplicado no conjunto de dados e observado que o primeiro modo explica $91 \%$ do total da variância e este, é associado à variação da magnitude da corrente. A análise da série temporal da FOE dominante mostrou um ciclo de menos de $7 \mathrm{~Sv}$ em setembro-janeiro a 25 Sv em janeiro-fevereiro e, portanto, foi definido um ciclo sazonal da CCOP.

No Atlântico Sul, a CCOP atravessa a latitude de $5^{\circ} \mathrm{S}$ e segue como uma corrente de contorno oeste estreita, levando a APAN ao longo da costa da América do Sul (Garzoli et al. 2015). Schott et al. (2005) fizeram o uso de perfilador acústico por Doppler LADCP (do inglês, Lowered Acoustic Doppler Current Profilers), que são utilizados em águas profundas e observaram que na latitude de $5^{\circ} \mathrm{S}$, a CCOP está centrada em $2000 \mathrm{~m}$, transporta em torno de 12 a 39 Sv na porção oeste de $33,5^{\circ} \mathrm{W}$ e possui um transporte médio para sul de $(25,5 \pm 8,3) \mathrm{Sv}$.

Em torno de $8^{\circ} \mathrm{S}$ e $11^{\circ} \mathrm{S}$, começa a ser dominada por flutuações de mesoescala e vórtices (Dengler et al. 2004; Schott et al. 2005). Com a utilização de dados de fundeio e modelagem do Family of Linked Atlantic Model Experiments (FLAME), Dengler et al. (2004) averiguaram que a sazonalidade na formação dos vórtices está associada a variações da intensidade da CCOP entre $4^{\circ} \mathrm{S}$ e $8^{\circ} \mathrm{S}$, sendo que em torno de de $5^{\circ} \mathrm{S}$ a CCOP possui um transporte médio de cerca de $20 \mathrm{~Sv}$, carregando a APAN em direção sul. Na latitude de $11^{\circ} \mathrm{S}$, o transporte para sul é de $(35,5 \pm 14,7) \mathrm{Sv}$ com recirculação na porção oceânica de $(10,9 \pm 16) \mathrm{Sv}$. Este escoamento pode variar, mas gira em torno de $60 \mathrm{~Sv}$ para sul e $20 \mathrm{~Sv}$ para norte, com desvio padrão de $\pm 14,0$ $\mathrm{Sv}$ (Schott et al. 2005). A circulação média na região de $5^{\circ} \mathrm{S}$ e $11^{\circ} \mathrm{S}$ foi descrita através de medições diretas de velocidade (Schott et al. 2005). Em $5^{\circ} \mathrm{S}$ foi observado um escoamento para sul em todas as seções com velocidades máximas na parte mais superficial da APAN e um transporte em torno de 12 a $39 \mathrm{~Sv}$ a oeste de $33,5^{\circ} \mathrm{W}$. Em $11^{\circ} \mathrm{S}$ o padrão do escoamento é similar ao encontrado em $5^{\circ} \mathrm{S}$, entretanto, à leste de $33,5^{\circ} \mathrm{W}$ é observado um fluxo no sentido norte com velocidades próximas a $3 \mathrm{~cm} . \mathrm{s}^{-1}$ na faixa de profundidade da APAN.

Segundo Dengler et al. (2004), entre os meses de abril e setembro a CCOP se inten- 
sifica e, portanto, ocorre uma aumento no número de vórtices. Já entre outubro e março a CCOP está mais fraca e é capaz de continuar sua trajetória em sentido sul como um escoamento aproximadamente laminar ao sul de $8^{\circ} \mathrm{S}$. Além disso, os autores especulam que variações de longo período na MOC podem estar relacionadas com fases de uma CCOP mais estável ou com intensa geração de vórtices.

Garzoli et al. (2015) utilizaram a climatologia de flutuadores Argo e também verificaram a existência de dois ramos predominantes no fluxo da CCOP após a Cadeia Vitória-Trindade (CVT), no qual o fluxo médio parece seguir duas vias diferentes. Uma parte desse fluxo, estimado em torno de 2,9 \pm 1,4 Sv flui para o leste através da cordilheira meso-oceânica em direção ao continente africano e o escoamento restante segue fluindo para o sul ao longo do contorno oeste, junto à plataforma continental da América do Sul (estimativas de 9,4 \pm 4,2 Sv). Além disso, a porção que segue em direção a bacia também se subdivide entre $18^{\circ} \mathrm{S}$ e $25^{\circ} \mathrm{S}$ e a parte mais intensa ocorre entre $18^{\circ} \mathrm{S}$ e $20^{\circ} \mathrm{S}$, na região da CVT. Neste mesmo trabalho, através de análises de seções de clorofluorcarbonetos (CFCs), oxigênio, salinidade obtidas por cruzeiros oceanográficos e duas análises adquiridas a partir do modelo oceânico Ocean General Circulation Model For the Earth Simulator (OFES), foi descoberto que a APAN, carregada pela CCOP segue 2 caminhos distintos após passar pela região da CVT, em torno de $22^{\circ} \mathrm{S}$. O caminho principal ( $\sim 71 \%$ ) segue em direção ao sul, ao longo da costa da América do Sul, e o restante do fluxo $(\sim 22 \%)$ vai para leste, no interior da bacia.

Mais ao sul, com a utilização de dados de correntômetros (Muller, Zangenberg, and Nonato 1998) e estimativas de velocidades geostróficas (Zangenberg and Siedler 1998), foi sugerida a existência da CCOP ao longo da plataforma continental entre 20 e $28^{\circ} \mathrm{S}$, com transporte para sul entre 2-10 Sv. A CCOP possui um transporte de volume total de aproximadamente 14 Sv (Garzoli et al. 2015), predominantemente para sul onde o transporte geostrófico para o sul no limite ocidental a $28^{\circ} \mathrm{S}$ é estimado em $10 \mathrm{~Sv}$, mas $4 \mathrm{~Sv}$ recirculam com uma componente para o norte (Zangenberg and Siedler 1998). Por fim, o último meandramento da CCOP (carregando a APAN) ocorre na região na $\mathrm{CBM}$, em torno de $38^{\circ} \mathrm{S}$, onde a corrente se separa da topografia (Garzoli et al. 2015) e segue até $45^{\circ} \mathrm{S}$.

Meinen et al. (2017) concentraram-se principalmente no estudo sobre a variabilidade de tempo do fluxo de CCOP em $34.5^{\circ} \mathrm{S}$, com a utilização de sensores de pressão acoplados em ecossondas invertidos (PIES). Eles analisaram o transporte de volume da CCOP no período de 2009-2014 (desvio padrão de 22,8 Sv e variação total pico-a-pico de 139,4 Sv) e mostraram que 
este excede em muito a sua média temporal (-15,2 Sv). Além disso, os seus resultados sugerem que os vórtices são a causa principal das variações de transporte perto da plataforma continental, sendo que esses vórtices se propagam para o oeste e modulam a intensidade do fluxo de CCOP para produzir anomalias para o sul ou para o norte, dependendo do fluxo associado aos vórtices.

É válido ressaltar que a CCOP é a corrente responsável em transportar um significativo volume profundo de água do Atlântico como parte da MOC, sendo assim, essa corrente é conhecida como o membro inferior da MOC (Molinari et al. 1998). Deste modo, a hipótese do trabalho é que alterações na variabilidade da CCOP podem provocar mudanças na AMOC. Desta maneira, procuraremos responder algumas questões sobre como acontece essa relação no Atlântico Sul. 


\section{Objetivos}

O foco deste projeto é investigar a existência de correlação entre a CCOP e a AMOC. Para isto, se faz necessário que seja realizada a caracterização da CCOP no oceano Atlântico Sul. Além disso, pretende-se determinar a intensidade e variabilidade da CCOP, assim como o seu transporte de volume ao longo do Atlântico Sul. Ademais, propõe-se obter estimativas da $\mathrm{CCOP}$ em $34.5^{\circ} \mathrm{S}$ no Atlântico Sul através da utilização de instrumentos de fundeio.

- Qual a variação meridional do transporte de volume da CCOP?

- A utilização de modelo de circulação consegue representar a média e a variabilidade da intensidade da CCOP?

- Qual a correlação da CCOP com a MOC?

- Qual a variabilidade espacial e temporal da CCOP?

\subsection{Objetivos Específicos}

O projeto apresenta os seguintes objetivos específicos:

- Determinar o transporte meridional de volume a partir do uso de instrumentos de fundeio instalados em $34.5^{\circ} \mathrm{S}$ no Atlântico Sul.

- Utilizar saídas de dois modelos de equações primitivas para analisar as possíveis variações da CCOP.

- Analisar as séries temporais em termos de contribuição relativa da variabilidade temporal observada desde intrasazonal até intradecadal.

- Determinar a correlação estatística entre a CCOP e a MOC ao longo do Atlântico Sul. 


\section{Dados e metodologia}

\section{1. Área de estudo}

Este estudo será realizado para região oeste do Atlântico Sul, compreendida pelos meridianos entre $60^{\circ} \mathrm{W}$ e $20^{\circ} \mathrm{W}$ e pelos paralelos entre $5^{\circ} \mathrm{S}$ e $50^{\circ} \mathrm{S}$ (Figura 5). Dentro dessa região, em torno de $2000 \mathrm{~m}$, temos o objeto de estudo deste trabalho, a CCOP, que bordeia o contorno oeste da bacia. A CCOP carrega massas de águas frias recém ventiladas do norte do Atlântico Norte para o Atlântico Sul (Bower and Hunt 2000). Desta forma, a CCOP é a principal corrente que transporta uma porção considerável de águas mais frias pela MOC e, portanto, um componente importante no balanço de calor global (Meinen et al. 2017).

A Figura 5 apresenta as 7 latitudes do Atlântico Sul $\left(10^{\circ} \mathrm{S}, 14^{\circ} \mathrm{S}, 18^{\circ} \mathrm{S}, 22^{\circ} \mathrm{S}, 26^{\circ} \mathrm{S}, 30^{\circ} \mathrm{S}\right.$ e $34.5^{\circ} \mathrm{S}$ ) que foram utilizadas no estudo da CCOP. Além disso, também podemos observar a localização de regiões do Atlântico Sul que possuem influência sobre a CCOP, como região da Cadeia Vitória Trindade (CVT) em $21^{\circ} \mathrm{S}$ e a Bifurcação de Santos em torno de $27^{\circ} \mathrm{S}$.

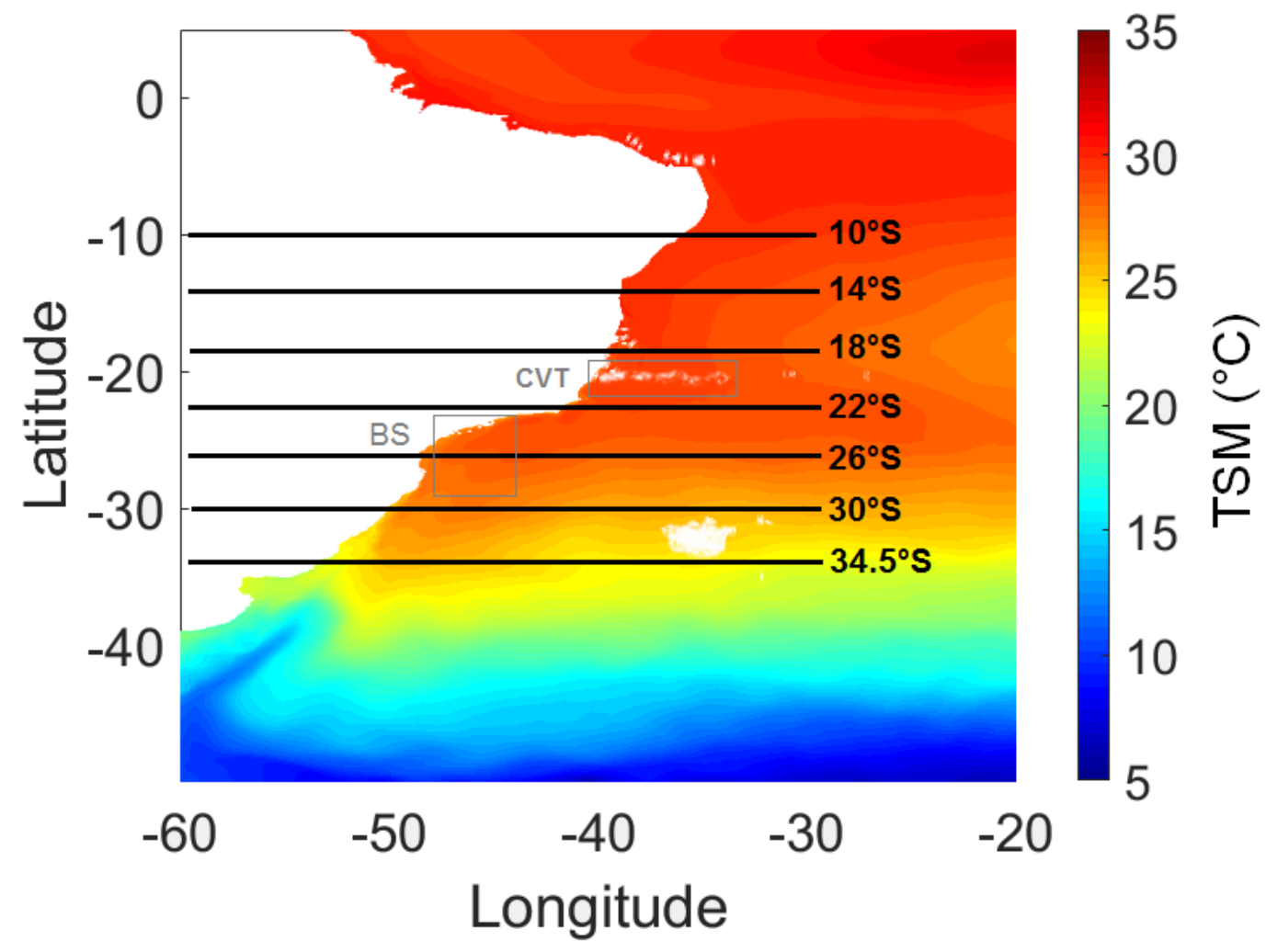

Figura 5. Representação da temperatura da superfície do mar (TSM) no Atlântico Sul obtida através do HYCOM utilizando a média de TSM entre 2005 e 2012, em torno de $2000 \mathrm{~m}$ de profundidade. São mostradas as 7 latitudes do Atlântico Sul que foram efetuadas as análises $\left(10^{\circ} \mathrm{S}, 14^{\circ} \mathrm{S}, 18^{\circ} \mathrm{S}, 22^{\circ} \mathrm{S}, 26^{\circ} \mathrm{S}, 30 \mathrm{~s}^{\circ} \mathrm{S}\right.$ e $\left.34.5^{\circ} \mathrm{S}\right)$. Em torno de $21^{\circ} \mathrm{S}$ temos a região da Cadeia Vitória Trindade (CVT). A Bifurcação de Santos acontece em torno de $27^{\circ} \mathrm{S}$, na região da Bacia de Santos (BS), que está localizada entre $23^{\circ} \mathrm{S}$ e $28^{\circ} \mathrm{S}$ e $44^{\circ} \mathrm{W}$ e $48^{\circ} \mathrm{W}$. 


\subsection{Dados}

Neste estudo, visamos obter estimativa da média, variância e variabilidade desde intrasazonal até interanual da CCOP no Atlântico Sul. Para esta estimativa, três conjuntos de dados serão utilizados: in situ e saídas de 2 modelos de equações primitivas.

\subsection{Dados observacionais}

O primeiro conjunto é referente aos dados de corrente obtidos a partir de correntômetros instalados em equipamentos com sensores de pressão acoplados em ecossondas invertidas (PIES). No Atlântico Sul, existe desde 2009, uma linha de boias fundeadas na latitude de $34.5^{\circ} \mathrm{S}$, de $44.5^{\circ} \mathrm{W}$ a $51.5^{\circ} \mathrm{W}$, equipadas com equipamentos PIES (Figura 6). Esses instrumentos foram instalados pelo projeto Southwest Atlantic MOC (SAM), com o intuito de quantificar a variabilidade diária dos principais componentes da MOC no Atlântico Sul.

As ecossondas invertidas são instrumentos alocados no fundo oceânico que medem o tempo de viagem acústica vertical $(\tau)$ do fundo até a superfície, além de ter autonomia para permanecer no fundo oceânico por até cinco anos, amostrando e registrando internamente informações. Quando um sensor de pressão é acoplado no equipamento, dá-se o nome de PIES. Além disso, é possível acoplar no equipamento um correntômetro e, neste caso, temos o CPIES (Figura 7).

O correntômetro é fixado por um cabo a $50 \mathrm{~m}$ do fundo, pois este nível é designado a medir a corrente geostrófica fora da camada limite inferior. Isto é necessário, pois, se o equipamento fizer as medidas dentro da camada limite inferior, as medições podem ser afetadas e incorporar erros devido ao cisalhamento ageostrófico. A distância de $50 \mathrm{~m}$ utilizada pelo CPIES não é arbitrária, ela é estimada a partir da espessura da camada limite inferior, que quando é $\leq$ $50 \mathrm{~m}$ é válida para velocidades de correntes de até $0,38 \mathrm{~m} . \mathrm{s}^{-1}$. A espessura da camada limite inferior estimada anteriormente de menor ou igual a $50 \mathrm{~m}$ é válida para velocidades de corrente de até $0,38 \mathrm{~m} \cdot \mathrm{s}^{-1}$ (Csanady 1967), assumindo um coeficiente de arrasto de $c_{d}=1,5 \times 10^{-3}$. O correntômetro mediu a velocidade das correntes uma vez a cada hora.

Inicialmente a linha possuía 6 instrumentos instalados: 4 PIES instalados pela National Oceanographic and Atmospheric Administration (NOAA - sob a responsabilidade do Dr. Christopher Meinen) e 2 CPIES instalados pelo IOUSP (sob a responsabilidade do Dr. Edmo Campos) (Tabela 1). Além disso, existe uma colaboração entre o Laboratório Meteorológico e Oceanográfico do Atlântico (AOML-PhOD) e colaboradores do Brasil e Argentina. O equipa- 


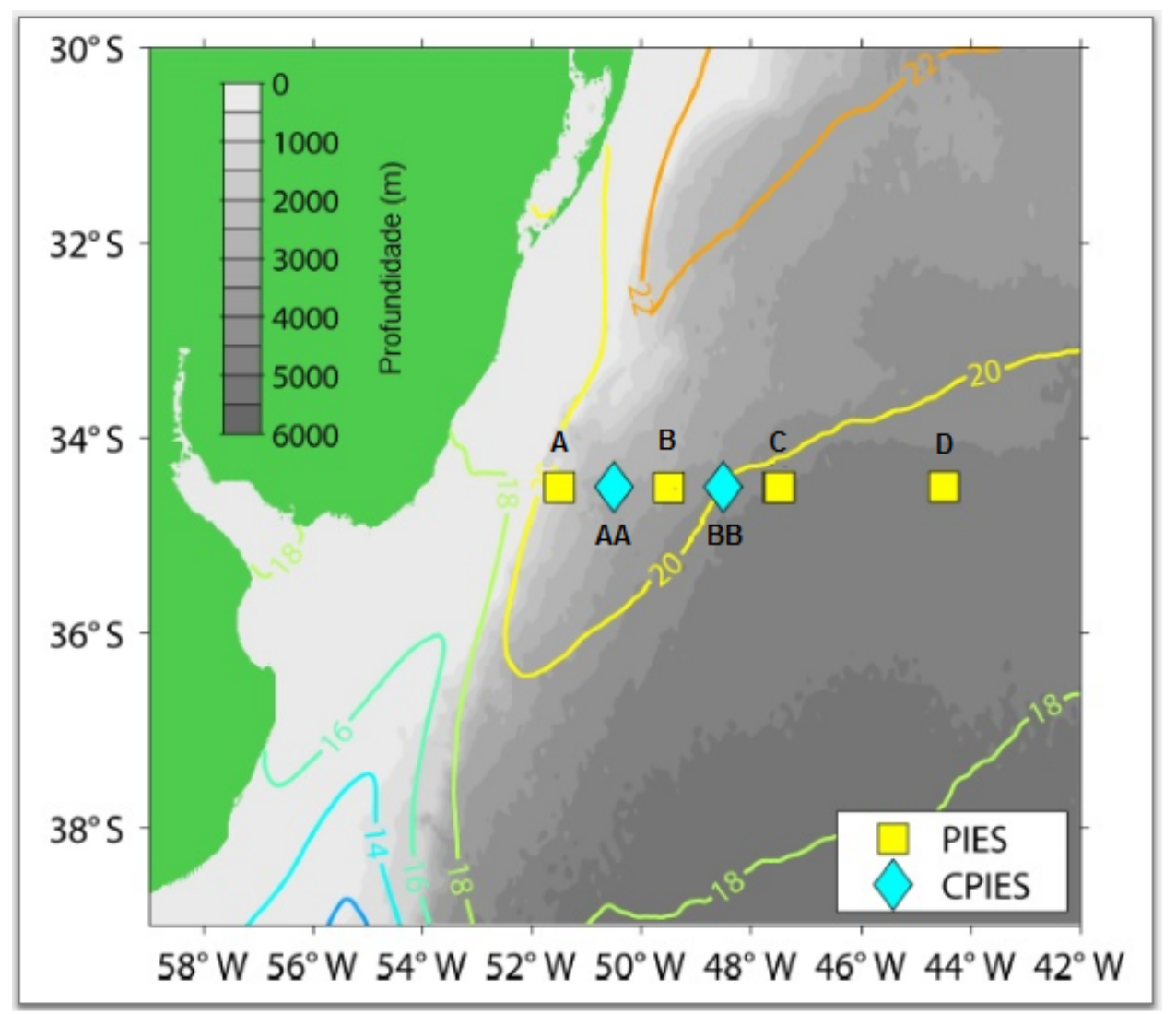

Figura 6. Localização de instalação dos instrumentos CPIES ( $A A$ e $B B$ ) fundeados pelo programa SAMOC no Atlântico Sul entre o período de 2012 e 2014.

mento PIES-B teve um defeito em 2010 e foi perdido durante uma tentativa de recuperação em julho de 2011 e, portanto, há uma lacuna de aproximadamente um ano nesse local entre 2010 e 2011. Os equipamentos foram instalados em profundidades que variam entre 1300 e $4700 \mathrm{~m}$, e se estende a cerca de $650 \mathrm{~km}$ da borda externa da plataforma continental.

Tabela 1. Tabela com os locais, profundidades e datas iniciais de implementação dos instrumentos PIES e CPIES.

\begin{tabular}{|c|c|c|c|c|c|}
\hline Legenda & Tipo de instrumento & Latitude & Longitude & Profundidade $(\mathrm{m})$ & Implementação \\
\hline A & PIES & $34^{\circ} 30.0^{\prime} \mathrm{O}$ & $51^{\circ} 30.0^{\prime} \mathrm{O}$ & 1360 & 18 MAR 2009 \\
\hline AA & CPIES & $34^{\circ} 30.0^{\prime} \mathrm{O}$ & $50^{\circ} 312^{\prime} \mathrm{O}$ & 2885 & 11 DEZ 2012 \\
\hline B & PIES & $34^{\circ} 30.0^{\prime} \mathrm{O}$ & $51^{\circ} 30.0^{\prime} \mathrm{O}$ & 3535 & 18 MAR 2009 \\
\hline BB & CPIES & $34^{\circ} 30.0^{\prime} \mathrm{O}$ & $51^{\circ} 30.0^{\prime} \mathrm{O}$ & 4140 & 12 DEZ 2012 \\
\hline C & PIES & $34^{\circ} 30^{\prime} 0^{\prime} \mathrm{O}$ & $51^{\circ} 30^{\circ} 0^{\prime} \mathrm{O}$ & 4540 & 19 MAR 2009 \\
\hline D & PIES & $3^{\circ} 30.0^{\prime} \mathrm{O}$ & $4^{\circ} 30.0^{\prime} \mathrm{O}$ & 4757 & 20 MAR 2009 \\
\hline
\end{tabular}

O intuito para a utilização desses instrumentos é observar a variabilidade da componente da MOC presente no Atlântico Sul. A localização da referida rede de observação é oportuna para uma observação direta da CCOP. Conforme é observado na Figura 6, a linha de PIES corta a porção oeste da região onde a CCOP pode ser detectada. Desta forma, com devido processamento, esses dados podem ser utilizados para avaliar as mudanças no interior do oceano 


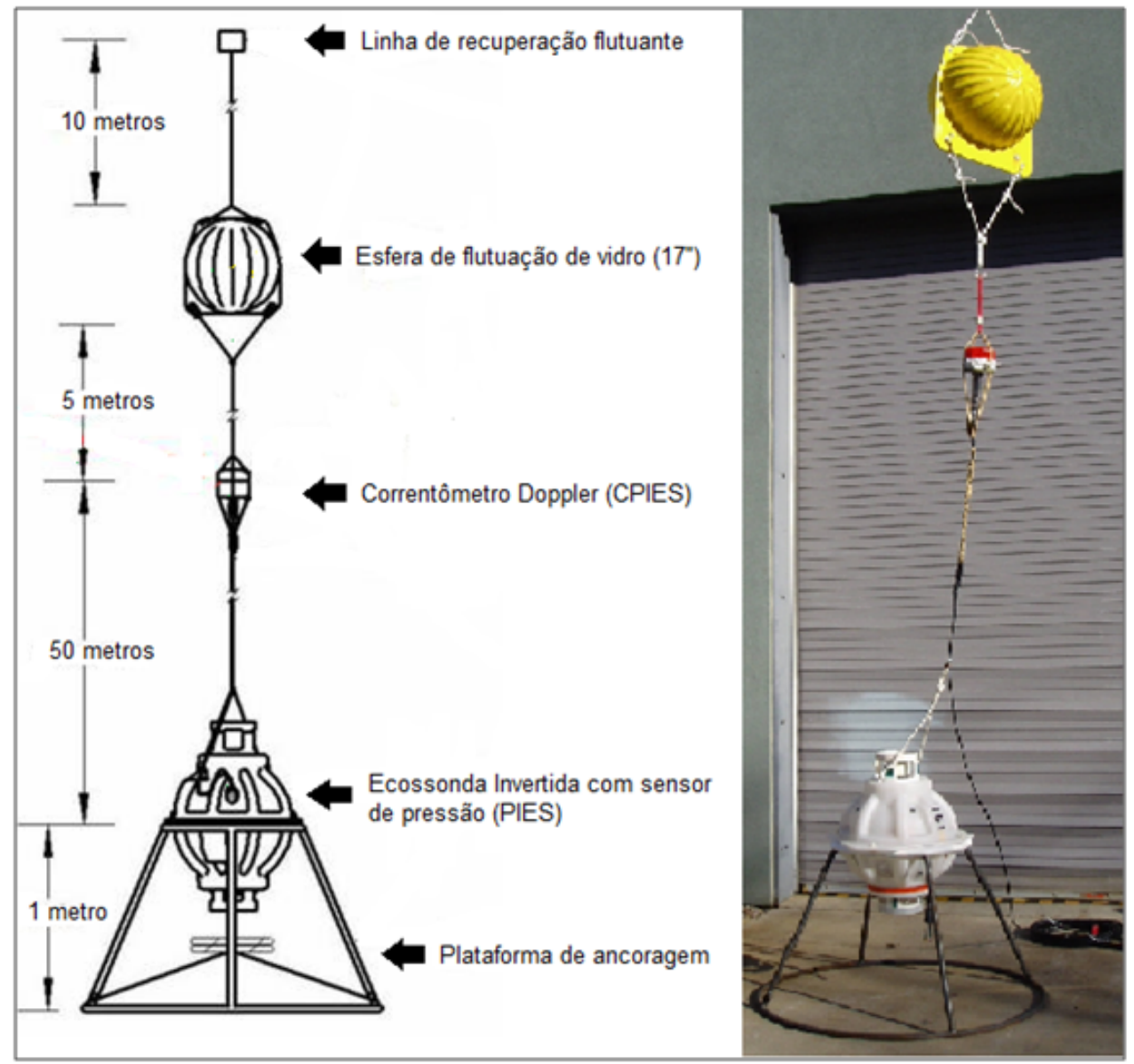

Figura 7. Modelo de ecossonda invertida acoplada com o sensor de pressão (PIES) e correntômetro (CPIES). Figura adaptada de Kennelly, Tracey and Watts (2007).

em termos de estrutura termohalina e sua relação com a dinâmica da CCOP. Neste trabalho, foram utilizados os dados de corrente obtidos pelos 2 equipamentos CPIES entre 2012 e 2014. Esses dados in situ foram usados como comparativos dos resultados de velocidade de correntes que foram obtidos pelas saídas dos 2 modelos oceânicos.

\subsection{Simulações de Modelos Numéricos}

\subsubsection{HYCOM}

O segundo conjunto de dados foram as simulações numéricas globais de alta resolução do modelo numérico HYbrid Coordinate Ocean Model (HYCOM). O HYCOM é um modelo de circulação geral dos oceanos baseado na solução de equações primitivas, que evoluiu do Miami Isopycnic-Coordinate Ocean Model (MICOM) (Bleck 2002). Maiores informações sobre esse modelo podem ser encontradas no site: https://hycom.org/hycom/overview. A batimetria 
utilizada foi a NRL DBDD2, do The Naval Research Laboratory, dos EUA, com 2 graus de resolução (http://WwW7320.nrlssc.navy.mil/DBDB2WWW).

O modelo HYCOM foi escolhido para a realização desse trabalho, pois apresenta características que o diferencia de outros modelos de circulação geral dos oceanos. Esse modelo consegue reproduzir as características das massas d'águas e representar os processos termodinâmicos e bioquímicos de acordo com parâmetros observados, e tem a capacidade de adaptar suas coordenadas verticais de acordo com as necessidades e características locais. O HYCOM combina os três principais tipos de coordenada vertical existentes, assumindo camadas isopicnais em regiões de oceano profundo, níveis $\sigma$ na plataforma continental e níveis de pressão para representar a camada de mistura do oceano. Nessa implementação foi adotada uma resolução horizontal de $1 / 12^{\circ}(\sim 8,5 \mathrm{~km}), 32$ níveis híbridos na vertical e a coleta de dados diária. Essa resolução é suficiente para resolver os processos de mesoescala, ou eddy resolving.

Através do trabalho de Bleck (2002) foram executadas duas rodadas: uma forçada com condições atmosféricas climatológicas e outra forçada com variabilidade interanual. Para ambos foram utilizados como forçante os dados de vento da Reanálise I do NCEP/NCAR (Kalnay et al. 1996) (http://www.esrl.noaa.gov/psd/), de 1960 a 2010. A rodada climatológica foi iniciada do repouso, com estrutura termoalina inicial definida pela climatologia do World Ocean Atlas (WOA) 1994 (Levitus, Burgett, and Boyer 1994). Após atingir uma situação de equilíbrio, o modelo foi executado por mais 28 anos. O estado final do modelo no último ano da rodada climatológica serviu como ponto inicial para a rodada com variabilidade interanual, forçada com os dados do NCEP, com entradas a cada 6 horas, desde 1949 até os dias atuais. Neste trabalho, foi utilizada a rodada do expt_18.3, que foi forçado com médias mensais de produtos do NCEP, com variabilidade interanual. Ou seja, são rodadas datadas. As variáveis utilizadas para forçar o modelo são: temperatura do ar,tensão de cisalhamento do vento, radiação de onda curta, fluxo radiativo líquido, razão de mistura de vapor e precipitação.

No presente trabalho, foram utilizadas as saídas do modelo das duas rodadas (médias diárias de temperatura, salinidade e a componente meridional da velocidade das correntes) no período de 1992 a 2015. Este período foi determinado pois as saídas do segundo modelo estão neste período, e deste modo, seria mais eficiente compará-los. No processamento da saída do modelo, esses dados foram recortados em três latitudes $\left(10^{\circ} \mathrm{S}, 22^{\circ} \mathrm{S}, 34.5^{\circ} \mathrm{S}\right)$ do Atlântico Sul, entre as longitudes de $55^{\circ} \mathrm{W}$ e $32^{\circ} \mathrm{W}$, pois a CCOP está inserida nessa região. Além disso, foi feita uma interpolação horizontal nos dados termoalinos para que a resolução fosse de $1 / 4^{\circ}$, as- 
sim como uma interpolação vertical para que os dados ficassem de acordo com as profundidade padrão (33 profundidades). Essas interpolações foram necessárias pois a resolução dos dados do World Ocean Altas 2018 utilizada foi de $1 / 4^{\circ}$ e esses dados foram usados como comparativos na validação do modelo. É válido ressaltar que após a validação do modelo, retornamos a resolução original do HYCOM de $1 / 12^{\circ}$ para execução das análises. Posteriormente, para avaliar de forma mais precisa o comportamento da CCOP durante seu percurso pelo Atlântico Sul, foram analisadas 7 latitudes $\left(10^{\circ} \mathrm{S}, 14^{\circ} \mathrm{S}, 18^{\circ} \mathrm{S}, 22^{\circ} \mathrm{S}, 26^{\circ} \mathrm{S}, 30^{\circ} \mathrm{S}\right.$ e $\left.34.5^{\circ} \mathrm{S}\right)$, mantendo o intervalo de longitudes de $55^{\circ} \mathrm{W}$ e $32^{\circ} \mathrm{W}$.

\subsubsection{ECCO}

O modelo Estimating the Circulation \& Climate of the Ocean (ECCO) teve suas origens no World Ocean Circulation Experiment (WOCE) e tem apresentado resultados pertinentes na representação da circulação oceânica e variabilidade da AMOC (Johnson and Chambers 2013; Liu et al. 2017). A versão do ECCO utilizada neste trabalho (Version 4 Release 3) combina modelos de circulação geral do oceano de última geração com os conjuntos de dados oceânicos globais de 1992 a 2015.

O ECCO usa uma configuração quase-global do Massachusetts Institute of Technology's General Circulation Mode (MIT GCM) (Marshall et al. 1997), com uma resolução horizontal de $1^{\circ}$ e 23 níveis verticais. Os dados podem ser acessados em http://grace.jpl.nasa.gov/data/ECCOOBP/ a partir de 21 de agosto de 1992 (Fukumori 2002; Kim, Lee, and Fukumori 2007). A estratégia de assimilação de dados do ECCO, descrita em detalhes por Wunsch and Heimbach (2007), envolve o ajuste dos fluxos de calor, dinâmica e água doce para trazer consistência ao modelo (dentro dos limites de erro) com várias fontes de dados.

As saídas do modelo são compostas pelas variáveis de temperatura, salinidade, velocidade, nível do mar, topografia dinâmica média, profundidade da água, pressão e fluxos de temperatura, sal, volume, conforme pode ser visto detalhadamente na Tabela 2. Os dados de climatologia hidrográfica são advindos de perfiladores Argo, de satélite gravimétrico (GRACE), de salinidade (Aquarius), do Programa Southern Elephant Seals as Oceanographic Samplers (SEaOS) coletados através de elefantes marinhos, principalmente do Atlântico sul e de medidas in situ através de seções de Condutividade, temperatura e profundidade (CTD) e Batitermógrafos descartáveis (XBTs). 
Tabela 2. Tabela com os dados utilizados nas estimativas do modelo ECCO.

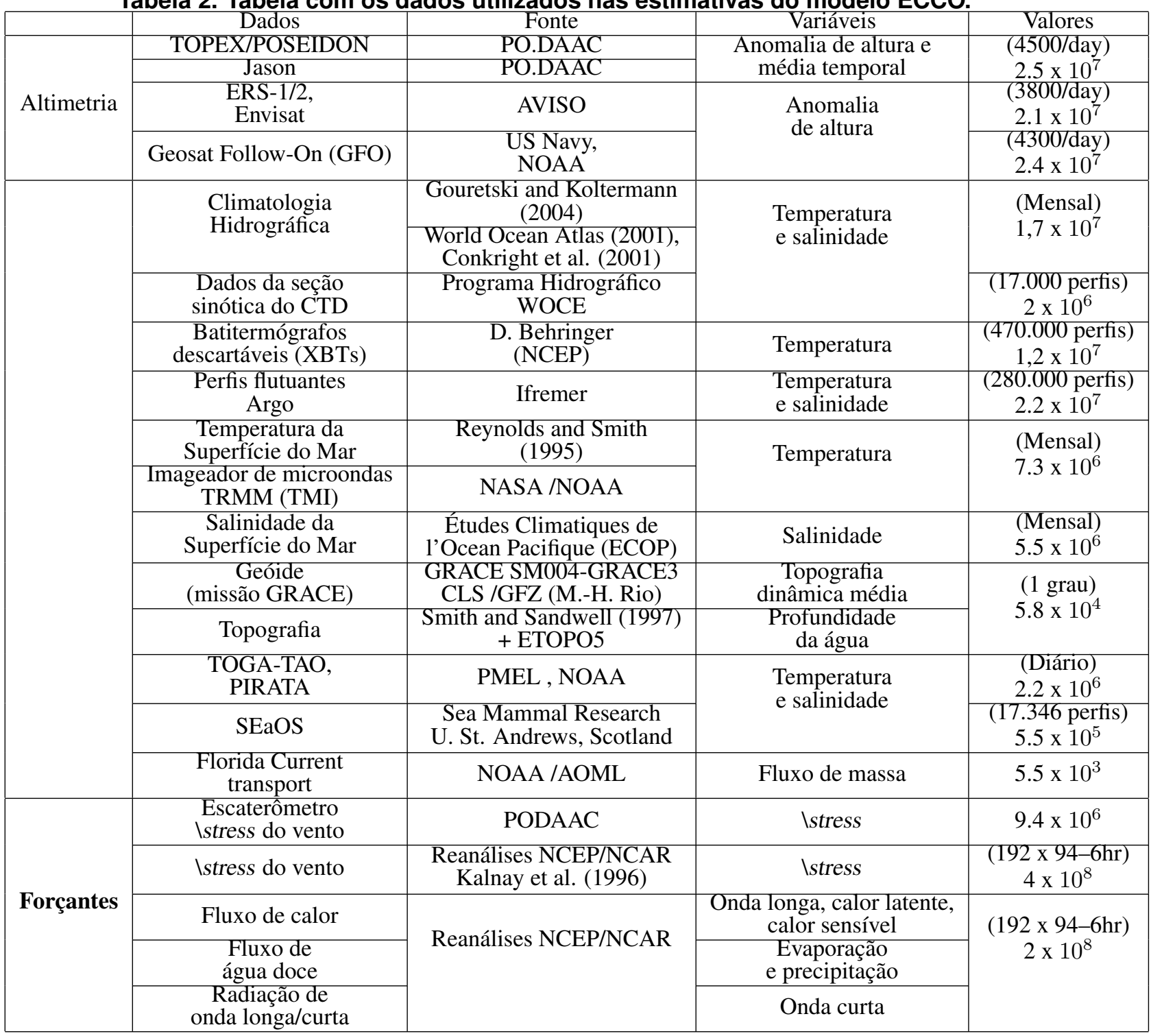

Os dados meteorológicos utilizados no modelo são obtidos indiretamente das estimativas feitas através da reanálise I do NCEP-NCAR (Kalnay et al. 1996; Kistler et al. 2001). É válido ressaltar que neste trabalho foram utilizados dados diários de temperatura de salinidade e dados mensais de velocidade. O mesmo processamento realizado no HYCOM foi executado no ECCO, ou seja, foi feita a interpolação de $1^{\circ}$ para $1 / 4^{\circ}$ e nas 33 profundidades padrão. Foram utilizadas as médias diárias de temperatura e salinidade, entretanto, em relação a componente de velocidade meridional, foram usadas as médias mensais, pois o ECCO não disponibiliza dados diários de velocidade. Os dados também foram recortados em três latitudes $\left(10^{\circ} \mathrm{S}, 22^{\circ} \mathrm{S}\right.$, $34.5^{\circ} \mathrm{S}$ ) do Atlântico sul, entre as longitudes de $55^{\circ} \mathrm{W}$ e $32^{\circ} \mathrm{W}$ ). Posteriormente, as análises foram feitas também para as 7 latitudes $\left(10^{\circ} \mathrm{S}, 14^{\circ} \mathrm{S}, 18^{\circ} \mathrm{S}, 22^{\circ} \mathrm{S}, 26^{\circ} \mathrm{S}, 30^{\circ} \mathrm{S}\right.$ e $\left.34.5^{\circ} \mathrm{S}\right)$. 


\subsection{Temperatura e salinidade climatológica}

Os dados de temperatura e salinidade do World Ocean Altas 2018 (WOA18) (Boyer 2018) foram usados usados como comparativos na validação dos modelos HYCOM e ECCO. Foram usadas as médias de todas as décadas do WOA18 nas mesmas três latitudes $\left(10^{\circ} \mathrm{S}, 22^{\circ} \mathrm{S}\right.$, $34.5^{\circ} \mathrm{S}$ ), entre as longitudes de $55^{\circ} \mathrm{W}$ e $32^{\circ} \mathrm{W}$ ), com resolução espacial de $0,25^{\circ} 5$ em níveis de profundidade padrão até uma profundidade máxima de $5500 \mathrm{~m}$. Os dados de temperatura do WOA18 também foram convertidos para temperatura potencial, que é a medida de temperatura adotada pelos modelos oceânicos.

O WOA18 é um conjunto de dados climatológicos disponibilizados em 5, 1 e 0,25ำ com médias nos períodos de: 1955-1964, 1965-1974, 1975-1984, 1985-1994, 1995-2004, 20052017, 1981-2010 e média de todas as décadas, sendo esta última que será usada neste trabalho . Neste trabalho foram usados os dados climatológicos $\left(0,25^{\circ}\right)$ in situ de temperatura e salinidade nos níveis de profundidade padrão em períodos anuais, sazonais e mensais de composição para o oceano global. Os dados são processados pela NOAA-NODC. Os conjuntos de dados de temperatura e salinidade advém de coletas de garrafas (termômetros de reversão), batitermógrafo mecânico, digital e descartável, CTD, flutuadores de perfilação, boias ancoradas e à deriva e gliders. Maiores detalhes sobre as informações do produtos obtidos pelo WOA18 estão disponíveis no site https://www.nodc.noaa.gov/OC5/woa18/.

\subsection{Análise de erro}

\subsubsection{Skill Score}

Em estatística a exatidão é um atributo que descreve a proximidade entre as previsões (f) e as observações (x) (Murphy and Katz 1997). Uma medida normalmente usada como exatidão das previsões é o erro quadrático médio:

$$
M S E(f, x)=E\left[(f-x)^{2}\right]
$$

O Skill Score (Wilks 1995) é uma forma de se medir a exatidão do modelo, isto é, uma análise de erro. Essa ferramenta estatística estatística é similar ao Coeficiente de Eficiência de Nash-Sutcliffe (COE), em que quanto mais próximo de um, melhor a previsão do modelo. Essa 
função interpreta a previsibilidade do modelo usando erro residual e variabilidade observada em seus dados. Um resultado equivalente a 1 significa um ajuste perfeito e igual ou menor que zero significa que o erro de modelo é maior que a variabilidade em seus dados.

Deste modo, a exatidão das previsões em relação a um sistema de previsão de referência (r) é conhecida como Skill Score. O MSE $(r, x)$ irá fornecer a exatidão para as previsões de referência (r). Portanto, o SkillScore (SS) é definido como:

$$
S S_{M S E}(r, f, x)=1-\frac{M S E(f, x)}{M S E(r, x)}
$$

Utilizando uma previsão da média $(\mu)$ como referência, temos que:

$$
\operatorname{MSE}(\mu, x)=E\left[(f-\mu)^{2}\right]=\sigma^{2},
$$

E portanto, SS pode ser dado como:

$$
S S_{M S E}(\mu, f, x)=1-\frac{M S E(f, x)}{\sigma^{2}}
$$

O segundo modo de avaliação da exatidão do modelo foi avaliar qual seria a diferença da média de $\mathrm{T}$ e $\mathrm{S}$ entre os dados observados e o modelado. Iremos denominar essa diferença como "Erro". Neste caso, para a efetuação do cálculo foram usadas as seções longitudinais de $10^{\circ} \mathrm{S}, 22^{\circ} \mathrm{S}$ e $34.5^{\circ} \mathrm{S}$ na região de localização da CCOP, isto é, entre as longitudes de $55^{\circ} \mathrm{W}$ e $\left.32^{\circ} \mathrm{W}\right)$. Deste modo, foram subtraídos os campos de $\mathrm{T}$ e $\mathrm{S}$ dos modelos do WOA18. Deste modo, o erro gerado pelos modelos foi calculado da seguinte forma:

Erro_HYCOM = Observado $($ WOA18) - Modelado $($ HYCOM $)$

Erro_ECCO $=$ Observado $($ WOA18 $)$ - Modelado $($ ECCO $)$ 


\subsection{Definição de massas d'água e identificação da CCOP}

Após a validação dos modelos oceânicos, foi feito um levantamento dos critérios existentes na literatura para a identificação da CCOP. No levantamento bibliográfico, foi visto que há divergências de informações sobre a localização da CCOP. Alguns autores como Schott et al. (1993), Dengler et al. (2004) e Fischer and Schott (1997) identificam a CCOP a partir das variáveis de temperatura, salinidade e densidade. Entretanto, mais recentemente, Meinen et al. (2017) e Garzoli et al. (2015), utilizaram critérios de temperatura, salinidade e densidade neutra para localizar a CCOP. Os dados de densidade neutra possuem maior precisão do que os dados de densidade, uma vez que, além de serem calculados a partir das variáveis de temperatura, salinidade e pressão, também é considerado a latitude e longitude da partícula. Neste trabalho, para a identificação da CCOP, usaremos as definições de massas de água profundas definidas por Preu et al. (2013):

- Água Profunda Circumpolar Superior (APCS): densidade neutra entre 27,75 kg.m ${ }^{-3} \mathrm{e}$ $27,90 \mathrm{~kg} . \mathrm{m}^{-3}$ com valores de oxigênio dissolvido abaixo de 4,5 mL.L ${ }^{-1}$;

- Água Profunda do Atlântico Norte (APAN): densidade neutra entre 27,90 kg.m ${ }^{-3}$ e $28,10 \mathrm{~kg} \cdot \mathrm{m}^{-3}$ com salinidade maior que 34,8 ;

- Água Profunda Circumpolar Superior (APCI): densidade neutra entre $28,06 \mathrm{~kg} \cdot \mathrm{m}^{-3} \mathrm{e}$ $28,20 \mathrm{~kg} \cdot \mathrm{m}^{-3}$ com salinidade menor que 34,8 ;

- Água Antártica de Fundo (AAF): temperatura potencial menor que de $0^{\circ} \mathrm{C}$.

Os dados de densidade neutra possuem maior precisão do que os dados de densidade, uma vez que, são calculados a partir das variáveis de temperatura, salinidade, pressão, latitude e longitude da partícula, e estes foram obtidos através do pacote de rotinas oceanográficas da The Gibbs Sea Water (GSW), com a utilização da nova Equação de Estado chamada Equação da Termodinâmica da Água do Mar, em inglês, Thermodynamic Equation of Seawater - 2010 (TEOS-10) (Commission et al. 2010). Esta nova descrição da água do mar é baseada na descrição de Gibbs, no qual as propriedades termodinâmicas como entalpia, entropia e entalpia potencial são calculadas diretamente.

\subsection{Cálculo do Transporte de Volume}

A CCOP faz parte do membro inferior da AMOC e, portanto, seu padrão irá influenciar nos fluxos de calor e água doce do Atlântico. Deste modo, o transporte de volume da CCOP foi 
usado como um indicador da variabilidade da corrente. Foram usadas as velocidades meridionais do HYCOM e do ECCO nas 7 latitudes analisadas $\left(10^{\circ} \mathrm{S}, 14^{\circ} \mathrm{S}, 18^{\circ} \mathrm{S}, 22^{\circ} \mathrm{S}, 26^{\circ} \mathrm{S}, 30^{\circ} \mathrm{S}\right.$ e $34.5^{\circ} \mathrm{S}$ ) para estimar o transporte da CCOP ao longo do Atlântico Sul.

Neste trabalho, foi usado o campo de velocidade meridional para calcular o transporte meridional de volume integrado $(V)$. Podemos defini-lo como:

$$
V=\int_{z_{0}}^{z} \int_{x}^{x_{0}} v d x d z
$$

onde $v$ é a componente meridional da velocidade da água densidade da água, $x$ e $x_{0}$ são os limite leste e oeste da CCOP, respectivamente.

No cálculo, foram utilizados dados de 1992 a 2015 para ambos os modelos. Foi necessário definir os limites verticais e horizontais da CCOP para resolver a equação 5 . A localização da CCOP durante seu percurso pelo Atlântico Sul é variável. Portanto, usamos os critério de Preu et al. (2013) para identificar a corrente. Deste modo, o transporte de volume integrado foi calculado usando os critérios de densidade neutra, salinidade e velocidade. O limite vertical superior $z$ na equação 5 foi definido como a profundidade cuja a densidade neutra de $27,9 \mathrm{~kg} \cdot \mathrm{m}^{-3}$ e o limite vertical inferior $z_{0}$ como $28,10 \mathrm{~kg} . \mathrm{m}^{-3}$ e salinidade maior que 34,8 . Os limites zonais foram definidos como a costa leste da bacia (limite leste $x$ ) e velocidade negativa $(v<0)$, pois a CCOP segue em direção para sul (limite oeste $x_{0}$ ).

A velocidade meridional $(v)$ pode ser decomposta em componente barotrópica e baroclínica (geostrófica) e a componente ageostrófica, que é assumida como efeito do transporte de Ekman. A baroclínica geralmente pode ser estimada pelo campo hidrográfico, e a barotrópica é geralmente usada como velocidade de referência para tornar a componente baroclínica absoluta (Garzoli and Baringer 2007). A velocidade fornecida pelos modelos é a velocidade meridional absoluta.

O transporte de volume da AMOC foi feito calculando integralmente toda a coluna d'água e o transporte calculado em si foi o volume líquido positivo, ou seja, que vai para norte, em toda a bacia do Atlântico Sul. Para isto, o cálculo do transporte meridional de volume da $\operatorname{AMOC}(V a)$ foi calculado usando a equação 5 , onde $v$ é a componente meridional da velocidade da água, $x$ e $x_{0}$ são os limite leste e oeste da bacia do Atlântico Sul, respectivamente. O limite vertical superior $(z)$ é dado pela superfície e o inferior $\left(z_{0}\right)$ vai até o ponto em que a velocidade 
troca de sinal.

\subsection{Variabilidade da CCOP e Análise Espectral}

As séries temporais originais de transporte de volume foram analisadas com o objetivo de identificar um possível sinal sazonal (ciclo anual). Mas de qualquer forma, um dos objetivos do trabalho é identificar possíveis sinais interanuais, por isso, é válido retirar sinais de alta frequência que possam interferir na análise dos resultados. Portanto, o ciclo médio anual foi separado dos dados originais de transporte de volume da CCOP para evitar possíveis interferências na análise dos resultados.

A análise espectral pode ser entendida como a soma da análise estatística das séries temporais somadas aos métodos de análise de Fourier. Segundo Aguirre (2013), a função de densidade espectral contém informações sobre a série original obtida dando ênfase sob um ponto de vista diferente: o domínio da frequência. Deste modo, é fornecido quais são as frequências que explicam as maiores proporções da variância total da série.

$\mathrm{Na}$ análise do espectro da variância do transporte de volume foi utilizado o método do periodograma médio de Welch (Welch 1967). Este método é mais adequado estimador da Densidade Espectral de Potência (DPE), no qual são utilizadas janelas temporais e a possibilidade de sobreposição dos intervalos de estimação dos espectros. Neste trabalho foi usada uma janela de 2 anos permitindo 1 ano de sobreposição. Foi feita a análise espectral para as latitudes $10^{\circ} \mathrm{S}$, $22^{\circ} \mathrm{S}$ e $34.5^{\circ} \mathrm{S}$ com o intuito de verificar a variância do transporte de volume da CCOP.

\subsection{Correlação da CCOP com a AMOC}

Como parte de um dos objetivos deste trabalho, foi verificado se existe uma correlação entre a CCOP e a AMOC. Quando consideramos dois processos que não se alteram estatisticamente com o tempo, como $x_{i}\left(x_{1}, x_{2}, \ldots, x_{n}\right)$ e $y_{i}\left(y_{1}, y_{2}, \ldots, y_{n}\right)$, no domínio temporal $t_{i}\left(t_{1}, t_{2}, \ldots, t_{n}\right)$, podemos calcular o coeficiente de correlação:

$$
r_{x y}(\gamma)=\frac{1}{N-k} \sum_{i=1}^{N-k} \frac{\left(x_{i+k}-\bar{x}\right)\left(y_{i}-\bar{y}\right)}{\sigma_{x} \sigma_{y}}
$$

no qual $x$ representa a série temporal do transporte de volume de AMOC e $y$ dos modelos (HYCOM e ECCO), e seus respectivos desvios padrões são dados por $\sigma_{x}$ e $\sigma_{y}$. O $\gamma=k \Delta t$ 
$(k=0, \ldots, M)$ representa o lag para cada $k$ incremento de tempo, com $M \ll N$

O coeficiente de correlação $r_{x y}$ varia entre -1 e 1, em que - 1 significa uma correlação máxima com $180^{\circ}$ fora de fase e 1 uma correlação máxima e em fase.

\section{Resultados e Discussão}

\subsection{Validação dos modelos oceânicos HYCOM e ECCO}

Os perfis de temperatura (T) e salinidade (S) das saídas dos modelos HYCOM e ECCO foram comparados com perfis médios climatológicos do World Ocean Altas 2018 (WOA18). A comparação entre saídas de modelos com observações é uma abordagem bastante usada para avaliar habilidades e limitações dos modelos. Os dados utilizados para ambos os modelos foram entre o período de 1992 a de 2015, e os dados de referência do WOA18 são todas as médias das décadas até o período recente. Para a validação dos modelos, as análises a seguir foram realizadas em três latitudes $\left(10^{\circ} \mathrm{S}, 22^{\circ} \mathrm{S}\right.$ e $\left.34.5^{\circ} \mathrm{S}\right)$, por serem as latitudes de interesse do estudo, entre as longitudes de $55^{\circ} \mathrm{W}$ e $32^{\circ} \mathrm{W}$ ), pois a CCOP está inserida nessa região. No Atlântico sul, a CCOP normalmente está centrada em torno de $2000 \mathrm{~m}$ (Schott et al. 2005).

Foi utilizado o método estatístico Skill Score para avaliar a precisão dos modelos numéricos quando comparados com os dados do WOA18. Este método realizado sobre os perfis de T e S na região de localização da CCOP. Em relação do HYCOM, foram obtidos os valores de 0,90 e 0,81 para os dados de T e S, respectivamente. Através do ECCO, encontramos os valores de 0,93 e 0,92 para T e S, respectivamente. As Figuras 8 e 9 representam as médias de todas as décadas do WOA18 (em preto) e as médias do HYCOM (em azul) e ECCO (vermelho) entre o período de agosto de 1992 a julho de 2015, de temperatura e salinidade, respectivamente.

Através da Figura 8 podemos observar que as médias de temperatura sobre as latitudes do HYCOM estão bem próximos aos valores dos dados in situ (WOA18), principalmente abaixo de $1500 \mathrm{~m}$ na região que normalmente a CCOP está localizada (centrada em torno de 2000 m). Quando analisamos as médias de salinidade do HYCOM, vemos que os dados estão mais distantes do WOA18 em comparação com os dados de temperatura, o que é corroborado pelos valores obtidos pelo SkillScore, entretanto, eles apresentam maior similaridade abaixo de 2000 m (Figura 9). Em relação ao ECCO, os resultados das médias de temperatura e salinidade são ainda mais similares aos dados do WOA18, tanto em relação aos dados de temperatura como de salinidade 8 e 9), o que também é corroborado pelos valores de SkillScore obtidos. 

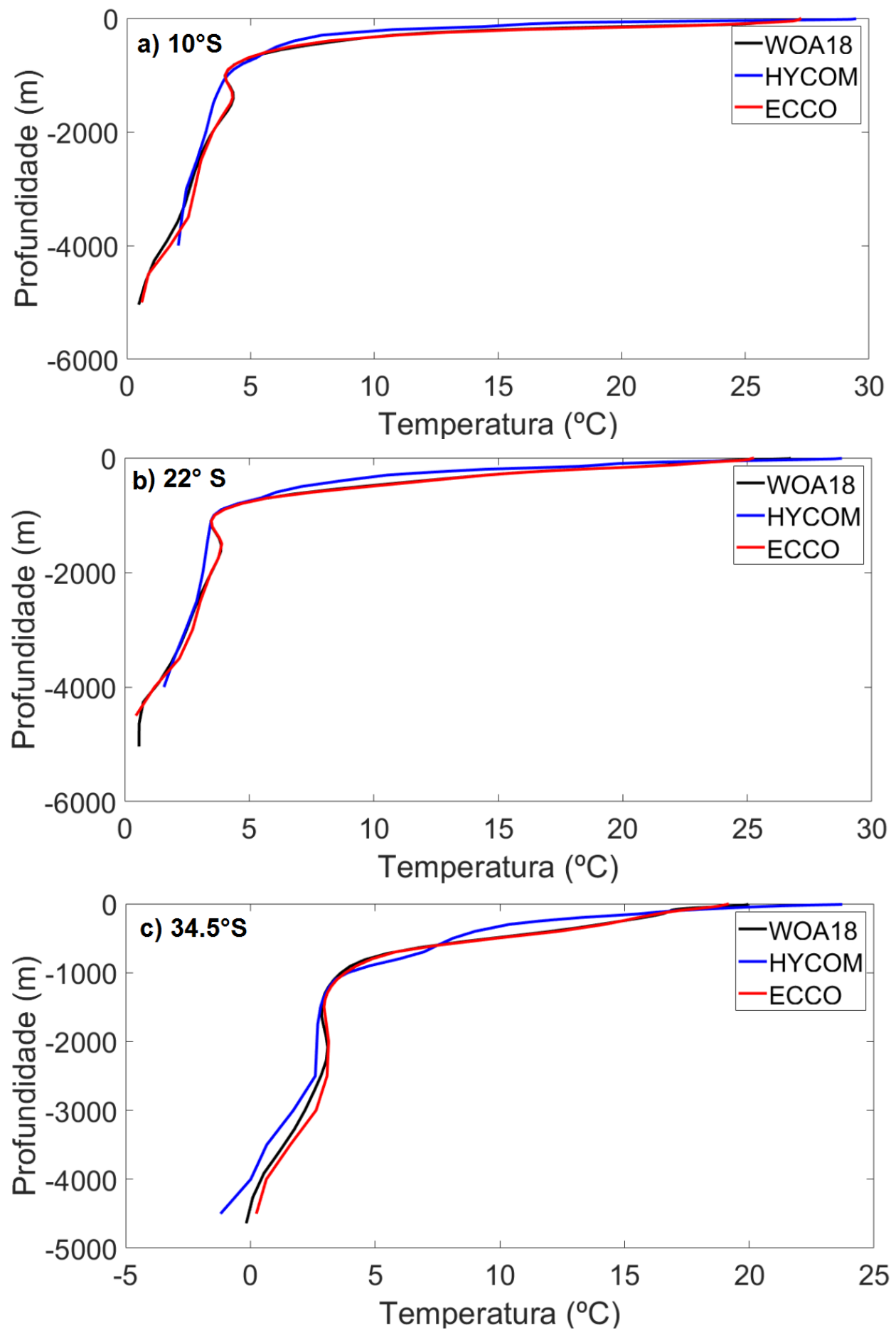

Figura 8. Perfis das médias de temperatura para as latitudes de $10^{\circ} \mathrm{S}$ (Painel a), $22^{\circ} \mathrm{S}$ (Painel b) e $34.5^{\circ} \mathrm{S}$ (Painel c), entre as longitudes de $55^{\circ} \mathrm{W}$ e $32^{\circ} \mathrm{W}$ ). As linhas representam o WOA 18 (em preto), HYCOM (em azul) e ECCO (em vermelho). A média usada pelo WOA18 é a média decadal total e para ambos os modelos foi usado a média entre agosto de 1992 a julho de 2015. 

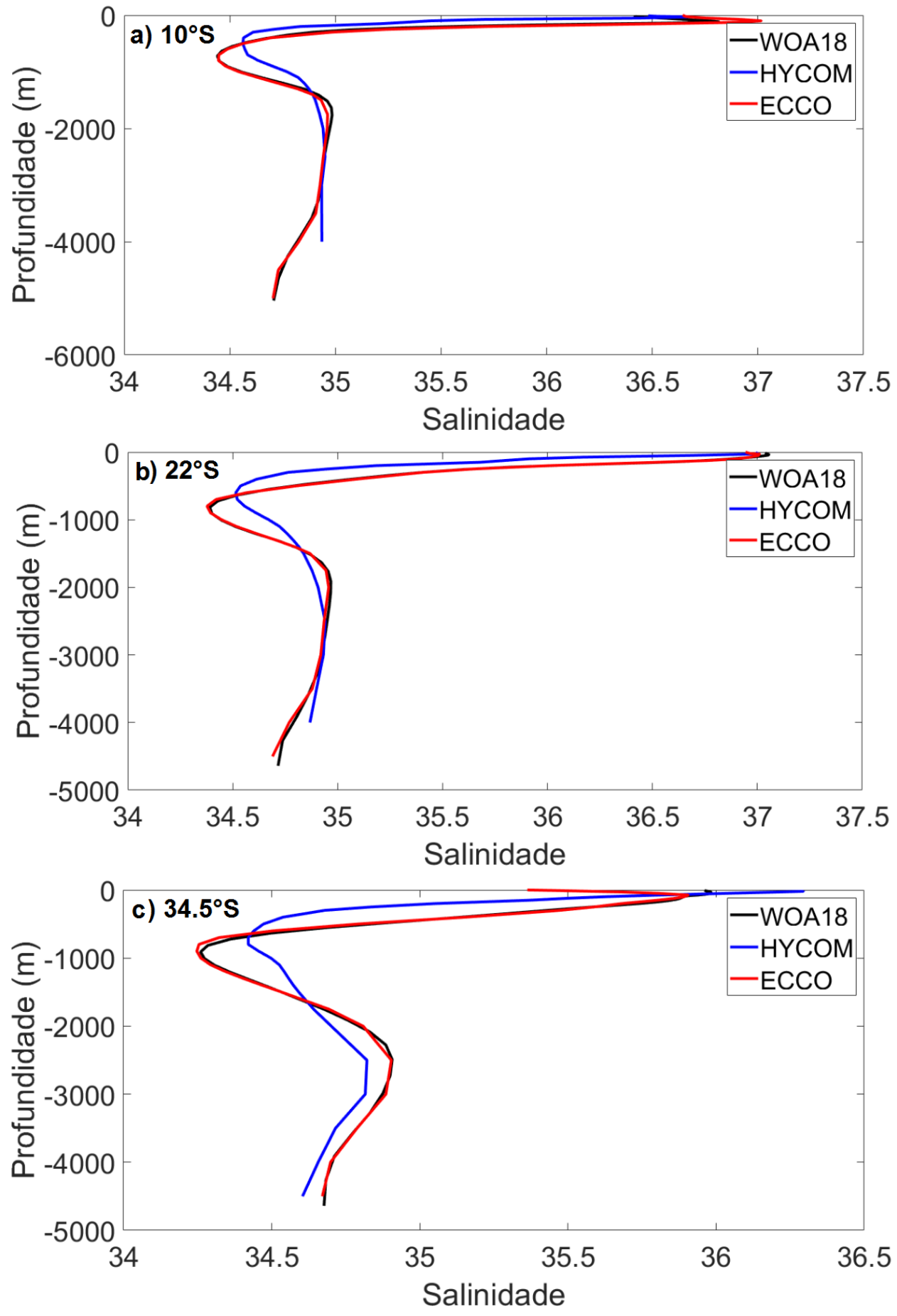

Figura 9. Figura análoga à 8 , porém referente aos dados de salinidade. 
Com o intuito de comparar de forma mais objetiva os dados dos modelos com os do WOA18, foram feitos perfis da diferença entre as média de temperatura e salinidade nas latitudes $10^{\circ} \mathrm{S}$ (Painéis a,b), $22^{\circ} \mathrm{S}$ (Painéis c,d) e $34.5^{\circ} \mathrm{S}$ (Painéis e,f) (Figura 10 e 11). A Figura 10 mostra a diferença da média de temperatura (HYCOM-WOA18) através dos painéis da esquerda (a,c,e). Notamos que as maiores diferenças estão nos dados de superfície com valores máximos de $4,1^{\circ} \mathrm{C}$ (Painel a), $4,0{ }^{\circ} \mathrm{C}$ (Painel c) e $4,9^{\circ} \mathrm{C}$ (Painel c) para as latitudes de $10^{\circ} \mathrm{S}, 22^{\circ}$ e $34.5^{\circ} \mathrm{S}$ (Painel e), respectivamente. Em relação ao ECCO, painéis da direita (b,d,f) da Figura 10 exibem a diferença de média de temperatura (ECCO-WOA18). Assim como no HYCOM, as menores diferenças em relação ao desvio padrão estão abaixo de $1500 \mathrm{~m}$ em todas as latitudes, entretanto o ECCO mostrou menores diferenças com base no desvio padrão entre os dados em todas as profundidades. Os valores máximos de diferença foram de $0,99{ }^{\circ} \mathrm{C}$ (Painel b), $0,88{ }^{\circ} \mathrm{C}$ (Painel d) e $0,90{ }^{\circ} \mathrm{C}$ (Painel f) nas latitudes $10^{\circ} \mathrm{S}, 22^{\circ} \mathrm{S}$ e $34.5^{\circ} \mathrm{S}$, respectivamente.
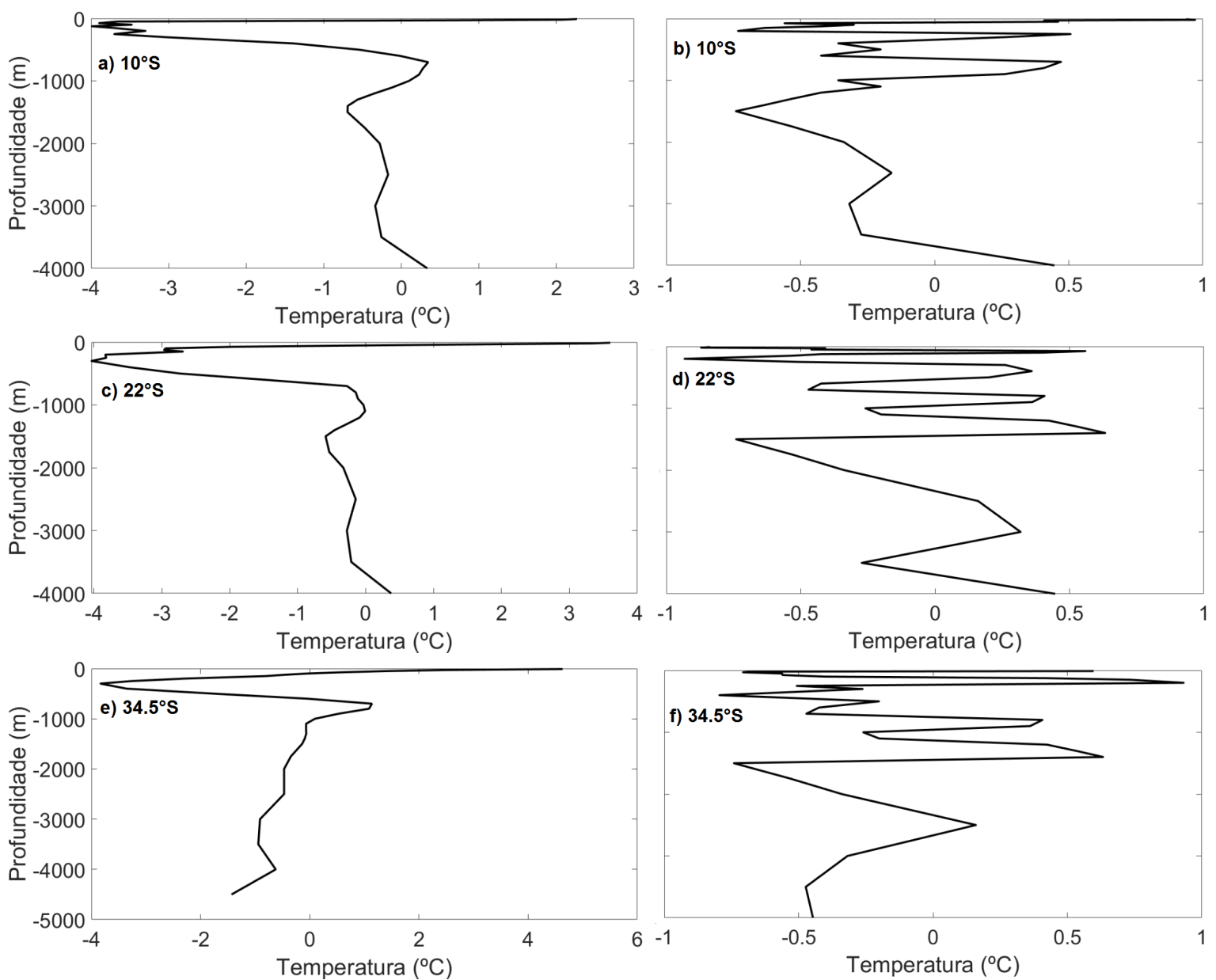

Figura 10. Diferença da média de temperatura nas latitudes $10^{\circ} \mathrm{S}$ (Painéis a,b), $22^{\circ} \mathrm{S}$ (Painéis c,d) e $34.5^{\circ} \mathrm{S}$ (Painéis e,f), entre as longitudes de $55^{\circ} \mathrm{W}$ e $32^{\circ} \mathrm{W}$ ) para o período de 1992 a 2015. Os painéis da esquerda (a,c,e) são referentes ao HYCOM e os painéis da direita $(b, d, f)$ ao ECCO. 
A Figura 11 mostra a diferença das média de salinidade (HYCOM-WOA18) através dos painéis da esquerda $(\mathrm{a}, \mathrm{c}, \mathrm{e})$. Assim como foi visto nos perfis de temperatura, também percebemos que as menores diferenças em relação ao desvio padrão se mantém abaixo de $1500 \mathrm{~m}$ para as três latitudes. As diferenças máximas foram de 1,6 (Painel a), 1,1 (Painel c) e 0,8 (Painel e) nas latitudes $10^{\circ} \mathrm{S}, 22^{\circ} \mathrm{S}$ e $34.5^{\circ} \mathrm{S}$, respectivamente. Quanto ao ECCO, painéis da direita (b,d,f) da Figura 11 mostram a diferença das média de salinidade (ECCO-WOA18). Novamente observamos que não existe grande variação dos resultados entre as profundidades, sendo que as diferenças máximas encontradas foram de $0,35{ }^{\circ} \mathrm{C}$ (Painel b), $0,34{ }^{\circ} \mathrm{C}$ (Painel d) e $0,69{ }^{\circ} \mathrm{C}$ (Painel f) nas latitudes $10^{\circ} \mathrm{S}, 22^{\circ} \mathrm{S}$ e $34.5^{\circ} \mathrm{S}$, respectivamente.
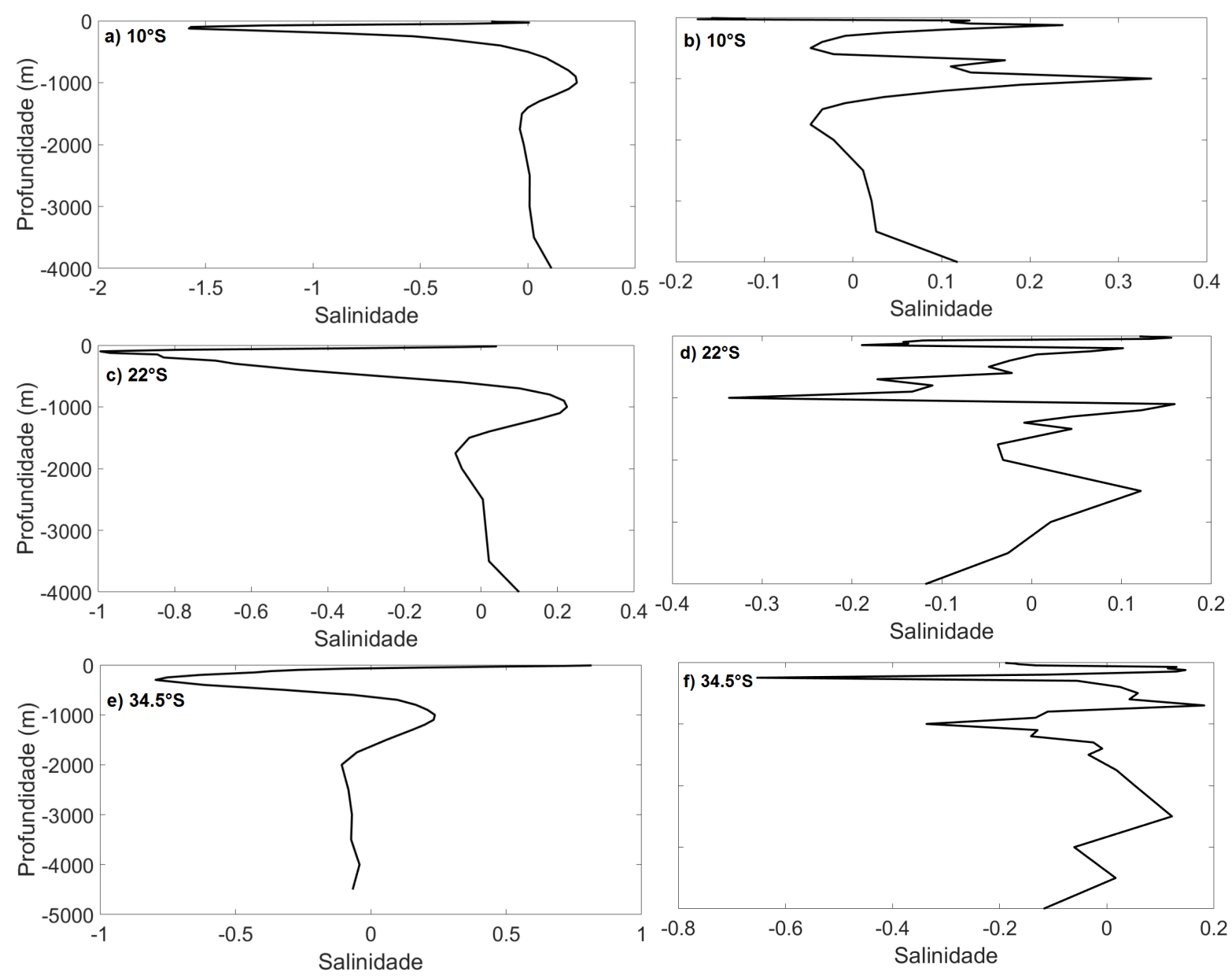

Figura 11. Figura análoga à 10 porém referente aos dados de salinidade.

Como as diferenças das médias dos dados termohalinos foram maiores no HYCOM, foi necessário observar melhor como o campo médio de temperatura e salinidade do modelo HYCOM difere da climatologia, e para isto, foi feita uma seção vertical das diferenças para toda a bacia do Atlântico Sul (Figuras 12 e 13, respectivamente). Pela diferença entre resultados obtidos pelo HYCOM e pelo WOA18 no mesmo local, é possível dizer se os dados do modelo 
estão condizentes com os dados in situ. Pode-se observar que os maiores valores de diferença entre a média de temperatura do HYCOM e a média da climatologia são vistos na superfície ( $-4{ }^{\circ} \mathrm{C}$ ) ou no fundo $\left(\sim-2{ }^{\circ} \mathrm{C}\right)$, abaixo de 5000 m nas três latitudes (Figura 12).

Em relação a diferença entre a média de salinidade do HYCOM e a média da climatologia para toda a bacia do Atlântico Sul, também vemos que as maiores diferenças estão na superfície (até $1200 \mathrm{~m}$ ) e no fundo (abaixo de $4000 \mathrm{~m}$ ). Em $10^{\circ} \mathrm{S}$, as maiores diferenças são de $-0,3$ e 0,1 na superfície e fundo, respectivamente. Em $22^{\circ} \mathrm{S}$, essas diferenças são de 0,3 e - 0,1 . Em $34.5^{\circ} \mathrm{S}$ observamos as maiores diferenças na superfície, que são $-0,5$ e novamente 0,1 no fundo (Figura 13 .

Como o enfoque do trabalho é a CCOP, é mais interessante inferir observações na região onde essa corrente é observada. Portanto as seções das diferenças dos campos médios de T e S entre modelos e climatologia estão nas das Figuras $12 \mathrm{e} 13$ que foram analisadas mais de perto, na região da localização da CCOP (abaixo de 1000 m e no máximo até $32^{\circ} \mathrm{W}$ ) (Figuras 14 e 15). Como já tinha sido observado, as menores diferenças de temperatura em relação ao desvio padrão estão abaixo de $1500 \mathrm{~m}$ para as três latitudes, com valores máximos de $0,9{ }^{\circ} \mathrm{C} \mathrm{em} 10^{\circ} \mathrm{S}$ e $22^{\circ} \mathrm{S}$ e $1,6 \mathrm{em} 34.5^{\circ} \mathrm{S}$ (resultados relativos a profundidade entre $1500 \mathrm{~m}$ e $3500 \mathrm{~m}$, pois a CCOP está contida nessa região) (Figura 14). Em relação ao ECCO, quando analisamos as diferenças de média entre profundidade $1500 \mathrm{~m}$ e $3500 \mathrm{~m}$, as maiores diferenças foram de $0,6^{\circ} \mathrm{C}$ em $10^{\circ} \mathrm{S}$ (Painel b) e $0,7^{\circ} \mathrm{C}$ em $22^{\circ} \mathrm{S}$ e $34.5^{\circ} \mathrm{S}$ (Painéis d,f) (Figura 10).

Quanto às diferenças de média de salinidade, também notamos que os menores valores estão entre $1500 \mathrm{~m}$ e $3500 \mathrm{~m}$, sendo que os máximos são -0,04, -0,02 e -0,12 em 10 $\mathrm{S}$ (Painel b) e $0,7^{\circ} \mathrm{C}$ em $22^{\circ} \mathrm{S}$ e $34.5^{\circ} \mathrm{S}$, respectivamente (Figura 15). Quando comparamos com os resultados do ECCO (entre $1500 \mathrm{~m}$ e $3500 \mathrm{~m}$ ), temos 0,04, 0,12 e 0,08 em $10^{\circ} \mathrm{S}$ (Painel b), $22^{\circ} \mathrm{S}$ (Painel d) e $34.5^{\circ} \mathrm{S}$ (Painéis f) (Figura 11 ).

Foi visto que o HYCOM representa melhor a distribuição de T e S na região mais funda do oceano em relação à climatologia, onde se encontra o objeto de estudo deste trabalho. A maior variabilidade nos dados de superfície talvez possa ser explicada pelo fato da climatologia ser suavizada e o HYCOM apresentar variabilidade de mesoescala. Além disso, na superfície, há maior interferência de agentes externos, como por exemplo, troca de calor com a atmosfera. Portanto, podemos dizer que o HYCOM e o ECCO são capazes de reproduzir características oceânicas e deste modo, representar de forma adequada a CCOP. 

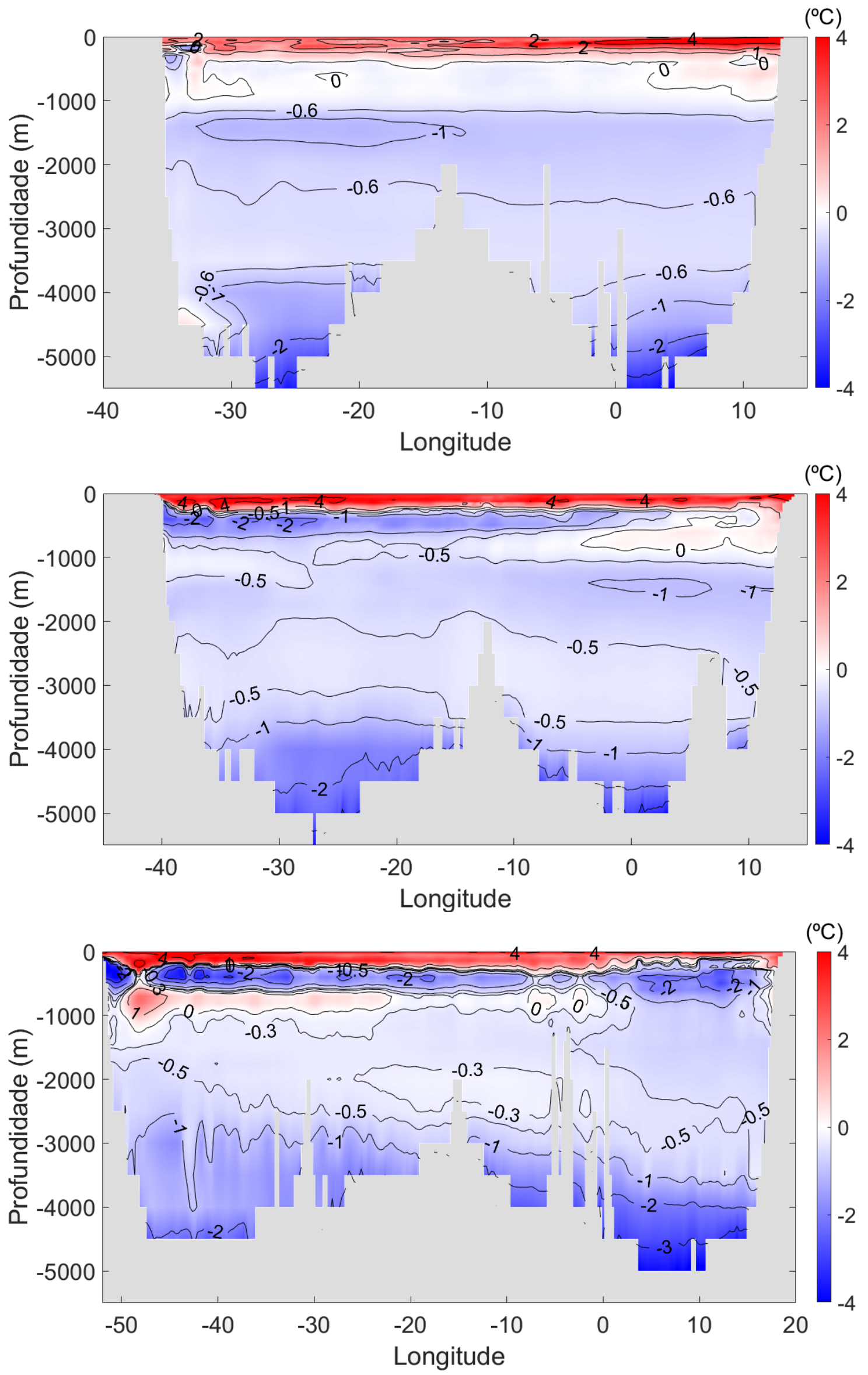

Figura 12. Diferença das temperaturas médias (WOA18-HYCOM) para as latitudes de $10^{\circ} \mathrm{S}$, $22^{\circ} S$ e $34.5^{\circ} S$ para a bacia do Atlântico Sul. 

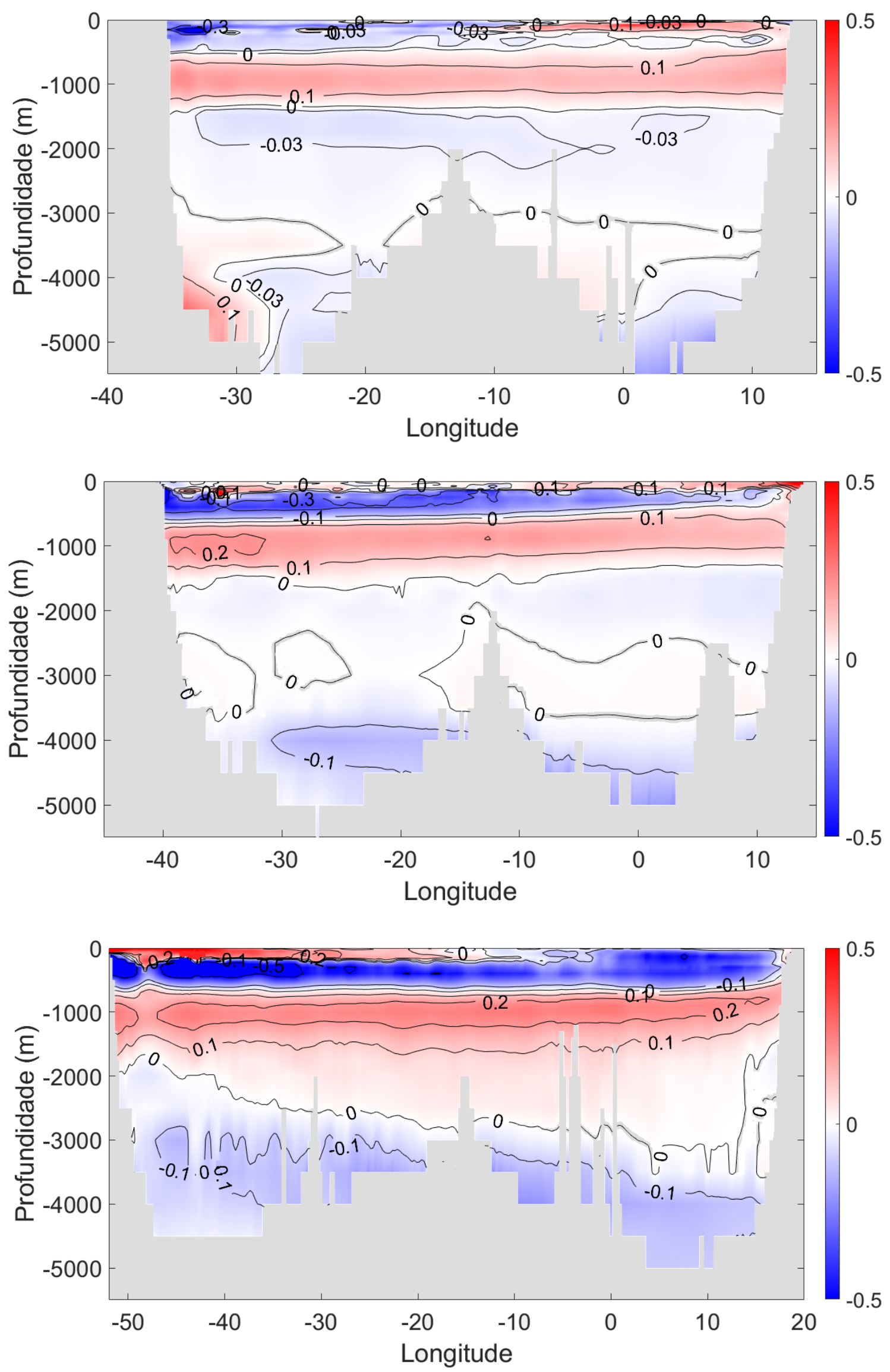

Figura 13. Análogo à Figura 12, porém referente aos dados de salinidade. 

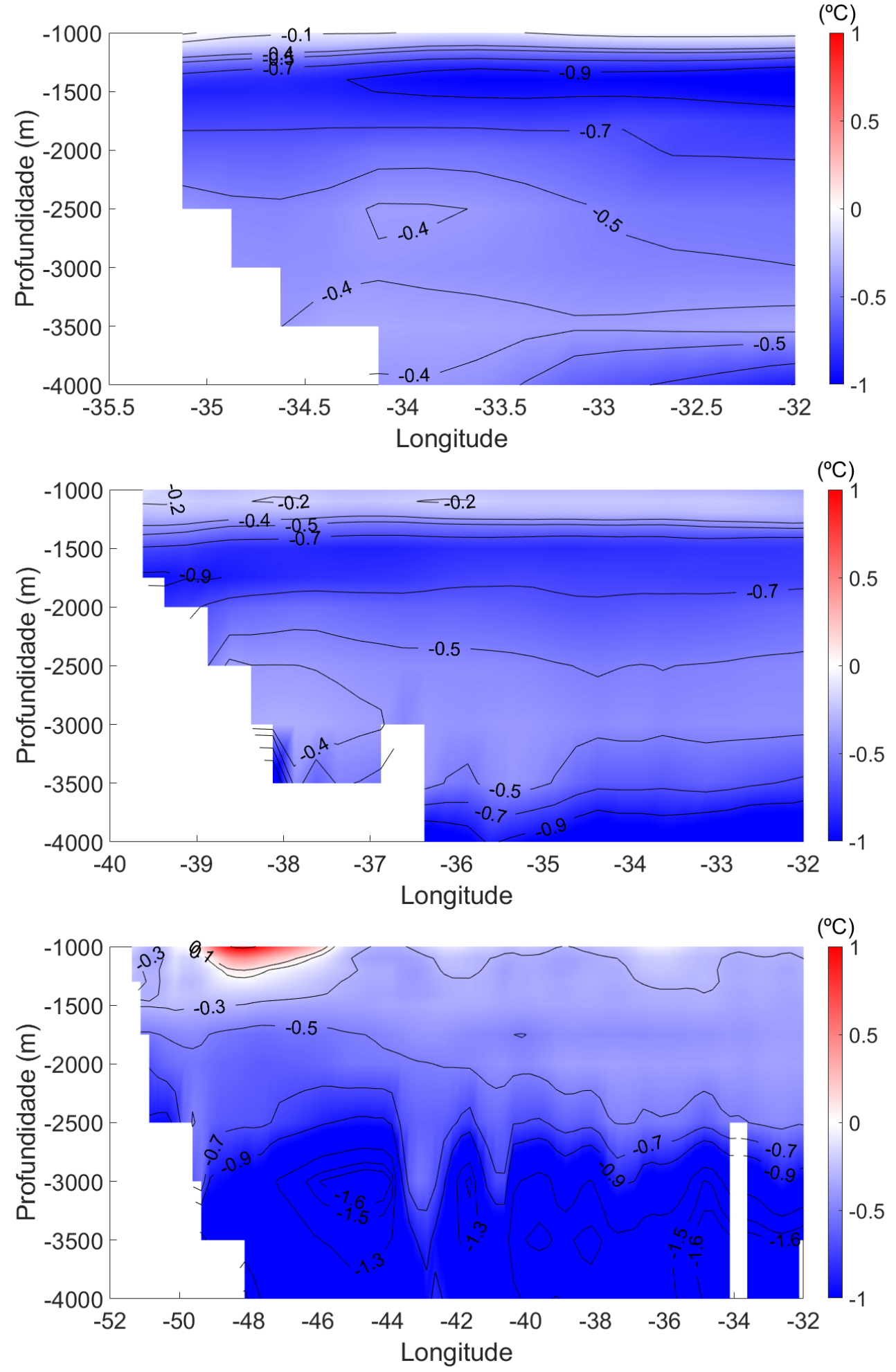

Figura 14. Diferença das temperaturas médias (WOA18-HYCOM) para as latitudes de $10^{\circ} \mathrm{S}$, $22^{\circ} \mathrm{S}$ e $34.5^{\circ} \mathrm{S}$ até $32^{\circ} \mathrm{W}$, abaixo da profundidade de $1000 \mathrm{~m}$, isto é, na região da CCOP. 

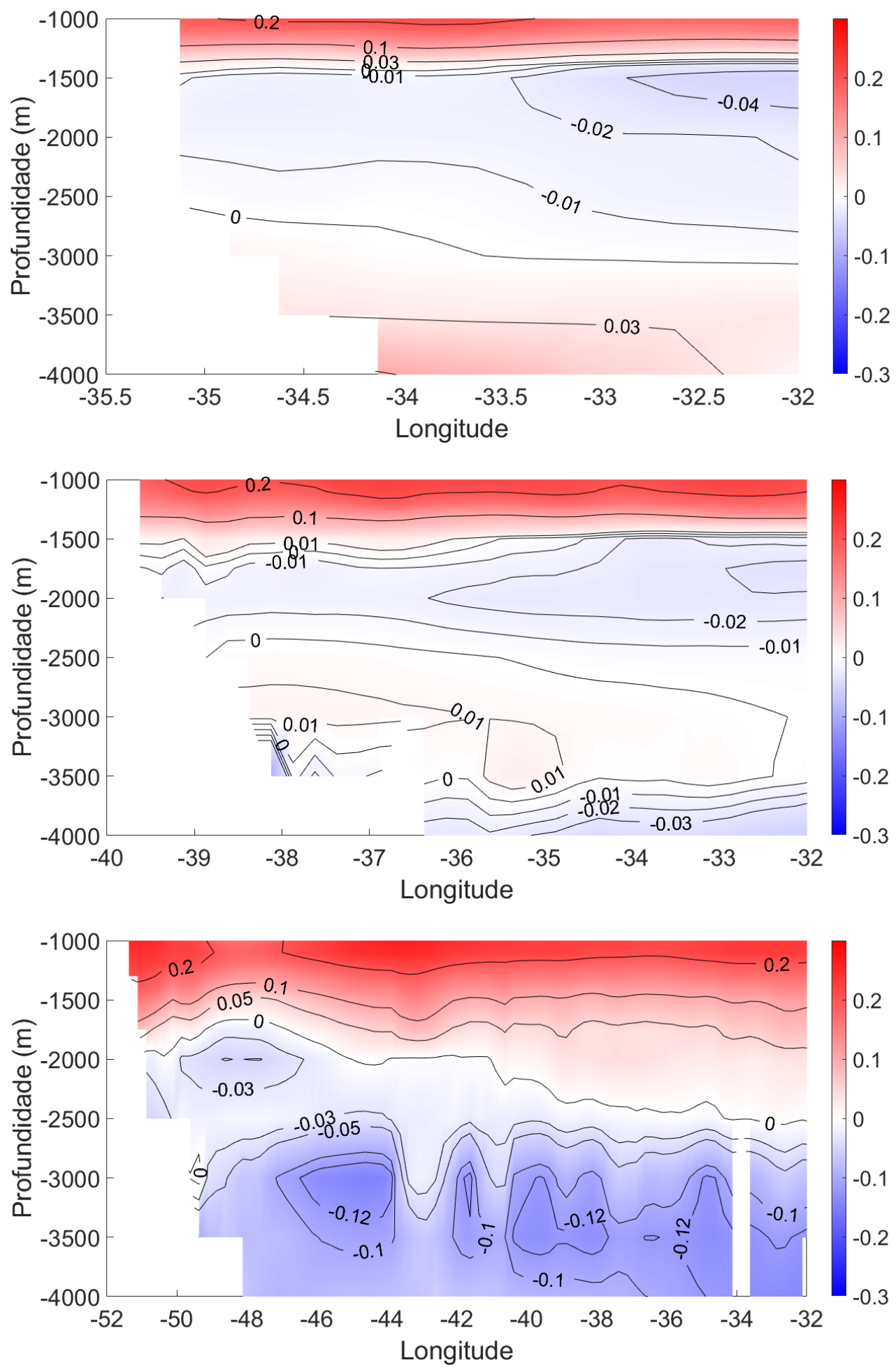

Figura 15. Análogo à Figura 14, porém referente aos dados de salinidade. 


\subsection{Identificação e localização da CCOP}

A partir dos critérios de definições de massas de água profundas, a posição da CCOP foi delimitada nas latitudes $10^{\circ} \mathrm{S}, 22^{\circ} \mathrm{S}$ e $34.5^{\circ} \mathrm{S}$ (Figura 16).
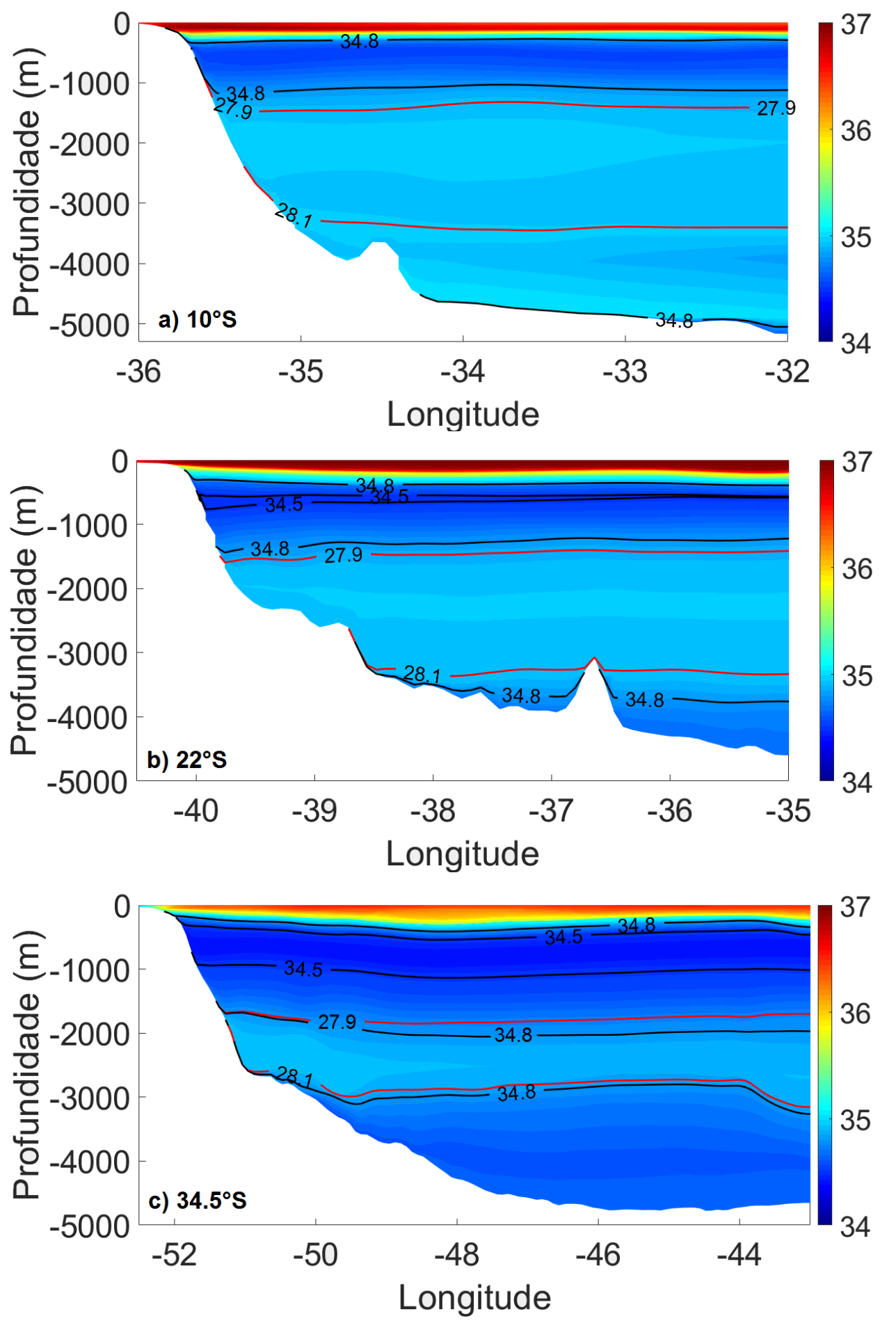

Figura 16. Seção zonal da média de salinidade do HYCOM nas latitudes $10^{\circ} \mathrm{S}$ (Painel a), $22^{\circ} S$ (Painel b) e $34.5^{\circ} S$ (Painel c) entre 1992 e 2015. Contornos em preto indicam os valores de salinidade e os contornos em vermelhos mostram os níveis densidade neutra entre 27,9 kg. $\mathrm{m}^{-3}$ e $28,10 \mathrm{~kg} \cdot \mathrm{m}^{-3}$, que são correspondentes as características da APAN. 


\subsection{Velocidades meridionais obtidas pelos CPIES}

Os instrumentos CPIES mediram as velocidades dos fluxos que percorreram em até $50 \mathrm{~m}$ acima dos equipamentos. O dois instrumentos CPIES (AA e BB) foram instalados em dezembro de 2012 e permaneceram até o final de 2014. A Figura 17]representa as medições de velocidades durante o período de 2012 a 2014 , em $34.5^{\circ} \mathrm{S}$. A velocidade média obtida pelo CPIES-AA foi de 2,83 $\pm 2,9 \mathrm{~cm} . \mathrm{s}^{-1}$ e $1,48 \pm 1,8 \mathrm{~cm} . \mathrm{s}^{-1}$ pelo CPIES-BB. Notamos que as velocidades são positivas, indicando fluxo para norte. Entretanto, Meinen et al. (2017) mostraram a presença de recirculações para o norte, tanto na camada superficial como na profunda com o uso dos PIES. Além disso, com a utilização dos CPIES os autores também observaram a existência de uma célula de recirculação (fluxo para norte) profunda que se estende até o fundo.

Ademais, Meinen et al. (2017) observaram que em julho de 2009, entre maio e junho de 2012 e entre fevereiro e e março de 2014 houve um transporte intenso e anômalo para norte na camada profunda em $34.5^{\circ} \mathrm{S}$. Eles notaram que esses eventos intensos de transporte são suficientemente grandes quando o fluxo integrado da APAN reverte seu sinal, e isto indica que a recirculação offshore ao norte às vezes excede o fluxo para o sul do própria CCOP. Foram analisadas as velocidades do HYCOM e do ECCO para as regiões mais próximas o possível dos locais de instalação dos CPIES, entre 2012 e 2014. As velocidades médias obtidas pelo HYCOM em $34.5^{\circ} \mathrm{S}$, nas longitudes de $50^{\circ} 31.2^{\prime} \mathrm{W}$ e $48^{\circ} 30.5^{\prime} \mathrm{W}$ foram de $-2,48 \pm 3,5 \mathrm{~cm} . \mathrm{s}^{-1} \mathrm{e}$ $-1,43 \pm 2,7 \mathrm{~cm} . \mathrm{s}^{-1}$, respectivamente.

Em relação ao ECCO, as velocidades foram captadas em $34.5^{\circ} \mathrm{S}$, nas longitudes de $50.5^{\circ} \mathrm{W}$ e $48.5^{\circ} \mathrm{W}$, e correspondem a $-1,78 \pm 1,5 \mathrm{~cm} . \mathrm{s}^{-1}$ e $-0,85 \pm 0,4 \mathrm{~cm} . \mathrm{s}^{-1}$, respectivamente. As velocidades médias mostradas pelo ECCO são ligeiramente menores do que as obtidas pelos correntômetros. Apesar dos resultados obtidos pelos modelos estarem na mesma ordem de grandeza que os dados CPIES, é importante notar que o sentido do fluxo é oposto. Portanto, vemos que os modelos não foram capazes de captar esse fluxo intenso e anômalo que ocorreu para norte entre 2009 e 2014.

\subsubsection{Seções Verticais de velocidade meridional obtidas pelo HYCOM}

$\mathrm{Na}$ análise de identificação da CCOP, foram feitas as seções verticais da velocidade meridional nas latitudes de $10^{\circ} \mathrm{S}, 14^{\circ} \mathrm{S}, 18^{\circ} \mathrm{S}, 22^{\circ} \mathrm{S}$ (Figura 18), $26^{\circ} \mathrm{S}, 30^{\circ} \mathrm{S}$ e $34.5^{\circ} \mathrm{S}$ (Figura

19]. As seções verticais são referentes ao período de 1992 a 2015. Nos painéis das Figuras 18 

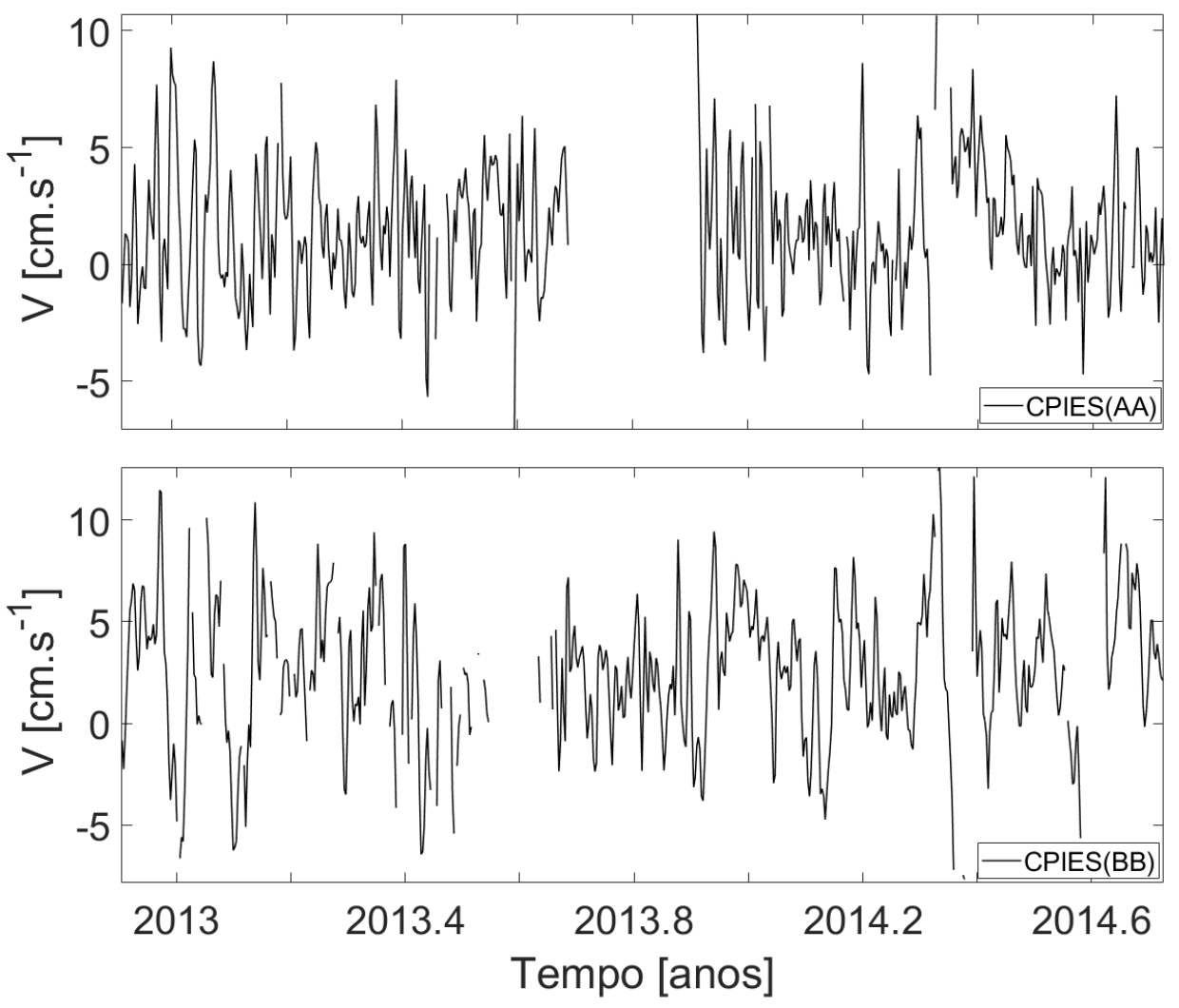

Figura 17. Velocidade meridional dos CPIES (AA e BB) fundeados pelo programa SAMOC no Atlântico Sul em $34.5^{\circ} \mathrm{S}$.

e 19, a CCOP foi delimitada através dos tracejados (em branco) que representam velocidade igual a zero. A CCOP é composta pela APAN, que flui em direção ao sul (velocidade negativa). Notamos que a CCOP diminui sua largura e velocidade a medida que a mesma segue em direção ao sul.

Na Figura 18, vemos que a CCOP está centrada entre 2000 e 2500 m, sendo que nas latitudes $10^{\circ} \mathrm{S}$ e $14^{\circ} \mathrm{S}$ vemos que ao lado leste da CCOP existe um fluxo de velocidade similar ao dessa corrente com sentido contrário, possivelmente relacionado à possíveis recirculações da corrente. Podemos observar que durante o seu percurso pelo Atlântico sul, a CCOP é influenciada pela batimetria de fundo e seu transporte vai decrescendo ao longo de seu trajeto.

Em $10^{\circ} \mathrm{S}$ vemos que a corrente está centrada em $2200 \mathrm{~m}$ com velocidades máximas em torno de $-0,08 \pm 0,9 \mathrm{~m} \cdot \mathrm{s}^{-1}$. Em $14^{\circ} \mathrm{S}$ o fluxo se intensifica e sua velocidade máxima chega a $-0,13 \pm 0,3 \mathrm{~m} \cdot \mathrm{s}^{-1}$. Ademais, a CCOP ganha profundidade e se centraliza em torno de $2500 \mathrm{~m}$ (entre $38.7^{\circ} \mathrm{W}$ e $37^{\circ} \mathrm{W}$ ) (Figura 18 ). Quando chega em $18^{\circ} \mathrm{S}$, devido à mudança na topografia, a CCOP reduz sua largura e se intensifica, com velocidades máximas por volta de $-0,19 \pm 0,2$ $\mathrm{m} . \mathrm{s}^{-1}$. Em $22^{\circ} \mathrm{S}$, após a passagem pela região da Cadeia Vitória Trindade (Figura 5), a intensi- 
dade máxima do fluxo diminui para $-0,11 \pm 0,4 \mathrm{~m} \cdot \mathrm{s}^{-1}$ e assim sua largura também se reduz. Em $26^{\circ} \mathrm{S}$ é possível observar de forma clara a atenuação da CCOP, onde sua velocidade máxima se reduz a $-0,04 \pm 0,06 \mathrm{~m} . \mathrm{s}^{-1}$ e nota-se o aumento de sua largura. Talvez essa redução de intensidade esteja relacionada com a diminuição de profundidade da borda oeste após a passagem pela CVT (Figura 19].

É interessante notar que em $30^{\circ} \mathrm{S}$ o centro da CCOP fica em torno de $3000 \mathrm{~m}$ e há uma intensificação da CCOP, com velocidades máximas em torno de $-0,12 \pm 0,1 \mathrm{~m} \cdot \mathrm{s}^{-1}$, possivelmente relacionada com a Bifurcação de Santos, que está localizada dentro da Bacia de Santos (entre $23^{\circ} \mathrm{S}$ e $28^{\circ} \mathrm{S}$ e $44^{\circ} \mathrm{W}$ e $48^{\circ} \mathrm{W}$ ), normalmente em $27^{\circ} \mathrm{S}$ (Figura 5). De acordo com Biló et al. (2014), em torno de $27^{\circ} \mathrm{S}$, a camada da AIA/APCS se bifurca e um ramo vai para norte (Corrente de Contorno Oeste Intermediária) e o outro ramo vai para sul. Este ramo que segue em direção sul provavelmente se incorpora com a CCOP. Boebel et al. (1999) usaram flutuadores lagrangeanos e mostraram que tanto a AIA quanto a APCS atingem a margem continental da América do Sul vinda do leste como parte intermediária/profunda do giro subtropical do Atlântico Sul. Em $34.5^{\circ} \mathrm{S}$, ainda é possível observar a presença da CCOP, e o interessante é que a corrente ficou menos profunda, com centro próximo de $1500 \mathrm{~m}$ e velocidades em torno de $-0,05 \pm 0,03$ m.s ${ }^{-1}$ (Figura 19. 

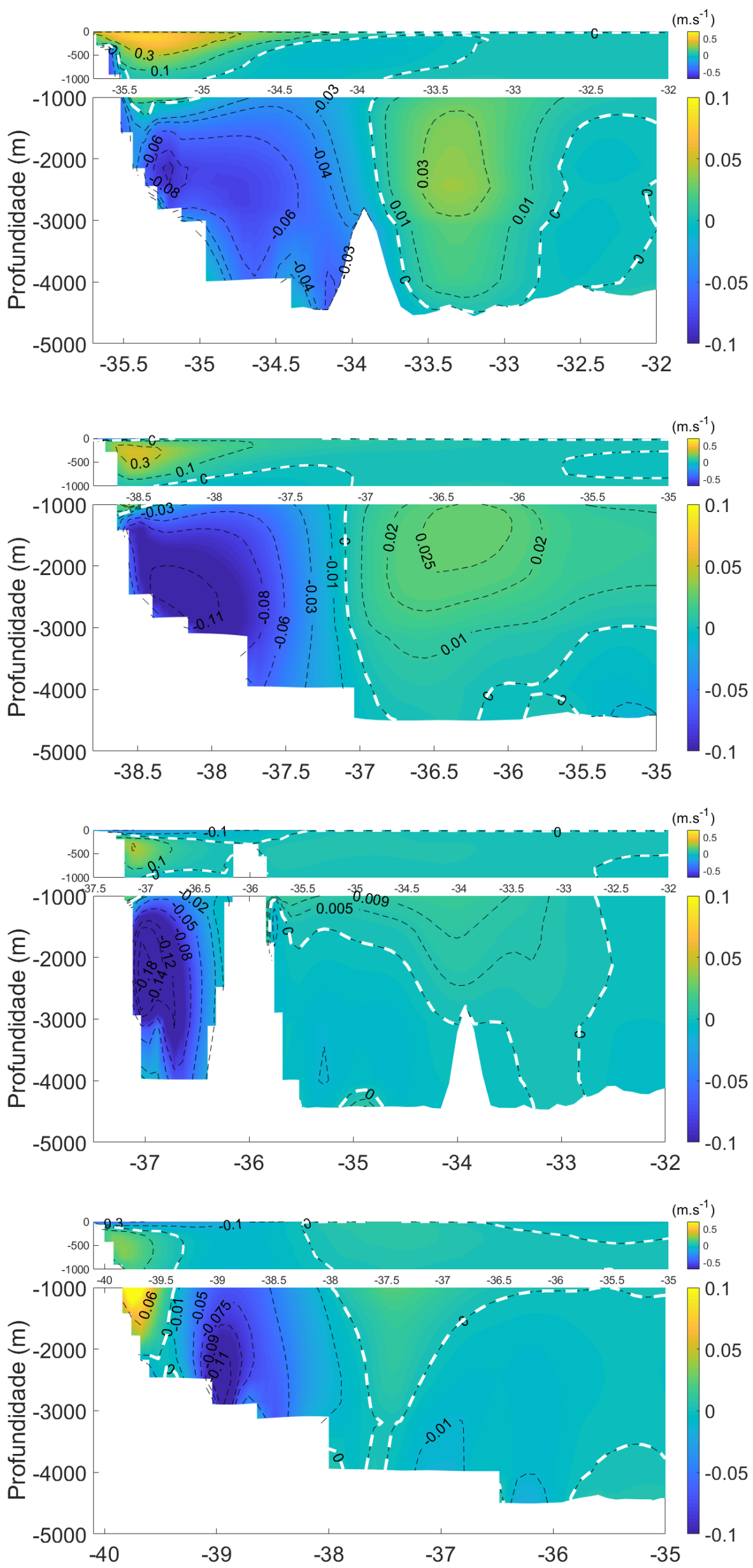

Figura 18. Seções verticais da velocidade meridional $\left(\mathrm{m}^{\left.-\mathrm{s}^{-1}\right)}\right.$ da CCOP obtidas através do HYCOM nas latitudes de $10^{\circ} \mathrm{S}, 14^{\circ} \mathrm{S}, 18^{\circ} \mathrm{S}$ e $22^{\circ} \mathrm{S}$ do Atlântico sul, no período entre 1992 a 2015. $O$ tracejado (linhas brancas) representa velocidade igual a zero. 

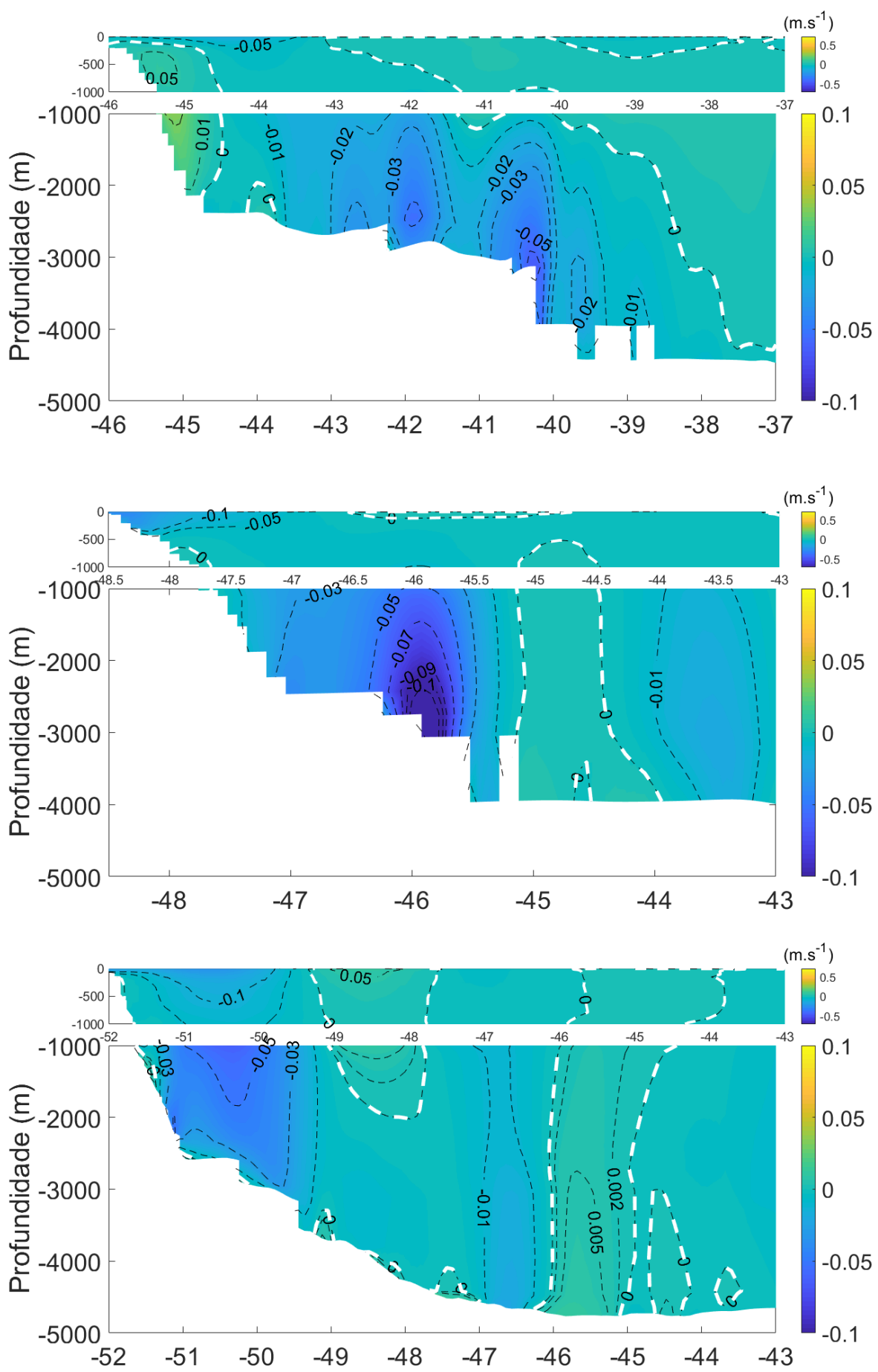

Figura 19. Seções verticais da velocidade meridional $\left(\mathrm{m}_{\mathrm{s}} \mathrm{s}^{-1}\right)$ da CCOP obtidas através do HYCOM nas latitudes de $26^{\circ} \mathrm{S}, 30^{\circ} \mathrm{S}$ e $34.5^{\circ} \mathrm{S}$ do Atlântico sul, no período entre 1992 a 2015. $O$ tracejado (linhas brancas) representa velocidade igual a zero. 
A Figura 20 mostra o padrão da CCOP relativo ao período de 2005 a 2012, resultante das simulações globais do modelo HYCOM referente à camada de $2200 \mathrm{~m}$. Vemos que CCOP entra no Atlântico Sul bordeando o contorno oeste com velocidades em torno de $-0,18 \pm 0,1 \mathrm{~m} \cdot \mathrm{s}^{-1}$. O fluxo segue em direção sul como um escoamento organizado até próximo a latitude de $21^{\circ} \mathrm{S}$, na região da CVT. Em seguida, devido às mudanças na batimetria, uma parte do fluxo segue o contorno e outra parte contorna a região da CVT. Podemos observar que na continuidade do percurso, a CCOP sofre diversas recirculações, conforme respaldado pela literatura (Meinen et al. 2012; Hummels et al. 2015). Além disso, vemos que o fluxo se separa do contorno oeste em torno de $38^{\circ} \mathrm{S}$, na região da Confluência Brasil-Malvinas, e segue em direção Sul até aproximadamente $45^{\circ} \mathrm{S}$, onde o mesmo se une com a CCA e segue para leste, o que é corroborado por Garzoli et al. (2015).

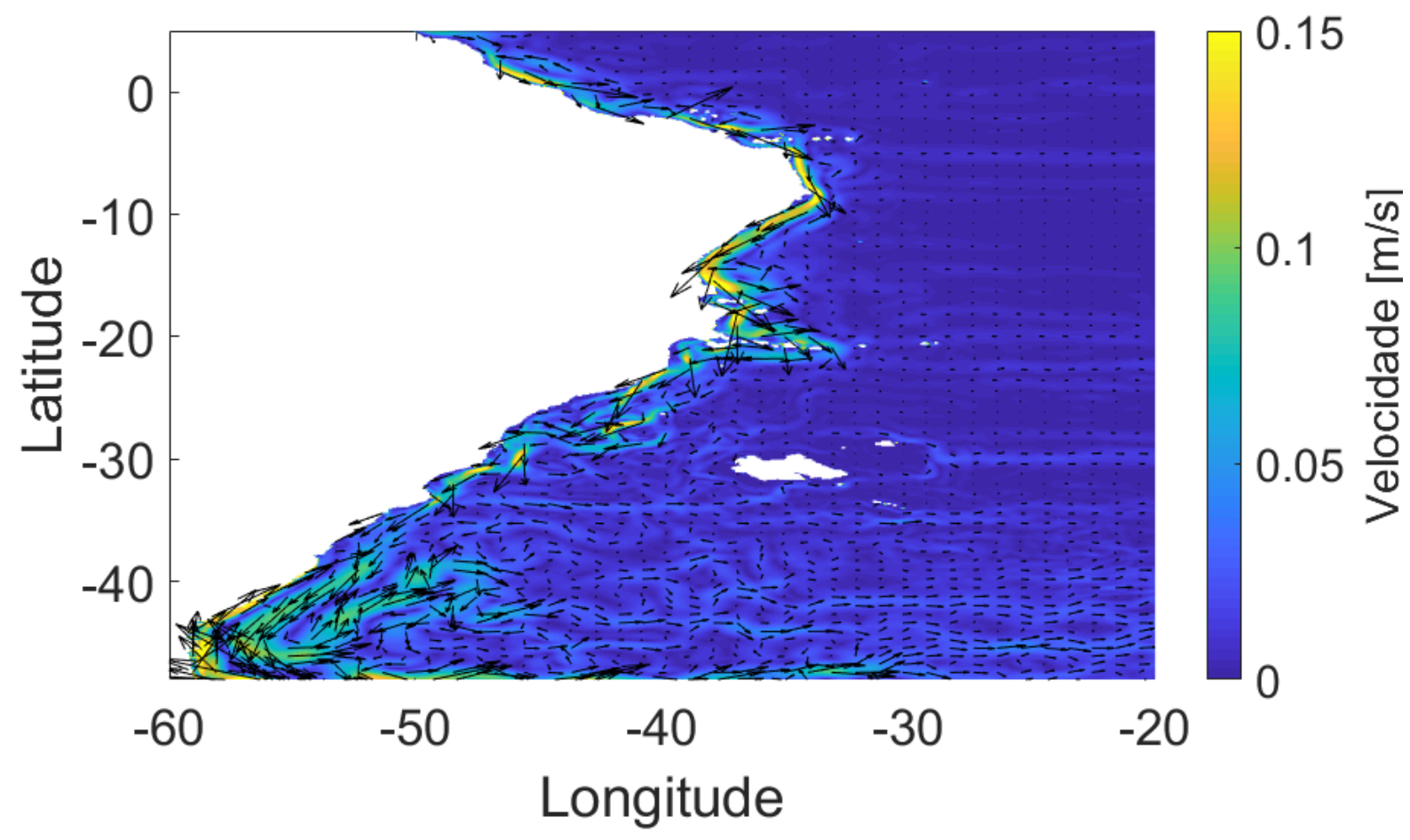

Figura 20. Média de velocidade no período de 2005 a 2012 para a profundidade de $2200 \mathrm{~m}$, oriundo da simulação global do modelo HYCOM. A magnitude da corrente é representada pelos vetores de velocidade.

\subsubsection{Seções Verticais de velocidade meridional obtidas pelo ECCO}

De forma análoga, foram feitas seções verticais da velocidade meridional nas latitudes de $10^{\circ} \mathrm{S}, 14^{\circ} \mathrm{S}, 18^{\circ} \mathrm{S}, 22^{\circ} \mathrm{S}$ (Figura 23), $26^{\circ} \mathrm{S}, 30^{\circ} \mathrm{S}$ e $34.5^{\circ} \mathrm{S}$ (Figura 24) obtidas pelo modelo 
ECCO, no período entre 1992 a 2015. As posições dessas latitudes no Atlântico Sul podem ser vistas na Figura 5. A CCOP foi delimitada através do tracejado (em branco) que representa velocidade igual a zero. Em $10^{\circ} \mathrm{S}$, vemos a CCOP centrada em torno de $2250 \mathrm{~m}$, com velocidades máximas em torno de $-0,045 \pm 0,03 \mathrm{~m} \cdot \mathrm{s}^{-1}$. Na latitude de $14^{\circ} \mathrm{S}$, a corrente sofre uma redução de velocidade máxima para $-0,025 \pm 0,02 \mathrm{~m} . \mathrm{s}^{-1}$ e se centraliza próximo de $2000 \mathrm{~m}$. Em $18^{\circ} \mathrm{S}$ e $22^{\circ} \mathrm{S}$, a CCOP ganha profundidade, seu centro pode ser visto em torno de $2500 \mathrm{~m}$, com velocidade máxima em torno de $-0,035 \pm 0,03 \mathrm{~m} . \mathrm{s}^{-1}$ e $-0,030 \pm 0,02 \mathrm{~m} . \mathrm{s}^{-1}$, respectivamente (Figura 23).

A partir de $26^{\circ} \mathrm{S}$, o fluxo perde intensidade e as velocidades se reduzem à $-0,015 \pm 0,025$ $\mathrm{m} . \mathrm{s}^{-1}$. Em $30^{\circ} \mathrm{S}$ a CCOP fica menos profunda, seu centro está em torno de $1500 \mathrm{~m}$, e também vemos novamente um aumento de velocidade máxima $\left(-0,030 \pm 0,01 \mathrm{~m} \cdot \mathrm{s}^{-1}\right)$. Em $34.5^{\circ} \mathrm{S}$, a velocidade máxima tem um aumento $\left(-0,04 \pm 0,02 \mathrm{~m} \cdot \mathrm{s}^{-1}\right)$ e a CCOP numa profundidade menor se mantém. Esse padrão também é visto na seção meridional em $34.5^{\circ} \mathrm{S}$ obtida pelo HYCOM, no qual o centro da CCOP está próximo de $1500 \mathrm{~m}$ com velocidades máximas em torno de $-0,05 \pm 0,03 \mathrm{~m} . \mathrm{s}^{-1}$ (Figura 24).

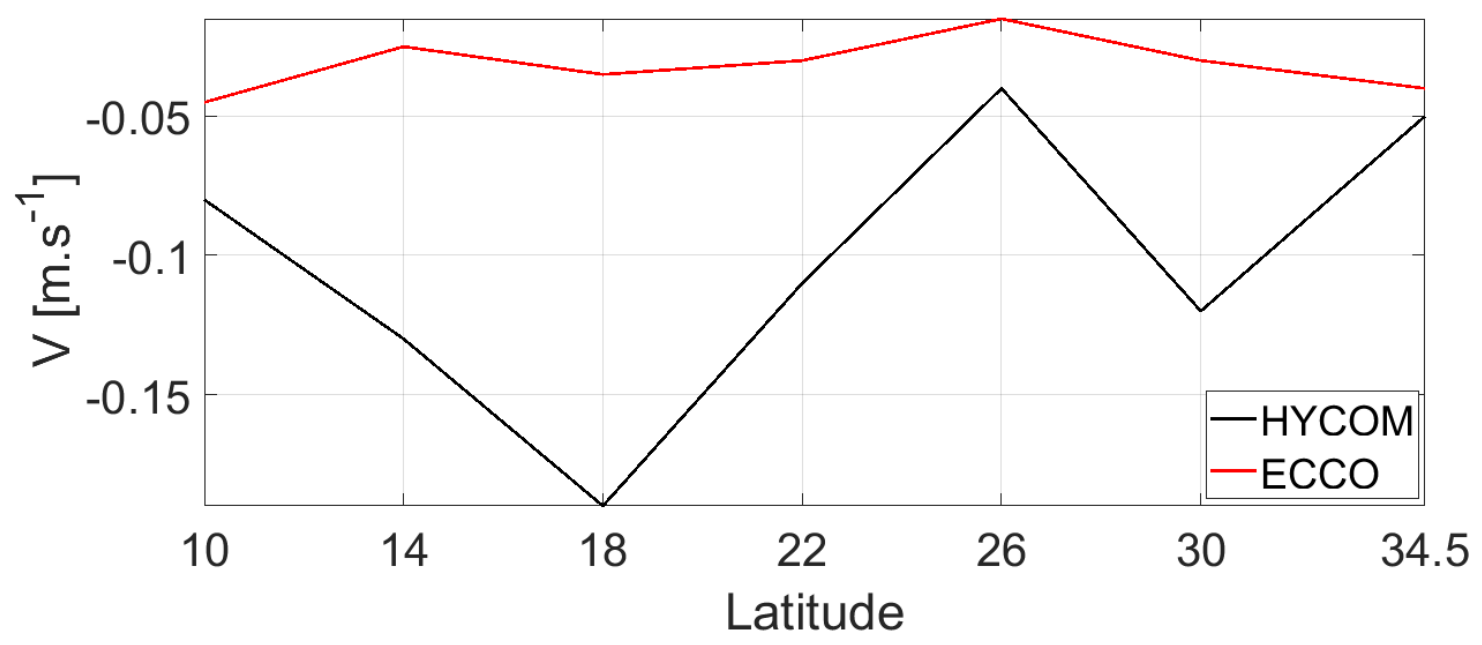

Figura 21. Velocidade máxima do HYCOM (linha preta) e do ECCO (linha vermelha) em função da latitude $\left(10^{\circ} \mathrm{S}, 14^{\circ} \mathrm{S}, 22^{\circ} \mathrm{S}, 26^{\circ} \mathrm{S}, 30^{\circ} \mathrm{S}\right.$ e $\left.34.5^{\circ} \mathrm{S}\right)$. 
As variações de velocidade máxima do HYCOM (linha preta) e do ECCO (linha vermelha) de acordo com as mudanças de latitude são mostradas na Figura 21. Podemos observar que as variações de velocidade máxima são maiores no ECCO. Além disso, em comparação ao HYCOM, o modelo ECCO exibe velocidades mais baixas para a CCOP, possivelmente pelo fato de que as saídas dos dados de velocidade são mensais ao invés de diárias como do HYCOM. Pelo HYCOM, o centro da CCOP possui velocidade média em torno de $-0,1 \pm 0,15 \mathrm{~m} . \mathrm{s}^{-1}$ até a latitude $22^{\circ} \mathrm{S}$ e conforme segue para sul as velocidades médias decrescem para $-0,05 \pm 0,09 \mathrm{~m} . \mathrm{s}^{-1}$, enquanto que no ECCO, no centro da CCOP, as velocidades médias decrescem de $-0,045 \pm 0,02$ $\mathrm{m} \cdot \mathrm{s}^{-1}$ a $-0,005 \pm 0,002 \mathrm{~m} \cdot \mathrm{s}^{-1}$ ao longo do Atlântico Sul.

A Figura 22 mostra as variações de profundidade do centro da CCOP do HYCOM (linha preta) e do ECCO (linha vermelha) de acordo com as mudanças de latitude. Podemos notar que em ambos os modelos, o centro da CCOP permanece entre $2000 \mathrm{~m}$ e $2500 \mathrm{~m}$ entre $10^{\circ} \mathrm{S}$ e $26^{\circ} \mathrm{S}$, sendo que entre $18^{\circ} \mathrm{S}$ e $26^{\circ} \mathrm{S}$, o centro se coincide em $2500 \mathrm{~m}$. Em $30^{\circ} \mathrm{S}$, o HYCOM mostra o centro da CCOP mais profundo (3000 m) e pelo ECCO, menos profundo (1500 m). Em $34.5^{\circ} \mathrm{S}$, em ambos os modelos, o centro está menos profundo, em torno de $1500 \mathrm{~m}$.

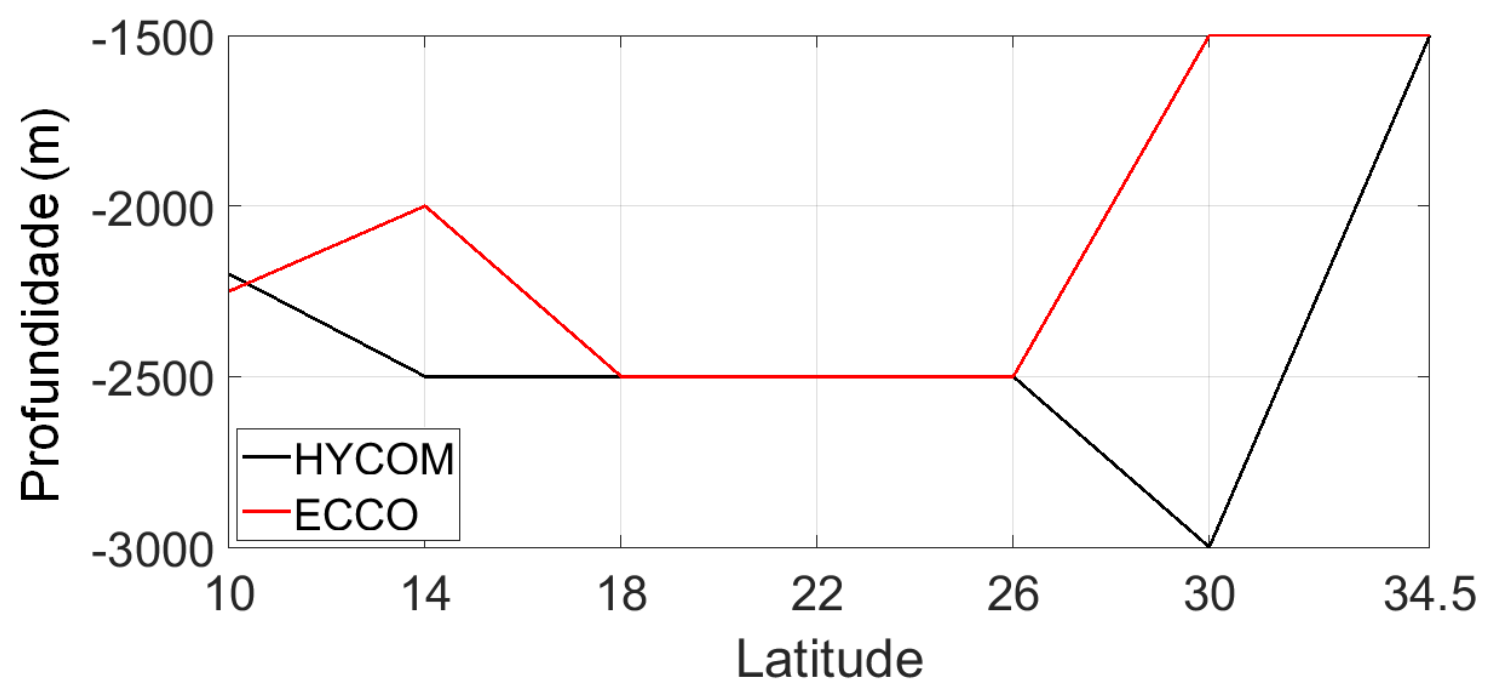

Figura 22. Profundidade do centro da CCOP no HYCOM (linha preta) e no ECCO (linha vermelha) em função da latitude $\left(10^{\circ} \mathrm{S}, 14^{\circ} \mathrm{S}, 22^{\circ} \mathrm{S}, 26^{\circ} \mathrm{S}, 30^{\circ} \mathrm{S}\right.$ e $\left.34.5^{\circ} \mathrm{S}\right)$. 

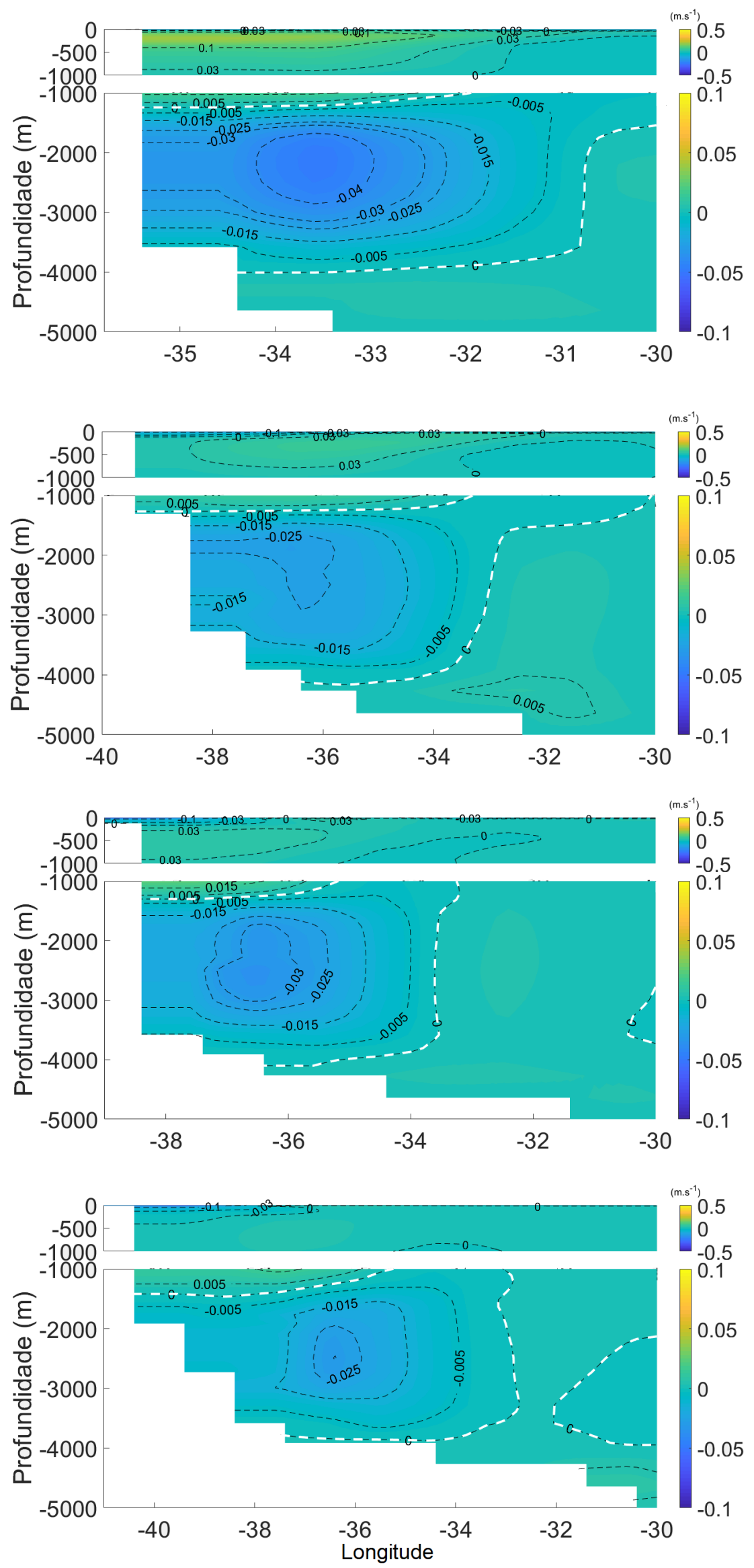

Figura 23. Seções verticais da velocidade meridional $\left(\mathrm{m} . \mathrm{s}^{-1}\right)$ da CCOP obtidas através do ECCO nas latitudes de $10^{\circ} \mathrm{S}, 14^{\circ} \mathrm{S}, 18^{\circ} \mathrm{S}$ e $22^{\circ} \mathrm{S}$ do Atlântico sul, no período entre 1992 a 2015. $O$ tracejado (linhas brancas) representa velocidade igual a zero. 

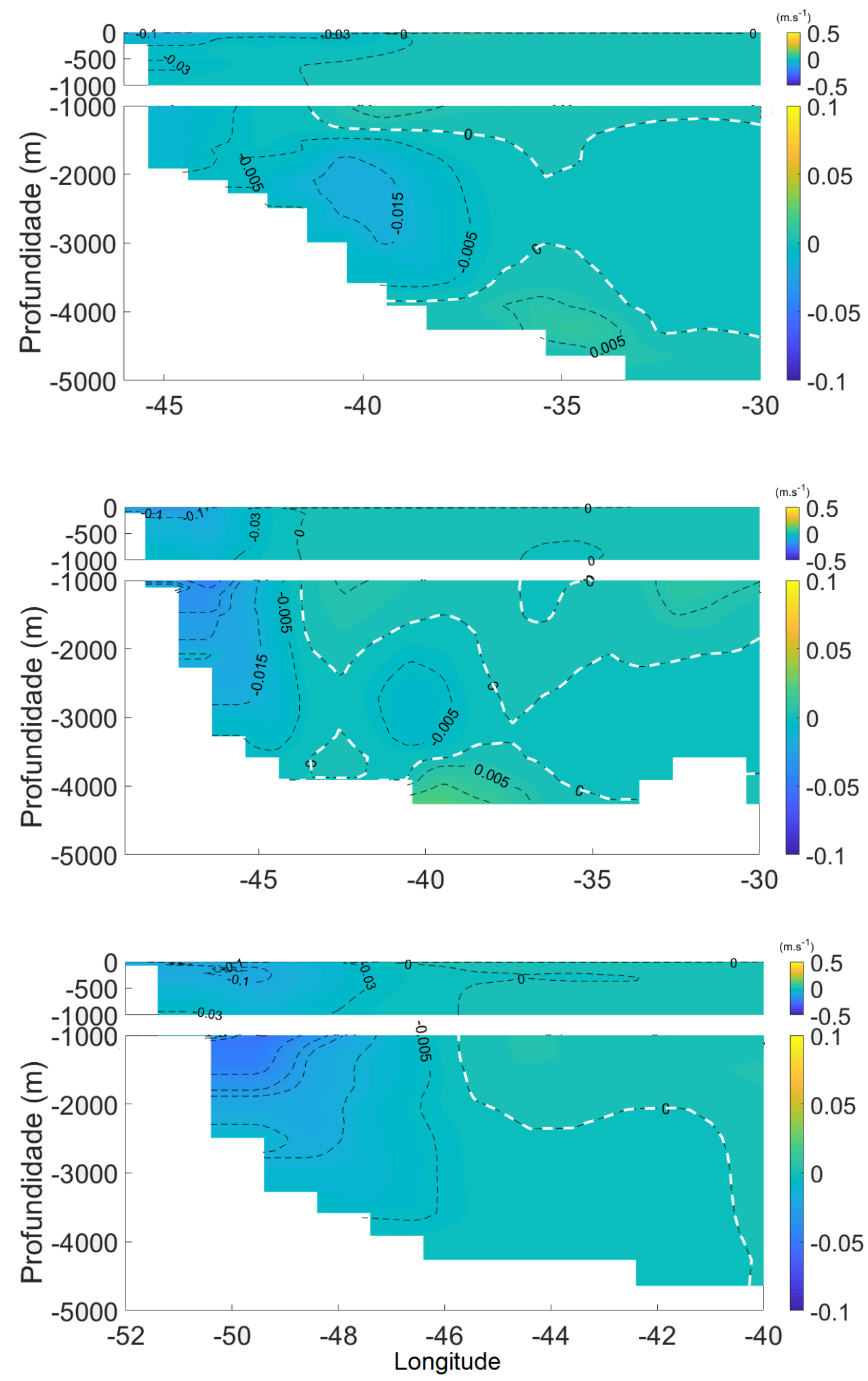

Figura 24. Seções verticais da velocidade meridional $\left(\mathrm{m} \cdot \mathrm{s}^{-1}\right)$ da CCOP obtidas através do ECCO nas latitudes de $26^{\circ} \mathrm{S}, 30^{\circ} \mathrm{S}$ e $34.5^{\circ} \mathrm{S}$ do Atlântico sul, no período entre 1992 a 2015 . $\mathrm{O}$ tracejado (linhas brancas) representa velocidade igual a zero. 


\subsection{Transporte de Volume (Sv)}

Após a identificação da CCOP, foram efetuados os cálculos do transporte de volume da CCOP pelo Atlântico Sul. A Tabela 3 mostra os valores médios de transporte da CCOP e seus respectivos desvios padrões obtidos através dos modelos HYCOM e ECCO. Conforme já mencionado, na identificação da CCOP foram usados os critérios de Preu et al. (2013), combinando as variáveis de densidade neutra e salinidade. Com a utilização desses critérios, a posição da CCOP teve variação durante o seu percurso pelo Atlântico Sul, variando entre 1500 m e 3500 m de profundidade.

Observamos que nas latitudes $10^{\circ} \mathrm{S}$ e $14^{\circ} \mathrm{S}$ os valores de transporte obtidos pelo HYCOM são maiores do que aqueles encontrados pelo ECCO. Essas médias estão associadas à elevados valores de desvios padrões. Esses resultados de desvio padrão estão relacionados com a variabilidade da CCOP. Possivelmente uma explicação para este fato seriam as recirculações que a CCOP sofre na camada da APAN ao longo do seu percurso (Meinen et al. 2012; Hummels et al. 2015).

Esses valores de transporte que foram obtidos por ambos os modelos e que são referentes à latitude $10^{\circ} \mathrm{S}$ corroboram com os resultados obtidos por Schott et al. (2005), onde foi estimado o transporte da CCOP em -22.5 Sv entre as profundidades de 800 a 4800 dbar e 16.9 Sv somente para a camada da APAN em $11^{\circ} \mathrm{S}$. A partir da latitude $18^{\circ} \mathrm{S}$, os resultados entre os modelos são bem similares. Entretanto, é visto que o HYCOM foi capaz de assimilar algumas alterações que o transporte da CCOP sofre em seu percurso, principalmente nas latitudes $22^{\circ} \mathrm{S}$ e $26^{\circ} \mathrm{S}$. Conforme já foi mencionado, essas mudanças são explicadas pela topografia da região, recirculações ou até mesmo entrada de fluxo de outras correntes.

Tabela 3. Tabela com as médias e desvios padrão de transporte de volume da CCOP
através do HYCOM e ECCO.
\begin{tabular}{|c|c|c|}
\hline Latitude & $\begin{array}{c}\text { Transporte (Sv) } \\
\text { HYCOM }\end{array}$ & $\begin{array}{c}\text { Transporte (Sv) } \\
\text { ECCO }\end{array}$ \\
\hline $10^{\circ} \mathrm{S}$ & $-19,9 \pm 9,3$ & $-15,6 \pm 2,3$ \\
\hline $14^{\circ} \mathrm{S}$ & $-19,4 \pm 8,3$ & $-15,8 \pm 2,0$ \\
\hline $18^{\circ} \mathrm{S}$ & $-14,4 \pm 5,3$ & $-14,2 \pm 1,6$ \\
\hline $22^{\circ} \mathrm{S}$ & $-11,0 \pm 3,7$ & $-14,1 \pm 1,7$ \\
\hline $26^{\circ} \mathrm{S}$ & $-14,4 \pm 3,5$ & $-10,1 \pm 2,0$ \\
\hline $30^{\circ} \mathrm{S}$ & $-11,0 \pm 4,2$ & $-9,6 \pm 2,8$ \\
\hline $34,5^{\circ} \mathrm{S}$ & $-9,9 \pm 4,4$ & $-8,2 \pm 2,2$ \\
\hline
\end{tabular}

Meinen et al. (2017) utilizaram os critérios de Preu et al. (2013) para identificar a camada da CCOP. Os autores usaram a técnica Gravest Empirical Mode (GEM) (Meinen et al. 2012) nos dados obtidos pelos equipamentos PIES no período de 2009 a 2014 que são convertidos 
em perfis de T e S que são integrados para obter o o transporte meridional através da maior camada possível da CCOP, de 800 a 4800 dbar, entre as longitudes de 51³0.0’ $\mathrm{W}$ e $44^{\circ} 30.0^{\prime} \mathrm{W}$ na latitude de $34^{\circ} 30.0^{\prime}$ S. A técnica GEM combina a hidrografia histórica com a medição da ecossonda invertida (IES) afim de obter informações do perfil vertical. Deste modo, esse método faz o ajuste dos dados hidrográficos históricos empiricamente. O transporte de volume obtido por Meinen et al. (2017) foi de $-15,2 \pm 22,8 \mathrm{~Sv}$. Como o desvio padrão encontrado foi bem alto, eles suavizaram os dados com um filtro passa-baixa de 30 dias, porém, o desvio padrão permaneceu alto ( $20,8 \mathrm{~Sv}$ ). Utilizando os mesmos critérios de profundidade ( 800 a $4800 \mathrm{dbar}$ ), o transporte de volume na latitude de $34.5^{\circ} \mathrm{S}$ através do HYCOM foi de $-14,9 \pm 4,6 \mathrm{~Sv}$, e do ECCO de $-15,3 \pm 3,5 \mathrm{~Sv}$.

Garzoli et al. (2015) também usaram os critérios de Preu et al. (2013) para encontrar a CCOP, entretanto, os autores utilizaram outros critérios para a definição de profundidade da CCOP. Foram utilizados um conjunto de dados hidrográficos e traçadores (dados de subsuperfície de perfiladores Argo), além de dados do modelo oceânico Ocean General Circulation Model for the Earth Simulator (OFES) no período de 1980 a 2006. Deste modo, o transporte de volume integrado obtido foi de $-7,5 \mathrm{~Sv}$ na latitude de $34.5^{\circ} \mathrm{S}$ entre a costa oeste e $40^{\circ} \mathrm{W}$, na profundidade entre 1700 e 3000 m e -14 Sv entre 1000 e 3500 m. Através do HYCOM e do ECCO, foi observado que a CCOP transporta em $34.5^{\circ} \mathrm{S}$ cerca de $-7,9 \mathrm{~Sv}$ e $-7,2 \mathrm{~Sv}$ entre 1700 e $3000 \mathrm{~m}$ e -14,1 Sv e -12,5 Sv entre 1000 e $3500 \mathrm{~m}$, respectivamente. Vemos que os resultados obtidos pelos dois modelos são muito satisfatórios.

Com o intuito de analisar outras latitudes, vemos que Schott et al. (2005) utilizaram seções hidrográficas e estimaram o transporte da CCOP em -17,3 Sv em $5^{\circ} \mathrm{S}$ e $-22,5 \mathrm{~Sv}$ em $11^{\circ} \mathrm{S}$, entre as profundidades de 800 a 4800 dbar e $16,9 \mathrm{~Sv}$ somente para a camada da APAN em $11^{\circ} \mathrm{S}$. Utilizando os mesmos critérios, o transporte estimado pelo HYCOM e ECCO foram de $-25,8 \mathrm{~Sv} \pm 11,1$ e $-16,2 \mathrm{~Sv} \pm 2,0$ em $10^{\circ} \mathrm{S}$, e somente na camada da APAN, $-18,2 \mathrm{~Sv} \pm 8,6$ e $-14,0 \mathrm{~Sv} \pm 2,3$, respectivamente. Com o uso de boias fundeadas em $11^{\circ} \mathrm{S}$, Hummels et al. (2015) estimaram o transporte da CCOP em 17,5 Sv.

Podemos observar que as médias de transporte da CCOP vão decrescendo ao longo do percurso pelo Atlântico Sul, o que é corroborado pelo trabalho da Garzoli et al. (2015), no qual é sugerido que em torno de $20^{\circ} \mathrm{S}$, na região da Cadeia Vitória Trindade, a CCOP se divide em 2 ramos, no qual em torno de $\sim 22 \%$ de seu fluxo vai para leste (em direção ao interior da bacia) e o restante do fluxo retorna à borda oeste e segue para sul. No trabalho de Garzoli et al. 
(2015), também foram calculados os transportes de volume da CCOP ao longo de seu percurso pelo Atlântico Sul e as latitudes analisadas foram semelhantes. Deste modo, a Tabela 4 mostra o comparativo dos transportes obtidos por Garzoli et al. (2015), pelo HYCOM e ECCO utilizando o mesmo intervalo de profundidade, ou seja, entre 1700 e $3000 \mathrm{~m}$.

Através da Tabela 4 vemos que os valores de transportes calculados pelos modelos são estatisticamente semelhantes aos valores encontrados por Garzoli et al. (2015), o que é corroborado pela Figura 25, pois os valores obtidos estão dentro do domínio do desvio padrão. Nota-se que os dados alcançados pelo modelo ECCO estão mais próximos aos valores de referência, além de serem mais precisos (menor desvio padrão). Entende-se que o ECCO é um modelo muito eficiente na representação do oceano profundo e, portanto, da CCOP. Ambos os modelos foram eficientes na tarefa de representar a CCOP.

Tabela 4. Tabela com as médias e desvios padrões de transporte de volume da CC
com os resultados obtidos pelo HYCOM, ECCO e por Garzoli et al. (2015), que foi usado
como parâmetro para comparação.
\begin{tabular}{|c|c|c|c|c|}
\hline Latitude & $\begin{array}{c}\text { Transporte (Sv) } \\
\text { Parâmetro }\end{array}$ & Latitude & $\begin{array}{c}\text { Transporte (Sv) } \\
\text { HYCOM }\end{array}$ & $\begin{array}{c}\text { Transporte (Sv) } \\
\text { ECCO }\end{array}$ \\
\hline $10^{\circ} \mathrm{S}$ & $-13,9 \pm 1,2$ & $10^{\circ} \mathrm{S}$ & $-16,3 \pm 8,3$ & $-14,0 \pm 2,2$ \\
\hline $15^{\circ} \mathrm{S}$ & $-12,5$ & $14^{\circ} \mathrm{S}$ & $-17,8 \pm 7,5$ & $-14,2 \pm 1,8$ \\
\hline $20^{\circ} \mathrm{S}$ & $-11,8 \pm 0,7$ & $18^{\circ} \mathrm{S}$ & $-11,4 \pm 4,0$ & $-12,9 \pm 1,5$ \\
\cline { 3 - 5 } & $22^{\circ} \mathrm{S}$ & $-10,9 \pm 3,5$ & $-12,8 \pm 1,6$ \\
\hline $25^{\circ} \mathrm{S}$ & $-12,0$ & $26^{\circ} \mathrm{S}$ & $-12,4 \pm 3,5$ & $-9,1 \pm 1,7$ \\
\hline $30^{\circ} \mathrm{S}$ & $-9,0 \pm 0,5$ & $30^{\circ} \mathrm{S}$ & $-9,3 \pm 3,9$ & $-9,0 \pm 2,4$ \\
\hline $34.5^{\circ} \mathrm{S}$ & $-7,5 \pm 0,3$ & $34.5^{\circ} \mathrm{S}$ & $-7,9 \pm 3,6$ & $-7,2 \pm 2,2$ \\
\hline
\end{tabular}

Ainda analisando a Tabela 4 , é interessante notar que nas latitudes $10^{\circ} \mathrm{S}$ e $14^{\circ} \mathrm{S}$, os valores de transporte do HYCOM não foram tão precisos quando comparados com o do ECCO, onde os valores de desvio padrão são altos e percebemos grande oscilação de transporte. Este fato pode ter acontecido pela localização dessas latitudes, uma vez que as mesmas estão mais próximas da bifurcação do ramo mais ao sul da Corrente Sul Equatorial $\left(10^{\circ} \mathrm{S}\right)$, onde ocorre a origem da CB e da CNB (Stramma 1991; da Silveira, de Miranda, and Brown 1994). E portanto, a corrente pode sofrer instabilidades e recirculações. Nota-se que a corrente ganha estabilidade a partir de $18^{\circ} \mathrm{S}$ e os valores tornam-se mais condizentes com o parâmetro. Apesar disso, o modelo HYCOM ainda é capaz de fornecer o transporte da CCOP de forma correta.

A Tabela 5 mostra os valores médios de transporte da CCOP obtidos pelo HYCOM para cada ano de 1993 a 2015 para as 7 latitudes que estão sendo analisadas neste trabalho. Destacamos novamente que o transporte médio da CCOP vai reduzindo conforme a mesma segue em direção Sul. Vemos que as latitudes $10^{\circ} \mathrm{S}$ e $14^{\circ} \mathrm{S}$ são as que mostram maiores volume 
de água. Em $22^{\circ} \mathrm{S}$, os valores são reduzidos possivelmente devido à passagem pela CVT. Em $34.5^{\circ} \mathrm{S}$, ainda vemos a presença da CCOP, mesmo com volume menor de transporte.

Tabela 5. Valores médios de transporte de volume da CCOP obtidos pelo HYCOM

\begin{tabular}{|c|c|c|c|c|c|c|c|}
\hline \multicolumn{7}{|c|}{ Transporte de volume médio da CCOP (Sv) } \\
\hline & $10^{\circ} \mathrm{S}$ & $14^{\circ} \mathrm{S}$ & $18^{\circ} \mathrm{S}$ & $22^{\circ} \mathrm{S}$ & $26^{\circ} \mathrm{S}$ & $30^{\circ} \mathrm{S}$ & $34.5^{\circ} \mathrm{S}$ \\
\hline 1993 & $-17,9$ & $-22,0$ & $-12,6$ & $-12,6$ & $-12,4$ & $-12,0$ & $-8,9$ \\
\hline 1994 & $-15,8$ & $-19,7$ & $-12,1$ & $-9,8$ & $-12,6$ & $-10,6$ & $-11,2$ \\
\hline 1995 & $-16,1$ & $-19,8$ & $-23,8$ & $-9,7$ & $-18,9$ & $-7,6$ & $-15,4$ \\
\hline 1996 & $-18,8$ & $-16,2$ & $-14,2$ & $-12,4$ & $-13,6$ & $-12,7$ & $-11,2$ \\
\hline 1997 & $-18,1$ & $-19,6$ & $-16,2$ & $-10,2$ & $-15,8$ & $-11,5$ & $-11,2$ \\
\hline 1998 & $-22,5$ & $-25,7$ & $-13,4$ & $-13,6$ & $-13,8$ & $-12,3$ & $-10,3$ \\
\hline 1999 & $-17,4$ & $-18,3$ & $-18,5$ & $-10,9$ & $-13,3$ & $-11,1$ & $-9,3$ \\
\hline 2000 & $-19,0$ & $-19,0$ & $-13,5$ & $-12,3$ & $-13,1$ & $-11,0$ & $-10,9$ \\
\hline 2001 & $-19,3$ & $-15,0$ & $-13,7$ & $-11,5$ & $-11,9$ & $-9,5$ & $-8,4$ \\
\hline 2002 & $-18,4$ & $-18,2$ & $-17,2$ & $-10,3$ & $-12,9$ & $-10,2$ & $-8,9$ \\
\hline 2003 & $-21,9$ & $-26,2$ & $-12,6$ & $-9,4$ & $-13,2$ & $-10,4$ & $-9,0$ \\
\hline 2004 & $-20,4$ & $-19,4$ & $-18,0$ & $-10,7$ & $-13,1$ & $-8,7$ & $-9,7$ \\
\hline 2005 & $-20,9$ & $-17,4$ & $-11,7$ & $-11,6$ & $-13,7$ & $-10,1$ & $-10,4$ \\
\hline 2006 & $-20,8$ & $-17,7$ & $-12,9$ & $-11,4$ & $-13,6$ & $-9,8$ & $-10,2$ \\
\hline 2007 & $-20,8$ & $-16,0$ & $-15,4$ & $-11,7$ & $-12,8$ & $-9,7$ & $-9,2$ \\
\hline 2008 & $-18,3$ & $-19,6$ & $-8,6$ & $-11,3$ & $-13,0$ & $-8,8$ & $-9,4$ \\
\hline 2009 & $-19,8$ & $-19,7$ & $-10,7$ & $-10,8$ & $-13,7$ & $-9,4$ & $-7,9$ \\
\hline 2010 & $-25,2$ & $-19,6$ & $-13,8$ & $-9,8$ & 12,6 & $-8,8$ & $-9,3$ \\
\hline 2011 & $-19,1$ & $-17,9$ & $-16,0$ & $-9,2$ & $-12,4$ & $-9,1$ & $-10,7$ \\
\hline 2012 & $-19,6$ & $-17,7$ & $-14,1$ & $-10,5$ & $-12,8$ & $-10,2$ & $-11,7$ \\
\hline 2013 & $-17,8$ & $-22,5$ & $-17,6$ & $-13,3$ & $-12,6$ & $-10,1$ & $-9,5$ \\
\hline 2014 & $-20,3$ & $-20,9$ & $-16,8$ & $-12,2$ & $-11,8$ & $-9,9$ & $-9,4$ \\
\hline 2015 & $-21,7$ & $-16,2$ & $-11,8$ & $-11,2$ & $-12,7$ & $-9,1$ & $-7,9$ \\
\hline
\end{tabular}

A Tabela 6 é análoga à Tabela 5, porém para os resultados obtidos pelo ECCO. Assim como foi visto pelo HYCOM, o transporte médio da CCOP vai reduzindo conforme a mesma segue em direção Sul. Vemos também que as médias de transporte são menores quando se comparado ao HYCOM. A redução do transporte ocorre de forma homogênea e não aparecem um aumento ou diminuição brusca de transporte como é visto no HYCOM, e talvez isso aconteça pelo fato do ECCO possuir menor resolução e não conseguir captar tantos detalhes.

A Figura 25 representa o transporte de volume médio da CCOP no período de 1992 a 2006 nas latitudes de $10^{\circ} \mathrm{S}, 14^{\circ} \mathrm{S}, 18^{\circ} \mathrm{S}, 22^{\circ} \mathrm{S}, 26^{\circ} \mathrm{S}, 30^{\circ} \mathrm{S}$ e $34.5^{\circ} \mathrm{S}$ para o HYCOM e ECCO. Os valores de transporte foram comparados com os valores de transporte encontrados por Garzoli et al. (2015). 
Tabela 6. Valores médios de transporte de volume da CCOP obtidos pelo ECCO

\begin{tabular}{|c|c|c|c|c|c|c|c|}
\hline \multicolumn{7}{|c|}{ Transporte de volume médio da CCOP (Sv) } \\
\hline & $10^{\circ} \mathrm{S}$ & $14^{\circ} \mathrm{S}$ & $18^{\circ} \mathrm{S}$ & $22^{\circ} \mathrm{S}$ & $26^{\circ} \mathrm{S}$ & $30^{\circ} \mathrm{S}$ & $34.5^{\circ} \mathrm{S}$ \\
\hline 1993 & $-15,2$ & $-16,3$ & $-11,4$ & $-11,5$ & $-10,6$ & $-11,1$ & $-9,8$ \\
\hline 1994 & $-13,4$ & $-15,7$ & $-10,7$ & $-11,3$ & $-9,5$ & $-11,7$ & $-10,5$ \\
\hline 1995 & $-14,6$ & $-14,4$ & $-18,8$ & $-19,5$ & $-9,8$ & $-8,8$ & $-9,5$ \\
\hline 1996 & $-14,8$ & $-13,2$ & $-13,3$ & $-11,8$ & $-11,5$ & $-11,9$ & $-8,3$ \\
\hline 1997 & $-18,7$ & $-13,7$ & $-15,4$ & $-11,9$ & $-9,8$ & $-11,7$ & $-7,4$ \\
\hline 1998 & $-22,3$ & $-15,5$ & $-13,9$ & $-14,1$ & $-13,6$ & $-10,5$ & $-10,2$ \\
\hline 1999 & $-15,2$ & $-15,3$ & $-15,6$ & $-11,5$ & $-9,4$ & $-10,2$ & $-9,5$ \\
\hline 2000 & $-14,8$ & $-12,9$ & $-13,1$ & $-13,2$ & $-13,3$ & $-12,0$ & $-8,8$ \\
\hline 2001 & $-14,5$ & $-13,0$ & $-12,8$ & $-10,6$ & $-11,8$ & $-9,8$ & $-9,5$ \\
\hline 2002 & $-13,7$ & $-14,7$ & $-15,4$ & $-9,8$ & $-12,8$ & $-11,3$ & $-9,8$ \\
\hline 2003 & $-21,3$ & $-20,2$ & $-11,3$ & $-9,6$ & $-13,3$ & $-9,7$ & $-10,1$ \\
\hline 2004 & $-20,9$ & $-14,3$ & $-17,8$ & $-10,8$ & $-13,2$ & 8,8 & $-8,6$ \\
\hline 2005 & $-14,2$ & $-13,7$ & $-12,2$ & $-12,9$ & $-13,6$ & $-11,5$ & $-10,3$ \\
\hline 2006 & $-16,2$ & $-14,7$ & $-11,7$ & $-11,3$ & $-13,8$ & $-9,6$ & $-9,1$ \\
\hline 2007 & $-14,4$ & $-13,5$ & $-14,7$ & $-10,9$ & $-12,3$ & $-10,7$ & $-11,3$ \\
\hline 2008 & $-18,7$ & $-15,2$ & $-8,4$ & $-8,3$ & $-13,0$ & $-8,8$ & $-12,5$ \\
\hline 2009 & $-13,1$ & $-14,8$ & $-11,6$ & $-11,3$ & $-13,6$ & $-8,5$ & $-9,6$ \\
\hline 2010 & $-23,0$ & $-14,6$ & $-13,7$ & $-9,5$ & $-12,5$ & $-8,8$ & $-9,5$ \\
\hline 2011 & $-16,5$ & $-13,9$ & $-17,1$ & $-10,4$ & $-12,3$ & $-9,2$ & $-10,2$ \\
\hline 2012 & $-19,2$ & $-15,2$ & $-13,6$ & $-9,8$ & $-12,7$ & $-9,3$ & $-11,1$ \\
\hline 2013 & $-17,8$ & $-16,5$ & $-17,6$ & $-13,9$ & $-12,7$ & $-11,7$ & $-8,6$ \\
\hline 2014 & $-17,7$ & $-20,4$ & $-15,9$ & $-12,3$ & $-11,9$ & $-9,8$ & $-10,2$ \\
\hline 2015 & $-16,7$ & $-15,3$ & $-14,6$ & $-13,1$ & $-12,6$ & $-9,3$ & $-8,4$ \\
\hline
\end{tabular}

Em ambos os modelos, para o cálculo do transporte, foi utilizada a mesma camada de profundidade usada por Garzoli et al. (2015), isto é, entre 1700 e 3000 m. Portanto, vemos que os resultados de ambos os modelos fora satisfatórios e, portanto, eles são capazes de representar o padrão da CCOP ao longo de seu caminho pelo Atlântico Sul.

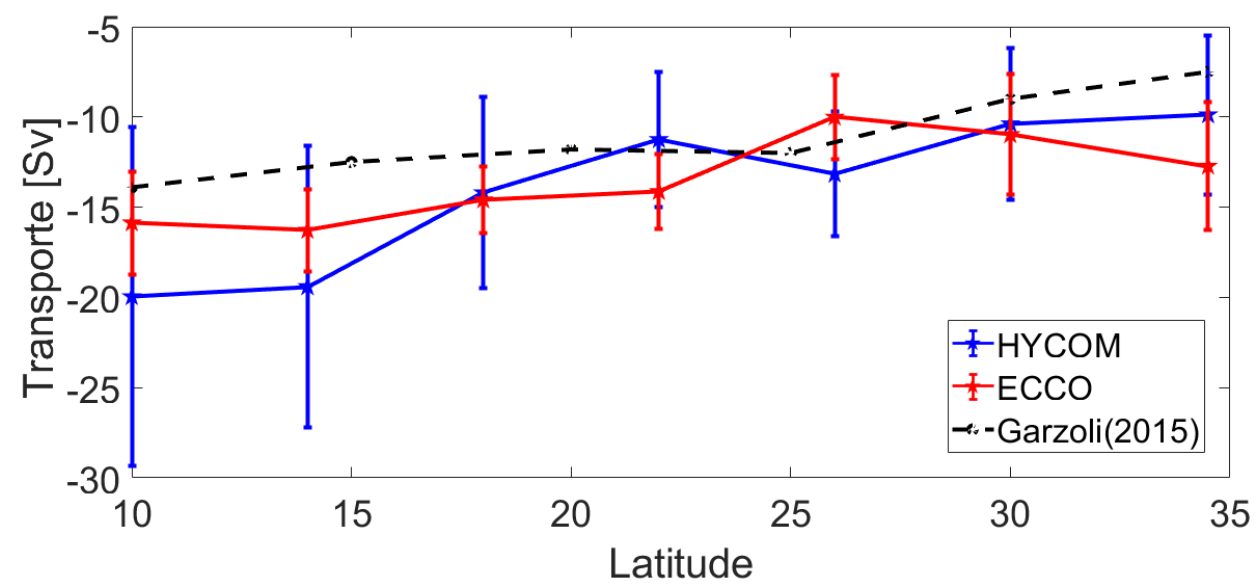

Figura 25. Média do transporte de volume da CCOP no período de 1992 a 2006 nas latitudes de $10^{\circ} \mathrm{S}, 14^{\circ} \mathrm{S}, 18^{\circ} \mathrm{S}, 22^{\circ} \mathrm{S}, 26^{\circ} \mathrm{S}, 30^{\circ} \mathrm{S}$ e $34.5^{\circ} \mathrm{S}$ do $\mathrm{HYCOM}$ (azul), do ECCO (vermelho) para o período de 1992 a 2006 e por Garzoli et al. (2015) nas latitudes $10^{\circ} \mathrm{S}, 15^{\circ} \mathrm{S}, 20^{\circ} \mathrm{S}$, $25^{\circ} \mathrm{S}, 30^{\circ} \mathrm{S}$ e $34.5^{\circ} \mathrm{S}$ para o período de 1980 a 2006. 


\subsection{Variabilidade da CCOP}

Um dos principais objetivos deste trabalho é avaliar a variabilidade da CCOP. Para isto, foram obtidas séries temporais do transporte da CCOP para as latitudes selecionadas, com o intuito de avaliar a evolução da corrente ao longo do tempo e investigar quais são as possíveis causas de sua variabilidade (Figuras 26, a 29) referentes ao HYCOM e ECCO, respectivamente). As linhas em vermelho e verde representam a tendência do transporte de volume da CCOP ao longo do tempo para o HYCOM e ECCO, respectivamente. Na Figura 26(Painel a), vemos que a latitude $10^{\circ} \mathrm{S}$ apresentou alta variabilidade, de acordo com seu alto desvio padrão $(9,3 \mathrm{~Sv})$ e volume de transporte (Tabela 4). Existe uma tendência de aumento de transporte de 0,054 Sv.

Este padrão de alta variabilidade $(8,3 \mathrm{~Sv})$ também é observado na latitude $14^{\circ} \mathrm{S}$ (Painel b) e há uma tendência de diminuição de transporte de $-0,083 \mathrm{~Sv}$. Observando as latitudes $10^{\circ} \mathrm{S}$ e $14^{\circ} \mathrm{S}$ (Painéis $\left.\mathrm{a}, \mathrm{b}\right)$ podemos perceber por que os valores de desvio padrão foram tão altos (Tabela 4), uma vez que o transporte de volume oscilou entre -5 e -45 Sv ao longo do tempo.

Em relação a latitude $18^{\circ} \mathrm{S}$ (Painel c), vemos que a variabilidade diminuiu (5,3 Sv/ano) e há uma tendência de aumento de transporte de 0,040 Sv/ano. Em $22^{\circ} \mathrm{S}$ (Painel d), a variabilidade da CCOP continua reduzindo $(3,7 \mathrm{~Sv})$ e temos uma tendência de redução de transporte de $-0,031$ Sv. Através da Figura 27, na latitude $26^{\circ} \mathrm{S}$ (Painel e), a tendência de transporte se mantém negativa, em -0,068 Sv/ano e notamos que a a variabilidade reduz ligeiramente $(3,5 \mathrm{~Sv})$, entretanto, o transporte de volume continua a diminuir conforme a CCOP percorre o Atlântico Sul. Em $30^{\circ} \mathrm{S}$ (Painel f), vemos uma a tendência de redução de transporte (-0,13 Sv/ano). Por fim, em $34.5^{\circ} \mathrm{S}$ (Painel $\mathrm{g}$ ), vemos que a variabilidade da CCOP tem um discreto aumento $(4,4 \mathrm{~Sv})$ e tendência de redução de transporte (-0,069 Sv/ano). Além disso, o transporte de volume também foi reduzido. É interessante notar que a tendência de aumento de transporte foi observada somente em $10^{\circ} \mathrm{S}$ (Painel a) e $18^{\circ} \mathrm{S}$ (Painel c) (Figura 26). Podemos observar que conforme a CCOP percorre o Atlântico Sul, a mesma perde intensidade, variabilidade, assim como seu volume de transporte.

Em relação ao ECCO (Figuras 28 e 29), vemos que na latitude $10^{\circ} \mathrm{S}$ (Painel a) existe uma tendência de aumento de transporte de 0,05 Sv/ano. Esse padrão de tendência de aumento de transporte, permanece nas latitudes de $14^{\circ} \mathrm{S}$ (Painel b), $18^{\circ} \mathrm{S}$ (Painel c), $22^{\circ} \mathrm{S}$ (Painel d) (Figura 28) e $26^{\circ} \mathrm{S}$ (Painel e) (Figura 29), com valores de 0,035 Sv/ano, 0,019 Sv/ano, 0,012 Sv/ano e 0,010 Sv/ano, respectivamente. Em $30^{\circ} \mathrm{S}$ (Painel f), a variabilidade do transporte aumenta e vemos uma tendência de redução de transporte em $-0,014 \mathrm{~Sv}$. Por último, em $34.5^{\circ} \mathrm{S}$ (Painel 
g), a tendência é novamente de aumento de transporte (0,041 Sv/ano). Portanto, vemos que somente em $30^{\circ} \mathrm{S}$ (Painel f) houve tendência de diminuição de transporte.

De modo geral, observamos que em todas as latitudes há um padrão mais estável de transporte de volume quando comparamos com o HYCOM. Assim, como observado no HYCOM, também há a redução do transporte total de volume conforme a CCOP segue para sul. Os resultados de tendência de transporte obtidos pelos modelos são pequenos, portanto, é difícil fazer suposições em relação a tendência de transporte de volume. É de vital importância conhecer a CCOP, pois essa corrente faz parte do membro inferior da AMOC e, portanto, seu padrão irá influenciar nos fluxos de calor e água doce do Atlântico. 

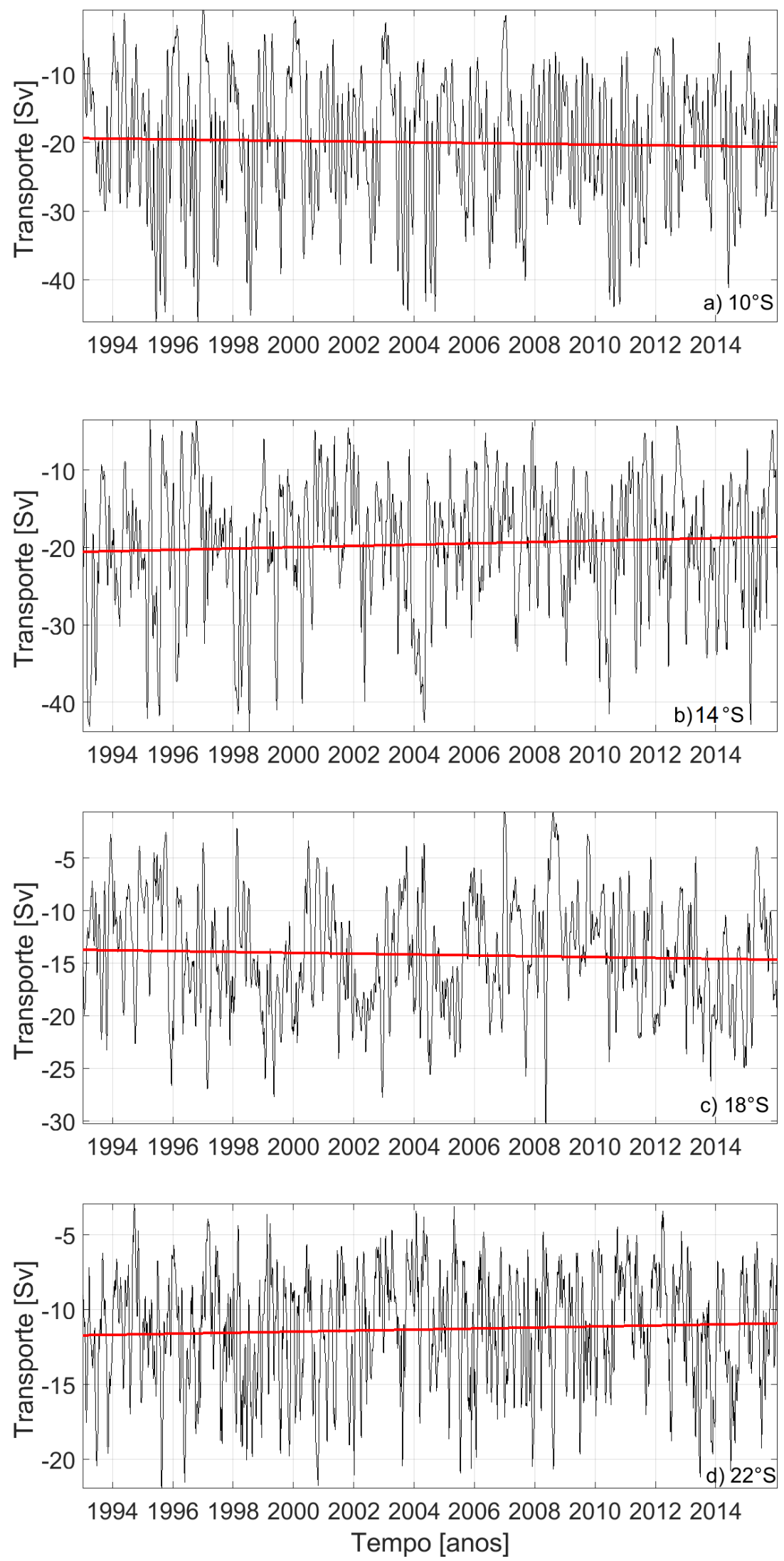

Figura 26. Séries temporais dos valores de transporte de volume da CCOP obtidos através do modelo HYCOM no período de 1992 a 2015 nas latitudes de $10^{\circ} \mathrm{S}$ (Painel a), $14^{\circ} \mathrm{S}$ (Painel b), $18^{\circ} \mathrm{S}$ (Painel c) e $22^{\circ} \mathrm{S}$ (Painel d) do Atlântico sul. 


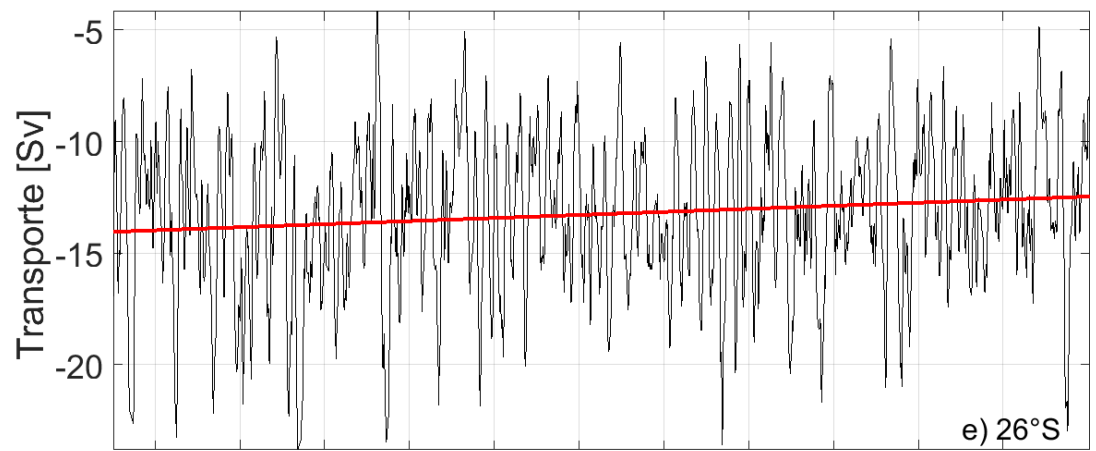

19941996199820002002200420062008201020122014
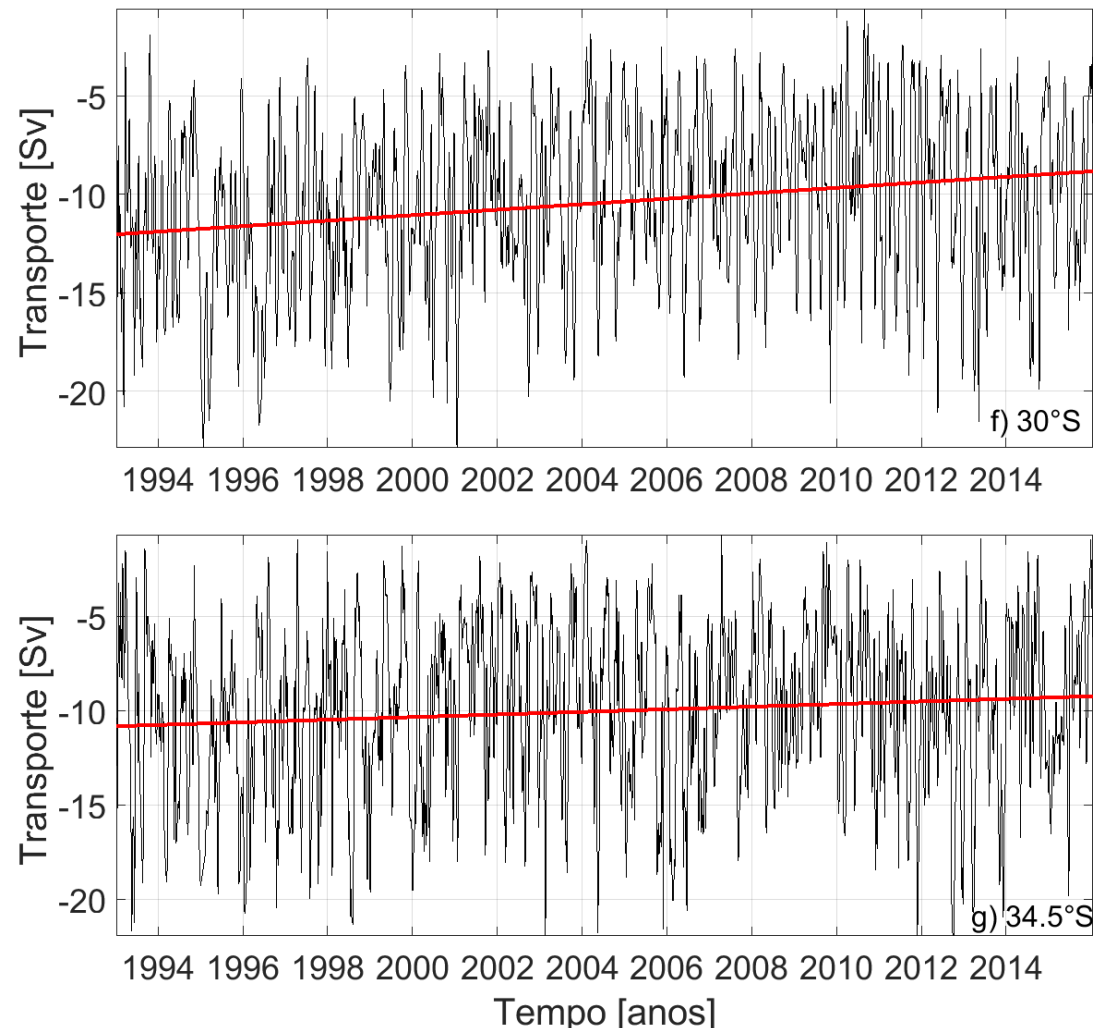

Figura 27. Análogo à Figura 26, porém referente às latitudes $26^{\circ} S$ (Painel e), $30^{\circ} S$ (Painel f) e $34.5^{\circ} \mathrm{S}$ (Painel g) do Atlântico sul. 


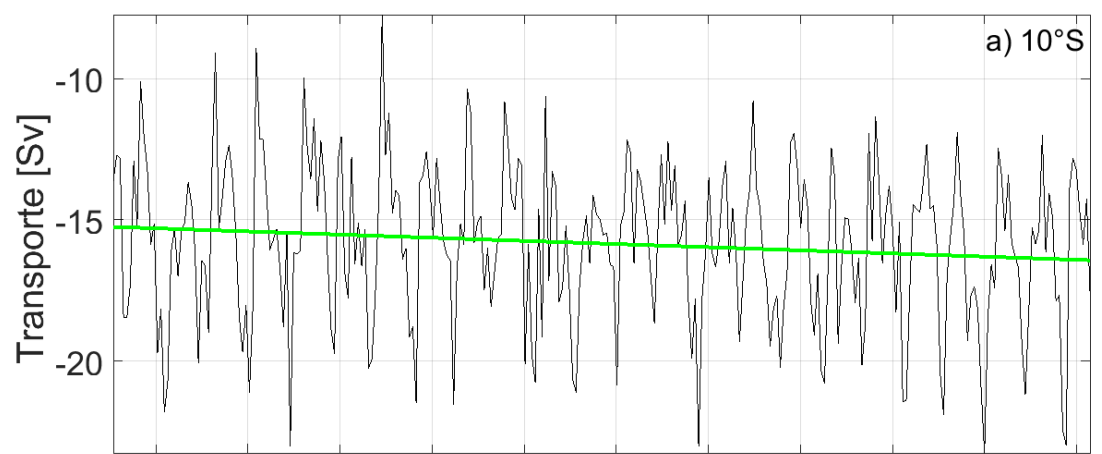

19941996199820002002200420062008201020122014

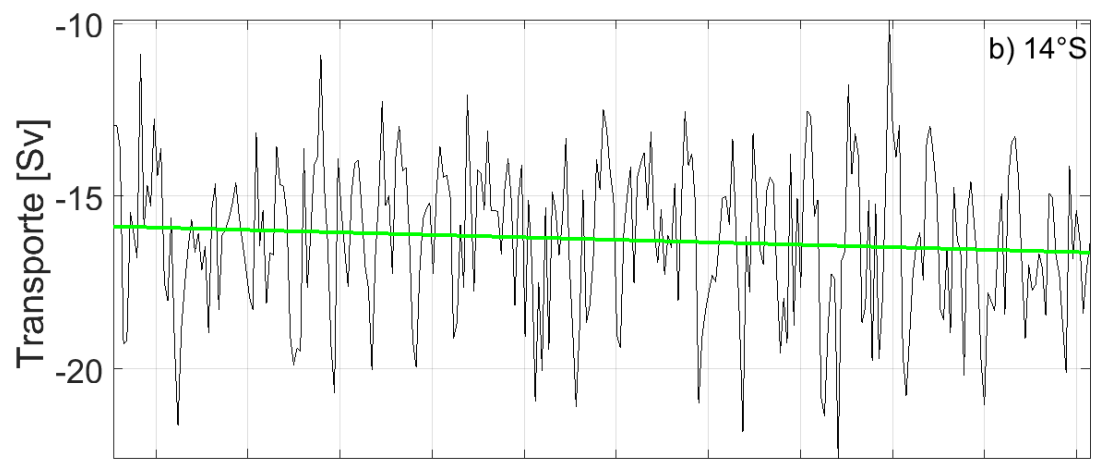

19941996199820002002200420062008201020122014
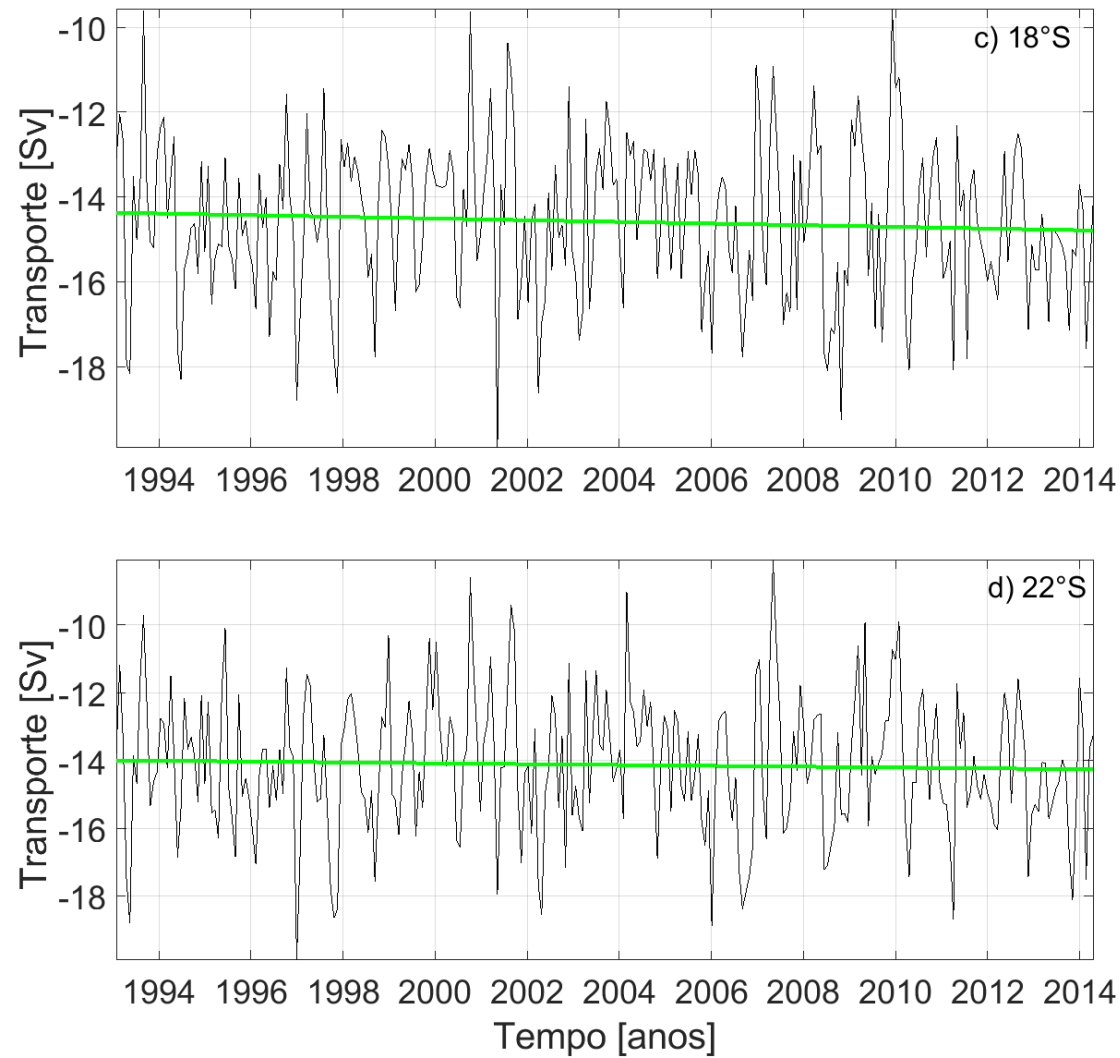

Figura 28. Séries temporais dos valores de transporte de volume da CCOP obtidos através do modelo ECCO no período de 1992 a 2015 nas latitudes de $10^{\circ} \mathrm{S}, 14^{\circ} \mathrm{S}, 18^{\circ} \mathrm{S}$ e $22^{\circ} \mathrm{S}$ do Atlântico sul. 

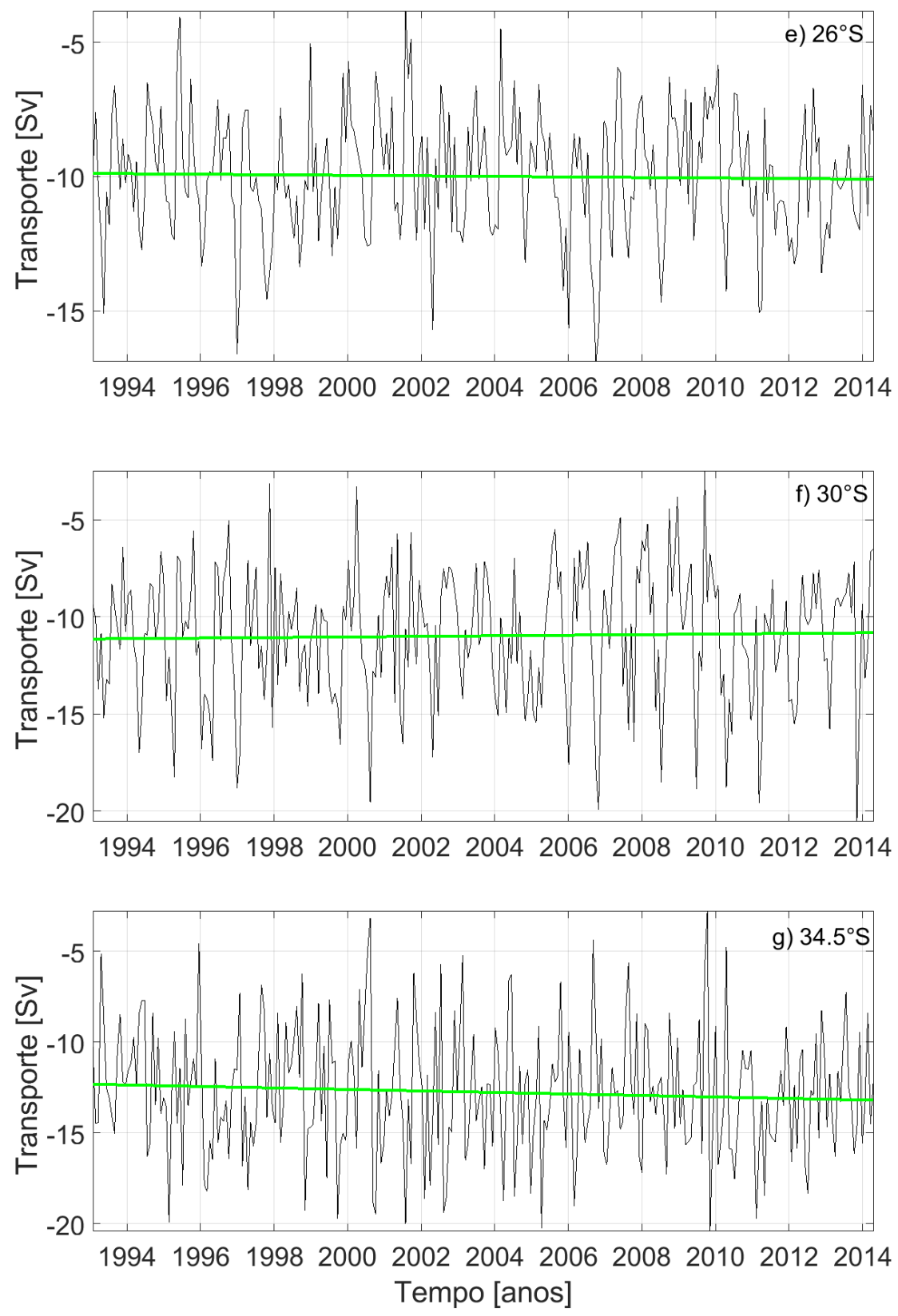

Figura 29. Análogo à Figura 28, porém referente às latitudes $26^{\circ} \mathrm{S}, 30^{\circ} \mathrm{S}$ e $34.5^{\circ} \mathrm{S}$ do Atlântico sul.

Uma das análises realizadas neste trabalho foi a verificação da existência de um ciclo sazonal da CCOP. Em 2012, Meinen et al. (2012) utilizaram o modelo OFES e foi sugerido que havia um sinal sazonal muito fraco, embora não significativo. Mesmo assim, os autores não conseguiram avaliar se havia um ciclo sazonal da CCOP em $34.5^{\circ} \mathrm{S}$. Em 2017, com os 5 anos de registros de dados reais obtidos pelos instrumentos PIES, Meinen et al. (2017) não observaram um ciclo sazonal evidente em $34.5^{\circ} \mathrm{S}$, mesmo após a aplicação de um filtro passabaixa de 30 dias para eliminar os maiores sinais de frequência. Entretanto, os resultados obtidos neste trabalho apontam para a existência de um ciclo médio da CCOP. A Figura 30 mostra esse 
ciclo anual nas latitudes $10^{\circ} \mathrm{S}, 22^{\circ} \mathrm{S}$ e $34.5^{\circ} \mathrm{S}$ obtido pelo HYCOM (Painéis a esquerda) e ECCO (Painéis a direita). Os ciclos médios mostrados na Figura 30 foram obtidos através das médias mensais em cada uma das três latitudes $\left(10^{\circ} \mathrm{S}, 22^{\circ} \mathrm{S}\right.$ e $\left.34.5^{\circ} \mathrm{S}\right)$.
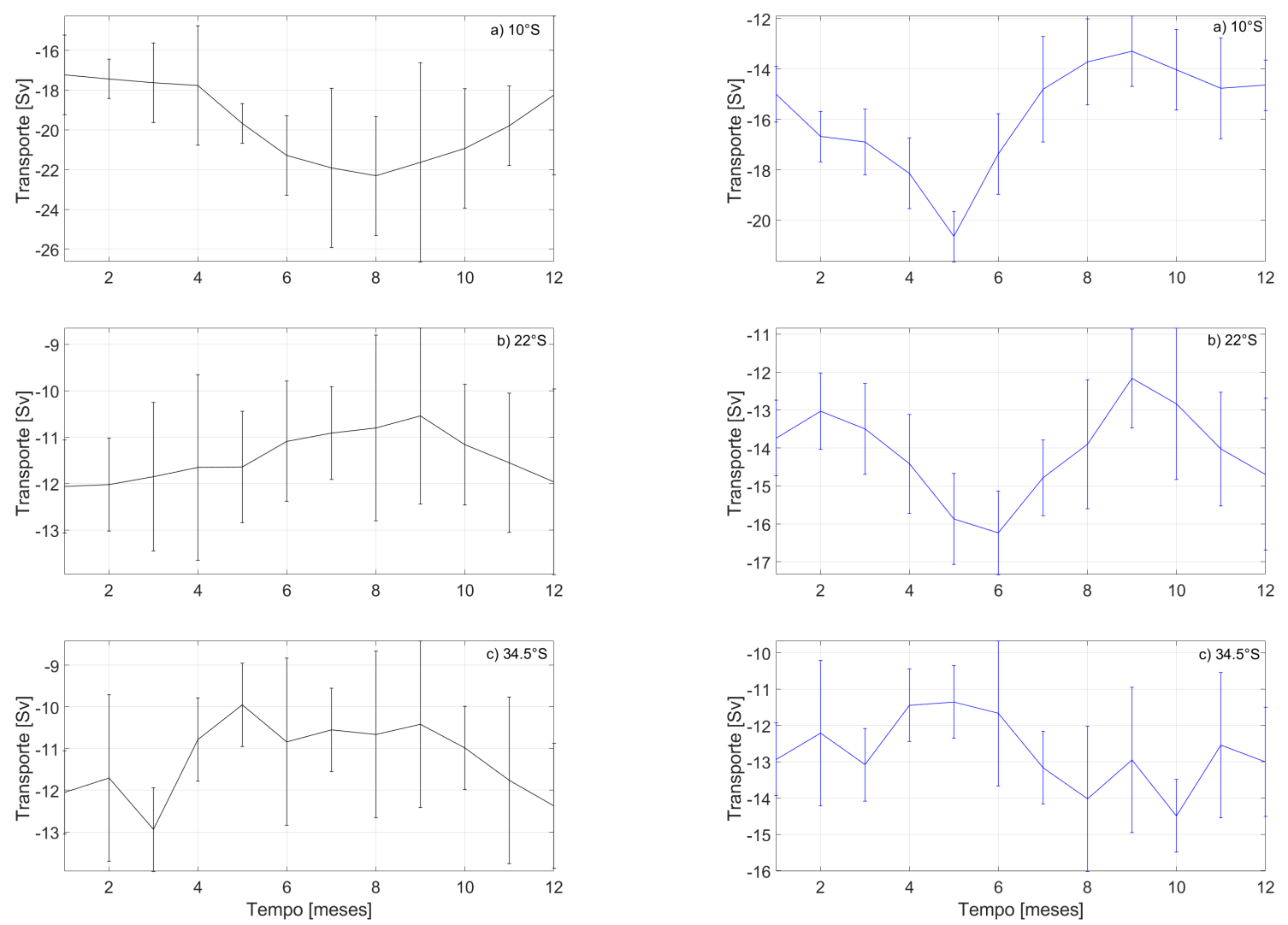

Figura 30. Ciclo anual da CCOP nas latitudes $10^{\circ} \mathrm{S}, 22^{\circ} \mathrm{S}$ e $34.5^{\circ} \mathrm{S}$ obtido pelo $\mathrm{HYCOM}$ (Painéis a esquerda) e ECCO (Painéis a direita) no período entre 1992 e 2015.

Primeiramente iremos analisar os dados obtidos pelo HYCOM. Como um dos objetivos deste trabalho é analisar as séries temporais em termos de contribuição relativa da variabilidade temporal considerando a variabilidade interanual, esse ciclo anual foi removido da série temporal dos dados originais. Quando ocorre essa remoção do sinal anual, nós obtemos a anomalia do transporte de volume (linhas em vermelho na Figura 31). Além, quando analisamos as séries temporais de transporte de volume (Figuras 26 e 27) foi visto que as séries tinham alta variabilidade, ou seja, muitos sinais de alta frequência. Por isso, foi passado um filtro de 25 meses (Filtro Hamming) para retirar esses sinais de alta frequência, uma vez que nosso interesse é analisar a variabilidade interanual da CCOP. Portanto, as linhas em preto na Figura 31 representam a anomalia do transporte após a passagem do filtro Hamming.

As anomalias positivas indicam que houve uma redução de transporte de volume em comparação com a sua média, e anomalia negativa indica o oposto. Assim sendo, ao analisar- 
mos os dados de anomalia após a passagem do filtro (linhas em preto na Figura 31) vemos que as latitudes $10^{\circ} \mathrm{S}$ e $22^{\circ} \mathrm{S}$ mostram um padrão de aumento de transporte entre 1995 e 1998, 2004 e 2007 e 2009 e 2012 . Em relação a latitude de $34.5^{\circ} \mathrm{S}$ o padrão é diferente e possui maior variabilidade, com aumento de transporte entre 1995 e 1997, 1999 e 2001, 2003 e 2004, 2007 e 2009, e 2011 2014. Além do mais, a anomalia em $10^{\circ} \mathrm{S}$ varia entre $\pm 10 \mathrm{~Sv}$, enquanto que em $22^{\circ} \mathrm{S}$ e $34.5^{\circ} \mathrm{S}$, varia entre $\pm 5 \mathrm{~Sv}$.
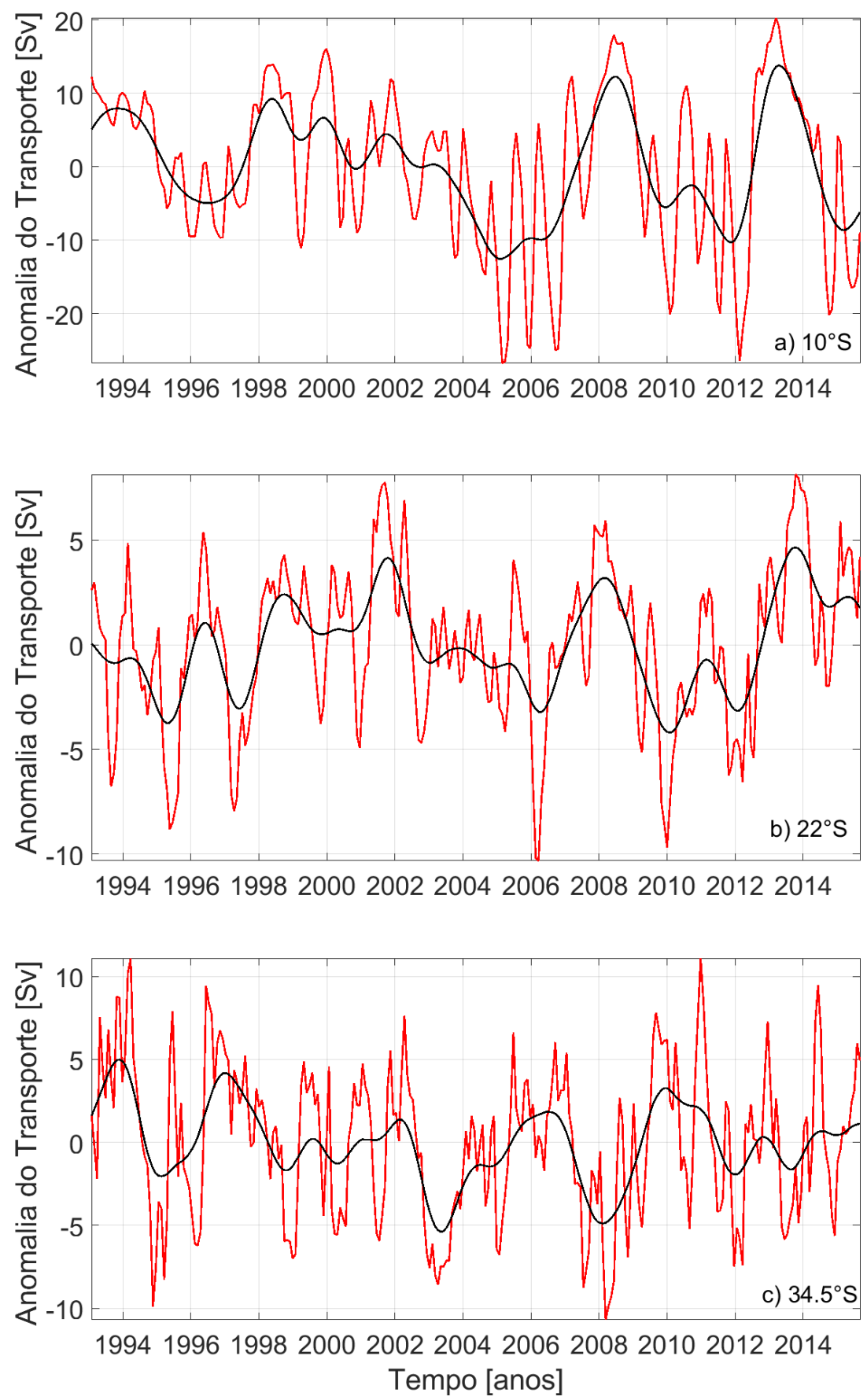

Figura 31. Anomalia do transporte de volume (linhas em vermelho) nas latitudes $10^{\circ} \mathrm{S}$ (Painel a) e $22^{\circ} S$ (Painel b) e $34.5^{\circ} S$ (Painel c) entre 1992 e 2015 obtida pelo HYCOM. As linhas em preto representam a anomalia do transporte após a passagem do filtro Hamming de 25 meses. 
A Figura 32 mostra as mesmas análises das séries temporais, só que para o modelo ECCO. Deste modo, as linhas em verde representam a anomalia do transporte de volume após a remoção do ciclo anual e as linhas em preto após a passagem do filtro de 25 meses (Figura 32). Uma das diferenças em relação ao HYCOM é que a oscilação de anomalia do transporte é bem menor, sendo menor do que $\pm 2 \mathrm{~Sv}$ nas 3 latitudes. Na latitude $10^{\circ} \mathrm{S}$, vemos que um aumento de transporte após o ano de 2003 (anomalia negativa). Em $22^{\circ} \mathrm{S}$ e $34.5^{\circ} \mathrm{S}$ o padrão é mais similar entre elas, com aumento de transporte entre 1995 e 1999 e após 2005. É interessante notar que ambos os modelos mostram um padrão similar nas latitudes $22^{\circ} \mathrm{S}$ e $34.5^{\circ} \mathrm{S}$.
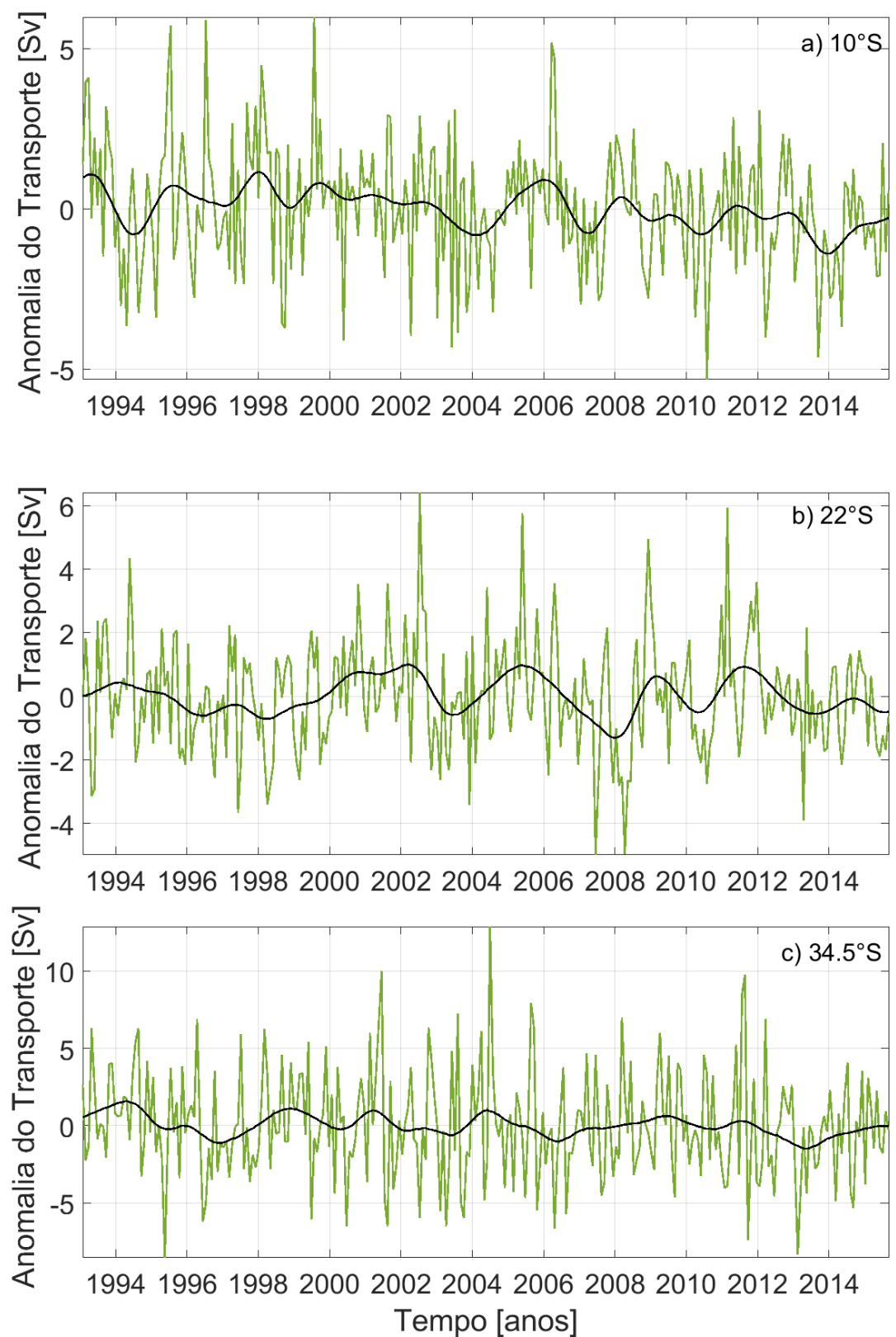

Figura 32. Anomalia do transporte de volume (linhas em verde) nas latitudes $10^{\circ} \mathrm{S}$ (Painel a) e $22^{\circ} S$ (Painel b) e $34.5^{\circ} S$ (Painel c) entre 1992 e 2015 obtida pelo ECCO. As linhas em preto representam a anomalia do transporte após a passagem do filtro Hamming de 25 meses. 


\subsection{Distribuição espectral de energia}

Pelas Figuras 26 e 27 observa-se através das séries temporais que os dados possuem alta frequência, e deste modo, foi feita uma análise da variância dos dados de transporte para o HYCOM (Tabela 7). Esse resultado é corroborado pela literatura, no qual já foi observado em outras latitudes do oceano Atlântico que ao longo do caminho da CCOP, a variabilidade temporal do fluxo excede grandemente os valores médios de transporte (Schott et al. 2004; Hummels et al. 2015).

Pela Tabela 7 vemos que a porcentagem de variação explicada pelo período anual ou semestral é aproximadamente $19 \%$ cada, ou seja, vemos alta energia nesses períodos. O período de maior concentração de energia foi o mesmo para as 3 latitudes, ou seja, entre 50 e 160 dias. Entretanto, também observamos alguns picos espectrais na faixa entre 5 e 50 dias.

Além disso, foi feita a análise espectral da variância das séries temporais de transporte de volume integrado da CCOP a partir do HYCOM usando um comprimento de janela de 2 anos com 50\% de sobreposição utilizando o método de Welch (Figura 33. Foi escolhida a janela de 2 anos porque não tínhamos interesse em analisar os sinais de alta frequência. Assim como foi verificado na Tabela 7, o modelo mostra um pico de energia centrado em torno de 120-160 dias nas 3 latitudes em análise $10^{\circ} \mathrm{S}$ (Painel a), $22^{\circ} \mathrm{S}$ (Painel b) e $34.5^{\circ} \mathrm{S}$ (Painel c) (Figura 33).

Em relação aos resultados obtidos pelo ECCO, porcentagem de variação explicada pelo período anual ou semestral também é relativamente alta, sendo em torno de $18 \%$ cada (Tabela 8). Portanto, assim como visto pelo HYCOM, foi detectado um ciclo sazonal. O período de maior concentração de energia também foi entre o período de 50 e 160 dias, sendo que o pico de energia foi visto em torno de 130 e 160 dias. É válido atentar de que a variância dos dados do ECCO foi menor do que a do HYCOM, conforme já tínhamos visto nos resultados anteriores.

Tabela 7. Variância do transporte de volume da CCOP em faixas de períodos obtidas através do HYCOM para as latitudes $10^{\circ} \mathrm{S}$ (Painel a), $22^{\circ} \mathrm{S}$ (Painel b) e $34.5^{\circ} \mathrm{S}$ (Painel c).

\begin{tabular}{|c|c|c|c|c|c|c|}
\hline Período (dias) & \multicolumn{3}{|c|}{ Variância $\left(\mathbf{S v}^{2}\right)$} & \multicolumn{3}{|c|}{$\begin{array}{c}\text { Porcentagem da } \\
\text { variância total }(\%)\end{array}$} \\
\hline & $10^{\circ} \mathrm{S}$ & $22^{\circ} \mathrm{S}$ & $34.5^{\circ} \mathrm{S}$ & $10^{\circ} \mathrm{S}$ & $22^{\circ} \mathrm{S}$ & $34.5^{\circ} \mathrm{S}$ \\
\hline 5 a 50 & 25 & 34 & 2 & 14,3 & 15,6 & 14,1 \\
\hline $50 a$ & 119,3 & 99 & & 34,0 & & 31,3 \\
\hline 160 a 190 & 25 & 34,5 & 35,2 & 10,1 & 10,2 & 10,4 \\
\hline 190 a 300 & 32,7 & 36,8 & 39,1 & 9,1 & 9,5 & 14,3 \\
\hline 300 a 400 & 58,2 & 53,1 & 54,6 & 20,7 & 18,8 & 19,7 \\
\hline 400 a 1000 & 17 & 28,7 & 22,8 & 7, & 9,8 & 7,0 \\
\hline$>100$ & 10 & 11,8 & 11,6 & 3,8 & 3,5 & 3,1 \\
\hline
\end{tabular}



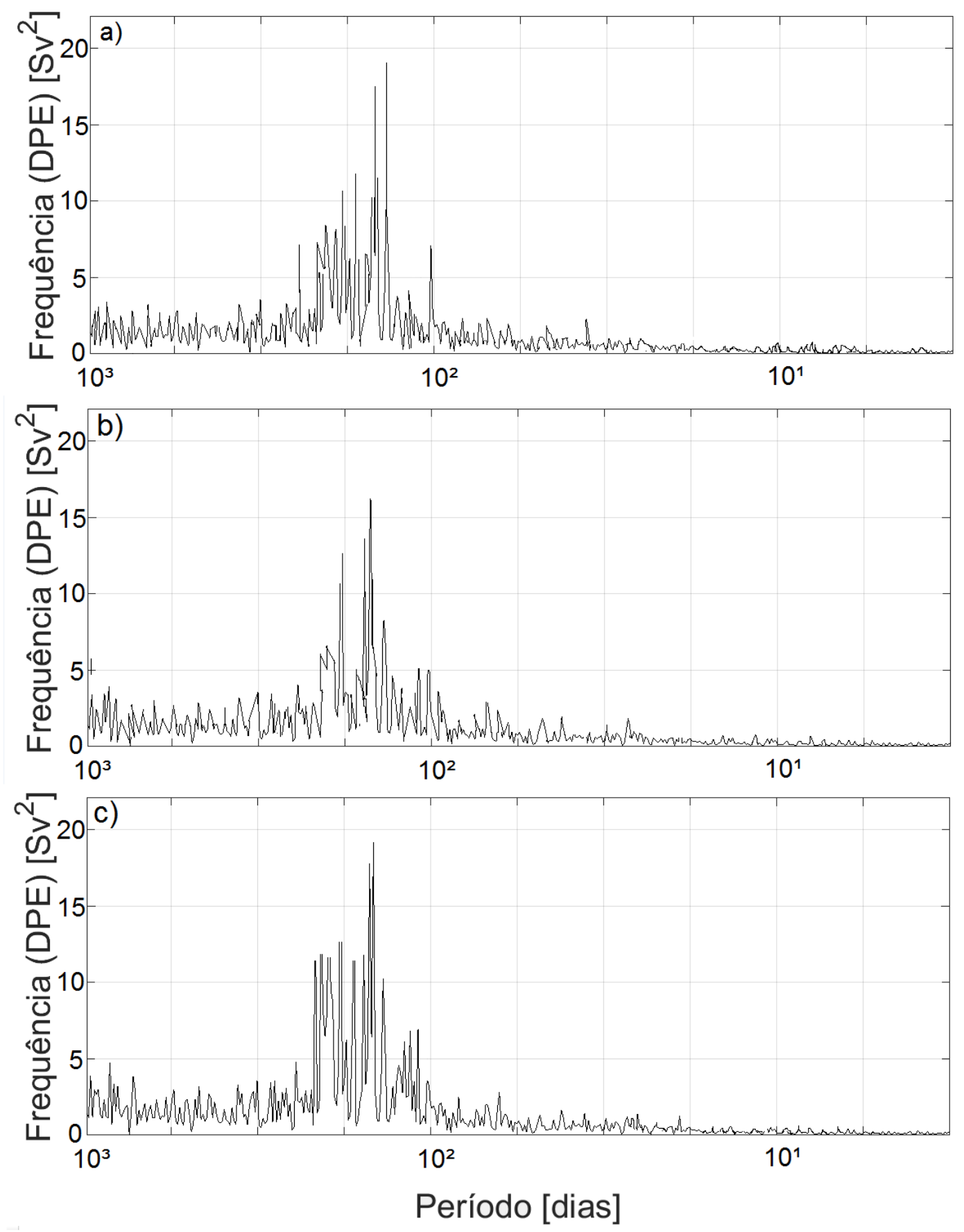

Figura 33. Análise espectral da variância da série temporal de volume integrado da CCOP nas latitudes $10^{\circ} \mathrm{S}$ (Painel a), $22^{\circ} \mathrm{S}$ (Painel b) e $34.5^{\circ} \mathrm{S}$ (Painel c) calculado a partir do HYCOM usando um comprimento de janela de 2 anos com $50 \%$ de sobreposição.

O HYCOM mostrou uma variância maior em $10^{\circ} \mathrm{S}$, possivelmente pelo fato dessa região estar mais próxima da bifurcação do ramo mais ao sul da Corrente Sul Equatorial $\left(10^{\circ} \mathrm{S}\right)$, onde ocorre a origem da CB e da CNB (Stramma 1991; da Silveira, de Miranda, and Brown 1994). De modo geral, o HYCOM apresentou maior variância quando comparado ao ECCO, isto se deve ao fato do HYCOM possuir maior resolução espacial. 
Tabela 8. Variância do transporte de volume da CCOP em faixas de períodos obtidas através do ECCO para as latitudes $10^{\circ} \mathrm{S}$ (Painel a), $22^{\circ} \mathrm{S}$ (Painel b) e $34.5^{\circ} \mathrm{S}$ (Painel c).

\begin{tabular}{|c|c|c|c|c|c|c|}
\hline Período (dias) & \multicolumn{3}{|c|}{ Variância $\left(\mathbf{S v}^{2}\right)$} & \multicolumn{3}{|c|}{$\begin{array}{c}\text { Porcentagem da } \\
\text { variância total }(\%)\end{array}$} \\
\hline & $10^{\circ} \mathrm{S}$ & $22^{\circ} \mathrm{S}$ & $34.5^{\circ} \mathrm{S}$ & $10^{\circ} \mathrm{S}$ & $22^{\circ} \mathrm{S}$ & $34.5^{\circ} \mathrm{S}$ \\
\hline 5 a 50 & 37,3 & 33, & 37,2 & 11,5 & 14,7 & 12,1 \\
\hline 50 & 90 & 88 & & 36,3 & 32,9 & 31,6 \\
\hline 160 a 190 & 30,1 & 30,5 & 29.2 & 9.8 & 9.9 & 10,5 \\
\hline 190 a 300 & 32,6 & 34,3 & 31,3 & 13,9 & 11,5 & 14,0 \\
\hline 300 a 400 & 35 & 33,4 & 31.5 & 17.7 & 18,1 & 19.0 \\
\hline 400 a 1000 & 19,9 & 21,7 & 20,3 & 7,3 & 8,7 & 7,9 \\
\hline$>1000$ & 9,1 & 10,4 & 11,6 & 3,4 & 3,2 & 4,7 \\
\hline
\end{tabular}

\subsection{Correlação entre a CCOP e a AMOC}

A CCOP faz parte do membro inferior da AMOC, e deste modo, seu padrão irá influenciar nos fluxos de calor e água doce do Atlântico. Portanto um dos objetivos deste trabalho foi verificar se existe uma correlação $\left(r_{x y}\right)$ entre essa corrente profunda e a AMOC. A Figura 34 representa a série temporal da anomalia do transporte de volume da CCOP (em preto) e da AMOC (em vermelho), no período entre 1992 e 2015 nas latitudes $10^{\circ} \mathrm{S}$ (Painel a), $22^{\circ} \mathrm{S}$ (Painel b) e $34.5^{\circ} \mathrm{S}$ (Painel c), obtida através do HYCOM. Em $10^{\circ} \mathrm{S}$ (Painel a), podemos ver que existe uma correlação positiva ( $\mathrm{r}=0,7)$, que é considerada como forte (SATANTON and Galton 2001), entre a CCOP e a AMOC. Na correlação negativa os picos possuem sinais opostos, ou seja, quando ocorre um aumento de transporte da CCOP, acontece também um aumento de transporte da AMOC. Isto ocorre pois os sinais das velocidades da CCOP e da AMOC são opostos. Em $22^{\circ} \mathrm{S}$ (Painel b) e $34.5^{\circ} \mathrm{S}$ (Painel c) ocorre o oposto, isto é, a correlação é positiva, no valor de $r=0,5$ (moderada) e $r=0,4$ (fraca), respectivamente. Vemos que os valores da correlação com a AMOC se reduz conforme a CCOP segue seu trajeto pelo Atlântico Sul, tendo estatística substancial somente em $10^{\circ} \mathrm{S}$.

As mesmas análises foram efetuadas utilizando o ECCO, como mostra a Figura 35, no qual vemos a série temporal da anomalia de transporte de volume da CCOP (em preto) e da AMOC (em azul), no período entre 1992 e 2015 nas latitudes $10^{\circ} \mathrm{S}$ (Painel a), $22^{\circ} \mathrm{S}$ (Painel b) e $34.5^{\circ} \mathrm{S}$ (Painel c). Os resultados são bastante similares aos encontrados pelo HYCOM. Em $10^{\circ} \mathrm{S}$ (Painel a) a correlação também foi de $\mathrm{r}=-0,7$, sendo considerada como forte. As latitudes de $22^{\circ} \mathrm{S}$ (Painel b) e $34.5^{\circ} \mathrm{S}$ (Painel c) apresentaram uma correlação negativa fraca, de $\mathrm{r}=-0,4$. Foi visto em ambos os modelos que somente a latitude $10^{\circ} \mathrm{S}$ apresentou correlação classificada como forte. Nas demais latitudes fica difícil tirar conclusões mais profundas sobre essa relação. 

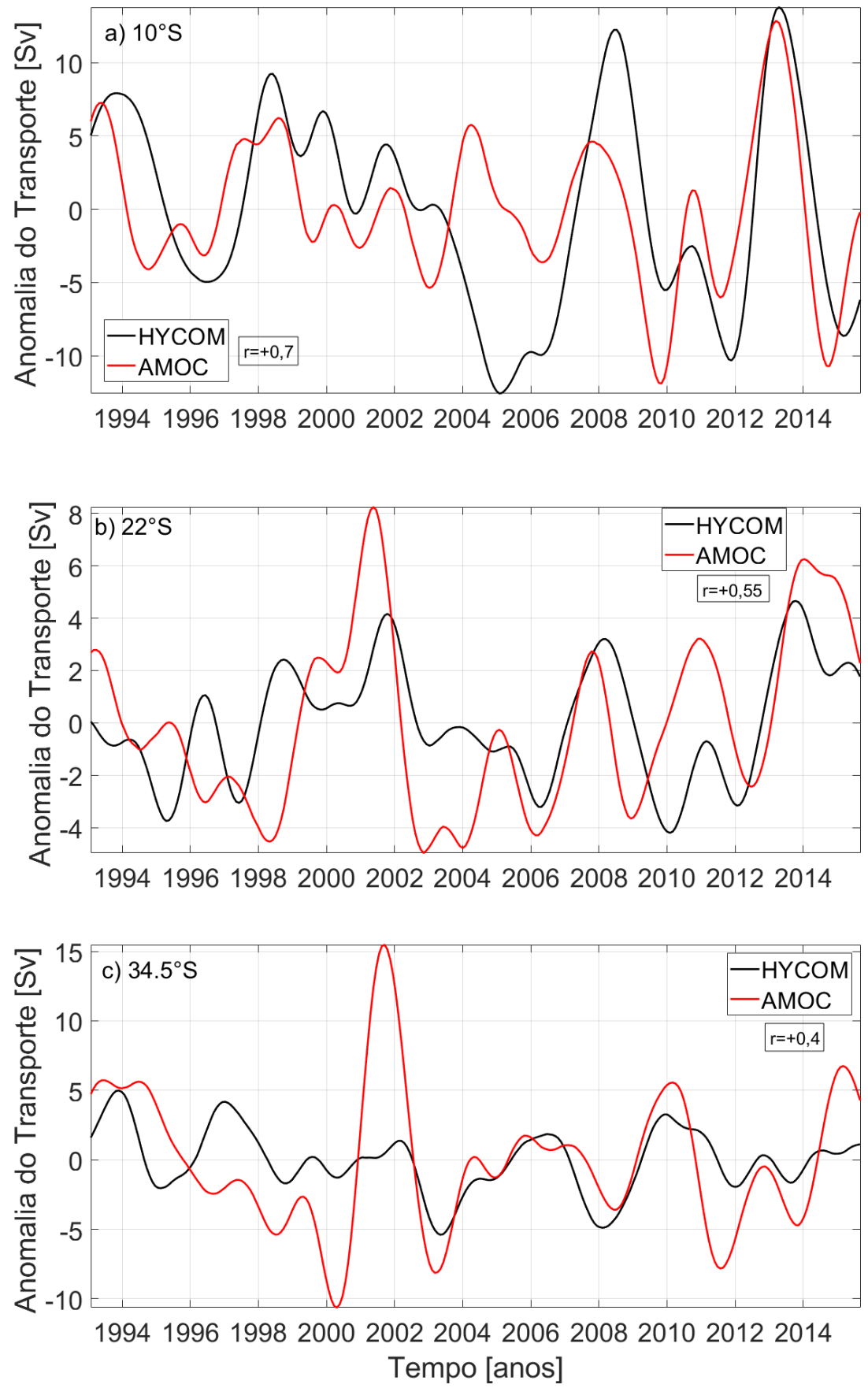

Figura 34. Anomalia do transporte de volume nas latitudes $10^{\circ} \mathrm{S}$ (Painel a) e $22^{\circ} \mathrm{S}$ (Painel b) e $34.5^{\circ} S$ (Painel c) entre 1992 e 2015. As linhas em preto são referentes ao HYCOM e as linhas em vermelho da AMOC. 

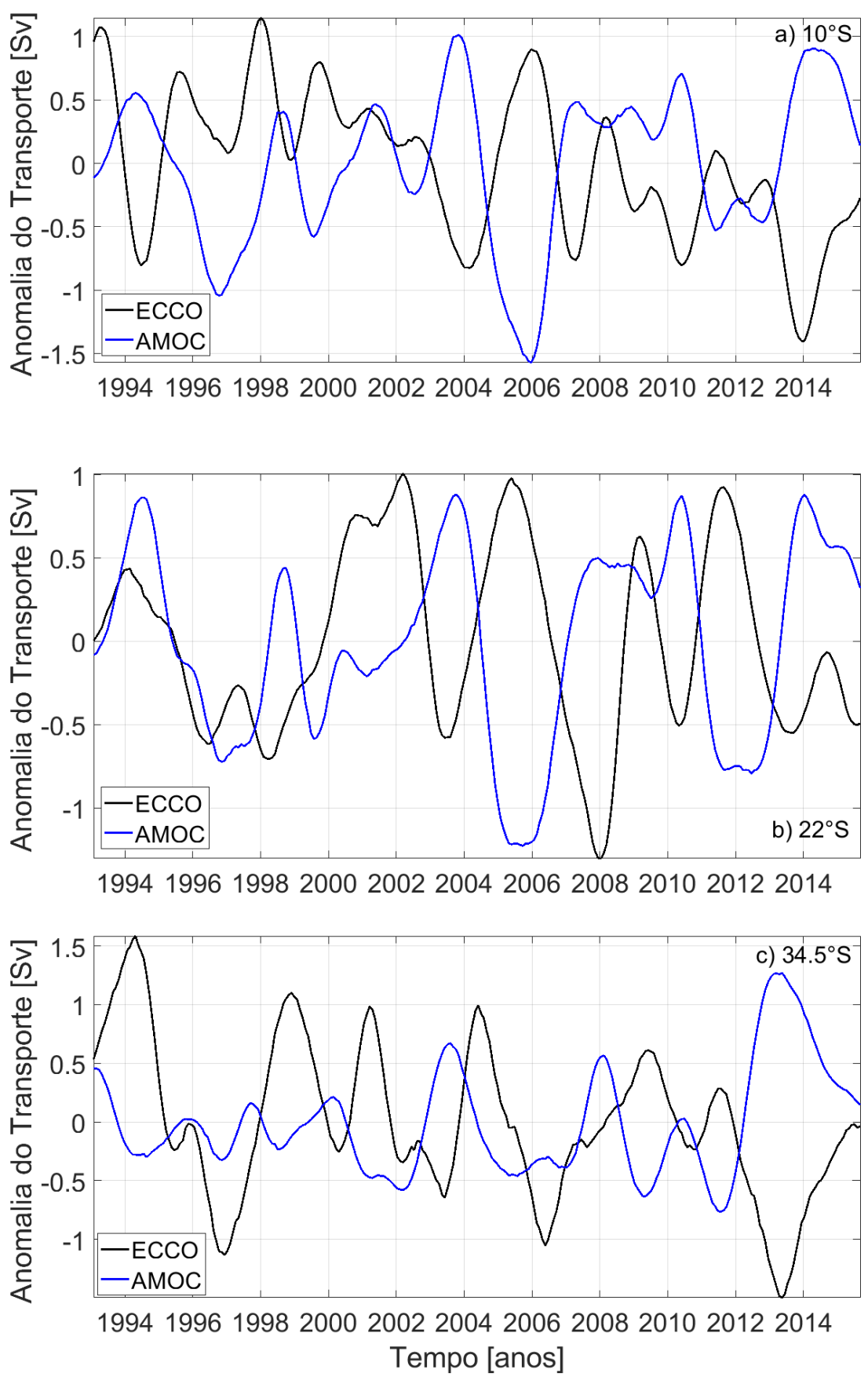

Figura 35. Anomalia do transporte de volume nas latitudes $10^{\circ} \mathrm{S}$ (Painel a) e $22^{\circ} \mathrm{S}$ (Painel b) e $34.5^{\circ} \mathrm{S}$ (Painel c) entre 1992 e 2015. As linhas em preto são referentes ao ECCO e as linhas em azul da AMOC. 


\section{Conclusão}

A Corrente de Contorno Oeste Profunda (CCOP) transporta massas de águas frias recém ventiladas do norte do Atlântico Norte para o Atlântico Sul através do contorno oeste da bacia. Essa corrente é responsável em carregar uma porção significativa do volume profundo do Atlântico como parte da MOC. Deste modo, a variabilidade observada na CCOP tem um impacto importante no fluxo meridional de calor, água doce e volume através do Atlântico, que por sua vez será notável em escalas regional e global. Entender o funcionamento da AMOC é essencial para compreender o clima, por causa de seu fluxo de calor meridional. Portanto, é necessário entender quais são e como funcionam os mecanismos que impulsionam o sistema da AMOC. Latif et al. (2007) mostrou que existe relação entre a convecção profunda, a CCOP e a MOC.

O objetivo principal deste trabalho foi a caracterização da CCOP no oceano Atlântico Sul. Deste modo, foi determinado a intensidade e variabilidade da CCOP, assim como o seu transporte de volume. Foram utilizadas as saídas de 2 modelos oceânicos, o HYbrid Coordinate Ocean Model (HYCOM) e o Estimating the Circulation Climate of the Ocean (ECCO) para investigar a presença da CCOP na região de estudo e analisar a sua variabilidade temporal e espacial. Além disso, foram usados dados de correntômetros instalados nos instrumentos PIES em $34.5^{\circ}$ S no Atlântico Sul.

Com o uso dos modelos HYCOM e ECCO no período entre 1992 e 2015, foram selecionadas três latitudes $\left(10^{\circ} \mathrm{S}, 14^{\circ} \mathrm{S}, 18^{\circ} \mathrm{S}, 22^{\circ} \mathrm{S}, 26^{\circ} \mathrm{S}, 30^{\circ} \mathrm{S}\right.$ e $\left.34.5^{\circ} \mathrm{S}\right)$ entre as longitudes de $55^{\circ} \mathrm{W}$ e $32^{\circ} \mathrm{W}$ ), no qual os perfis de temperatura e salinidade das saídas dos modelos foram comparados com perfis médios climatológicos do World Ocean Altas 2018 (WOA18). Foi usado o método estatístico Skill Score para avaliar a precisão dos modelos numéricos quando comparados com os dados do WOA18. Os resultados obtidos foram de 0,90 e 0,81 (HYCOM) e 0,93 e 0,92 (ECCO) para temperatura e salinidade, respectivamente. Ambos os modelos apresentaram os melhores resultados abaixo de $1500 \mathrm{~m}$, e este fato é muito importante, pois a CCOP é encontrada abaixo dessa profundidade. Portanto, os modelos se mostraram capazes de reproduzir as características oceânicas.

A identificação da CCOP foi baseada nos dados de temperatura, salinidade e densidade neutra, a partir das definições utilizadas por Preu et al. (2013). Através desses critérios, a posição da CCOP teve variação durante o seu percurso pelo Atlântico Sul, variando entre $1500 \mathrm{~m}$ e $3500 \mathrm{~m}$ de profundidade. Com a utilização dos correntômetros, a velocidade média obtida pelo 
CPIES (AA) foi de $2,83 \mathrm{~cm} \cdot \mathrm{s}^{-1}$ e $1,48 \mathrm{~cm} \cdot \mathrm{s}^{-1}$ pelo CPIES (BB). Analisando as regiões mais próximas o possível dos locais de instalação dos CPIES, as velocidades médias obtidas pelo $\mathrm{HYCOM}$ em $34.5^{\circ} \mathrm{S}$, nas longitudes de $50^{\circ} 31.2^{\prime} \mathrm{W}$ e $48^{\circ} 30.5^{\prime} \mathrm{W}$ foram de $-2,48 \pm 3,5 \mathrm{~cm} . \mathrm{s}^{-1}$ e $-1,43 \pm 2,7 \mathrm{~cm} . \mathrm{s}^{-1}$, respectivamente. Em relação ao ECCO, as velocidades em $34.5^{\circ} \mathrm{S}$ nas longitudes de $50.5^{\circ} \mathrm{W}$ e $48.5^{\circ} \mathrm{W}$ correspondem à $-1,78 \pm 1,5 \mathrm{~cm} . \mathrm{s}^{-1}$ e $-0,85 \pm 0,4 \mathrm{~cm} . \mathrm{s}^{-1}$, respectivamente. Apesar das velocidades médias estarem na mesma ordem de grandeza, vemos que as velocidades obtidas pelos modelos possuem sentido oposto as velocidades dos CPIES.

Meinen et al. (2017) observaram que em julho de 2009, entre maio e junho de 2012 e entre fevereiro e e março de 2014 houve um transporte intenso e anômalo para norte na camada profunda em $34.5^{\circ} \mathrm{S}$. Eles notaram que esses eventos intensos de transporte são suficientemente grandes quando o fluxo integrado da APAN reverte seu sinal, e isto indica que a recirculação offshore ao norte às vezes excede a fluxo para o sul do própria CCOP. Logo, observamos que os modelos não foram capazes de captar esse transporte intenso e anômalo que ocorreu entre 2009 e 2014.

Os valores de transporte de volume foram calculados para as latitudes de $10^{\circ} \mathrm{S}, 14^{\circ} \mathrm{S}$, $18^{\circ} \mathrm{S}, 22^{\circ} \mathrm{S}, 26^{\circ} \mathrm{S}, 30^{\circ} \mathrm{S}$ e $34.5^{\circ} \mathrm{S}$. Observamos que as médias de transporte da CCOP vão decrescendo ao longo do percurso pelo Atlântico Sul, o que é corroborado pelo trabalho da Garzoli et al. (2015). Foi visto que a CCOP está centrada entre 2000 e 2500 m e que o fluxo observado ao seu lado com velocidade similar e sentido oposto são recirculações da corrente. Essas recirculações da CCOP são comumente observadas no Atlântico Norte (Talley et al. 2011). Além disso, durante o seu percurso pelo Atlântico sul, a CCOP é influenciada pela batimetria de fundo e seu transporte vai decrescendo ao longo de seu trajeto.

Através do HYCOM, vimos que a CCOP centrada entre 2200 m 2500 m com velocidade média em torno de $-0,1 \pm 0,9 \mathrm{~m} \cdot \mathrm{s}^{-1}$ em $10^{\circ} \mathrm{S}$ e $14^{\circ} \mathrm{S}$. Em $18^{\circ} \mathrm{S}$, a CCOP reduz sua largura e se intensifica, e deste modo, a velocidade máxima fica em torno de $-0,19 \pm 0,2 \mathrm{~m} \cdot \mathrm{s}^{-1}$. Após a passagem pela latitude $22^{\circ} \mathrm{S}$, na região da Cadeia Vitória Trindade, a intensidade máxima do fluxo diminui para $-0,11 \pm 0,4 \mathrm{~m} . \mathrm{s}^{-1}$ e sua largura também se reduz. Essa redução no transporte da CCOP também foi observada por Garzoli et al. (2015). Em $30^{\circ} \mathrm{S}$ vemos novamente uma intensificação da corrente, possivelmente relacionada com a Bifurcação de Santos. Em $34.5^{\circ} \mathrm{S}$, a CCOP está fraca, com velocidades máximas em torno de $-0,05 \pm 0,03 \mathrm{~m} \cdot \mathrm{s}^{-1}$ e menos profunda (centrada em torno de $1500 \mathrm{~m}$ ).

Em relação ao ECCO, foram observadas velocidades máximas mais baixas para da 
CCOP quando comparado ao HYCOM. Em $10^{\circ} \mathrm{S}$, a CCOP está centrada em torno de 2250 $\mathrm{m}$, com velocidades máximas em torno de $-0,045 \pm 0,03 \mathrm{~m} \cdot \mathrm{s}^{-1}$. Em $14^{\circ} \mathrm{S}$, a corrente sofre uma redução de velocidade máxima para $-0,025 \pm 0,02 \mathrm{~m} . \mathrm{s}^{-1}$ e se centraliza próximo de $2000 \mathrm{~m}$. Em $18^{\circ} \mathrm{S}$ e $22^{\circ} \mathrm{S}$, a CCOP fica mais profunda (centrada em torno de $2500 \mathrm{~m}$ ) com velocidade máxima em torno de $-0,035 \pm 0,03 \mathrm{~m} . \mathrm{s}^{-1} \mathrm{e}-0,030 \pm 0,02 \mathrm{~m} . \mathrm{s}^{-1}$, respectivamente. A partir de $26^{\circ} \mathrm{S}$, a corrente novamente fica menos intensa e as velocidades se reduzem à $-0,015 \pm 0,025 \mathrm{~m} \cdot \mathrm{s}^{-1}$. Em $30^{\circ} \mathrm{S}$ a CCOP fica menos profunda (centrada em torno de $1500 \mathrm{~m}$ ) e se intensifica, exibindo velocidade máxima de $-0,030 \pm 0,02 \mathrm{~m} \cdot \mathrm{s}^{-1}$. Em $34.5^{\circ} \mathrm{S}$, a velocidade máxima tem um aumento $\left(-0,040 \pm 0,03 \mathrm{~m} \cdot \mathrm{s}^{-1}\right)$. Esse padrão de profundidade mais rasa da CCOP também é visto na seção meridional em $34.5^{\circ} \mathrm{S}$ obtida pelo HYCOM, no qual o centro da CCOP está próximo de $1500 \mathrm{~m}$ com velocidades máximas em torno de $-0,05 \pm 0,03 \mathrm{~m} \cdot \mathrm{s}^{-1}$.

A redução das velocidades em $22^{\circ} \mathrm{S}$ não foi observada pelo ECCO, assim como o aumento de velocidade em $34.5^{\circ} \mathrm{S}$, e possivelmente isto ocorre devido a diferença de resolução espacial dos modelos. De modo geral, as velocidades obtidas pelo ECCO foram menores que as obtidas pelo HYCOM. Foi possível constatar que ambos os modelos foram eficientes em representar a CCOP, exibindo velocidades corroborados por trabalhos já existentes na literatura. Em relação ao transporte de volume da CCOP, vimos que nas latitudes $10^{\circ} \mathrm{S}$ e $14^{\circ} \mathrm{S}$ os valores de transporte obtidos pelo HYCOM são maiores do que aqueles encontrados pelo ECCO. Essas médias estão associadas elevados valores de desvios padrões. Isto provavelmente ocorre por causa das recirculações que a CCOP sofre na camada da APAN ao longo do seu percurso, como já foi visto por Meinen et al. (2012, Hummels et al. (2015).

Os transporte de volume encontrados em $10^{\circ} \mathrm{S}$, isto é, (-19,9 $\pm 9,3 \mathrm{~Sv}$ pelo HYCOM) e (-15,6 $\pm 2,3 \mathrm{~Sv}$ pelo ECCO) corroboram com os resultados obtidos por Schott et al. (2005), onde foi estimado o transporte da CCOP em -22,5 Sv entre as profundidades de 800 a 4800 dbar e 16,9 Sv somente para a camada da APAN em $11^{\circ} \mathrm{S}$. Nas demais latitudes, os 2 modelos apresentaram resultados similares, todavia, o HYCOM foi capaz de assimilar algumas mudanças que o transporte da CCOP sofre em seu percurso, principalmente nas latitudes $22^{\circ} \mathrm{S}$ e $26^{\circ} \mathrm{S}$. Os dados de transporte de volume obtidos pelos modelos são estatisticamente semelhantes aos valores encontrados por Garzoli et al. (2015), levando em conta que estão dentro do domínio do desvio padrão. Nota-se que os dados alcançados pelo modelo ECCO estão mais próximos aos valores de referência, além de serem mais precisos (menor desvio padrão). Entende-se que o ECCO é um modelo muito eficiente na representação do oceano profundo e, portanto, da CCOP. 
Entretanto, o HYCOM foi capaz de assimilar mais características da CCOP durante seu trajeto. Deste modo, ambos os modelos foram eficientes na tarefa de representar a CCOP.

Com o intuito de avaliar o padrão da CCOP, estudar sua evolução no tempo e investigar quais são as possíveis causas de sua variabilidade, foram feitas séries temporais do transporte da CCOP para as sete latitudes selecionadas. Ao longo dos 22 anos da série temporal, o HYCOM mostrou que somente nas latitudes $10^{\circ} \mathrm{S}$ e $18^{\circ} \mathrm{S}$ existe uma tendência de aumento de transporte de volume de -0,054 Sv/ano e -0,083 Sv/ano, respectivamente, sendo que as demais latitudes mostram uma tendência de redução de transporte. Vimos que conforme a CCOP percorre o Atlântico Sul, a mesma perde intensidade, variabilidade, assim como seu volume de transporte.

Quando analisamos o ECCO, observamos em todas as latitudes uma tendência de aumento de transporte ao longo dos 22 anos da série temporal, exceto em $30^{\circ} \mathrm{S}$, onde há uma tendência de diminuição do transporte de volume 0,014 Sv/ano. De modo geral, observamos que em todas as latitudes há um padrão mais estável de transporte de volume quando comparamos com o HYCOM. Ainda assim, em ambos os modelos vemos que ocorre a redução do transporte total de volume conforme a CCOP segue para sul. Os resultados de tendência de transporte obtidos pelos modelos são pequenos, portanto, é difícil fazer suposições em relação a tendência de transporte de volume. As séries temporais de ambos os modelos mostraram que os dados de transporte de volume tinham alta frequência, o que está de acordo com os resultados encontrados na literatura, que mostraram que ao longo do oceano Atlântico, a variabilidade temporal da CCOP excede grandemente os valores médios de transporte (Schott et al. 2004; Hummels et al. 2015).

Os resultados obtidos neste trabalho indicam a existência de um ciclo anual da CCOP. Como queríamos analisar as séries temporais em termos de variabilidade interanual, esse provável ciclo anual foi removido da série temporal dos dados originais, fornecendo a anomalia do transporte de volume. Os resultados do HYCOM mostraram que as latitudes $10^{\circ} \mathrm{S}$ e $22^{\circ} \mathrm{S}$ apresentaram um padrão de aumento de transporte entre 1995-1998, 2004-2007 e 2009-2012. Em relação a latitude de $34.5^{\circ} \mathrm{S}$ o padrão é diferente e possui maior variabilidade, com aumento de transporte entre 1995-1997, 1999-2001, 2003-2004, 2007-2009, e 2011-2014. Além disso, a anomalia em $10^{\circ} \mathrm{S}$ varia entre $\pm 10 \mathrm{~Sv}$, enquanto que em $22^{\circ} \mathrm{S}$ e $34.5^{\circ} \mathrm{S}$, varia entre $\pm 5 \mathrm{~Sv}$.

Em relação ao ECCO vimos que na latitude $10^{\circ} \mathrm{S}$ houve um aumento de transporte após o ano de 2003 (anomalia negativa). Em $22^{\circ} \mathrm{S}$ e $34.5^{\circ} \mathrm{S}$ o padrão é mais similar entre elas, com aumento de transporte entre 1995 e 1999 e após 2005. Uma das diferenças em relação ao 
HYCOM é que a oscilação de anomalia do transporte é bem menor, sendo menor do que $\pm 2 \mathrm{~Sv}$ nas 3 latitudes. Notamos que ambos os modelos mostram um padrão similar nas latitudes $22^{\circ} \mathrm{S}$ e $34.5^{\circ} \mathrm{S}$.

Usando o HYCOM, vimos que a porcentagem de variação explicada pelo período anual ou semestral é aproximadamente $19 \%$ cada, ou seja, com energia moderada nesses períodos. Portanto, o ciclo anual foi removido. O período de maior concentração de energia foi o mesmo para as 3 latitudes, ou seja, entre 50 e 160 dias. Entretanto, também observamos alguns picos espectrais na faixa entre 5 e 50 dias. Através da análise espectral da variância das séries temporais de transporte de volume integrado da CCOP, usando um comprimento de janela de 2 anos com $50 \%$ de sobreposição através do método de Welch, foi visto que existe um pico de energia centrado em torno de 120-160 dias nas 3 latitudes.

Através do ECCO, a porcentagem de variação explicada pelo período anual ou semestral é por volta de $18 \%$. O período de maior concentração de energia também foi entre o período de 50 e 160 dias, sendo que o pico de energia foi visto em torno de 130 e 160 dias. É válido atentar de que a variância dos dados do ECCO foi menor do que a do HYCOM, conforme já tínhamos visto nos resultados anteriores. O resultado de maior variância em $10^{\circ} \mathrm{S}$ mostrado pelo HYCOM provavelmente tem relação com o fato dessa região estar mais próxima da bifurcação do ramo mais ao sul da Corrente Sul Equatorial $\left(10^{\circ} \mathrm{S}\right)$, onde ocorre a origem da $\mathrm{CB}$ e da CNB (Stramma 1991; da Silveira, de Miranda, and Brown 1994). De modo geral, o HYCOM apresentou maior variância quando comparado ao ECCO, isto se deve ao fato do HYCOM possuir maior resolução espacial.

Conforme já foi dito, a CCOP é conhecida como a camada inferior da AMOC e, portanto, é de vital importância ter conhecimento sobre a relação entre essa corrente de fundo e a AMOC. As análises do HYCOM mostraram que nas latitudes $10^{\circ} \mathrm{S}, 22^{\circ} \mathrm{S}$ e $34.5^{\circ} \mathrm{S}$ a correlação foi de $r=0,7$ (forte), $r=0,55$ (moderada) e $r=0,4$ (fraca), respectivamente. Portanto, vemos que somente a latitude de $10^{\circ} \mathrm{S}$ mostrou correlação com estatística substancial com a AMOC. Foi visto que os valores da correlação com a AMOC se reduz conforme a CCOP segue seu trajeto pelo Atlântico Sul. O ECCO apresentou resultados similares ao HYCOM, no qual a correlação em $10^{\circ} \mathrm{S}, 22^{\circ} \mathrm{S}$ e $34.5^{\circ} \mathrm{S}$ foi de $\mathrm{r}=-0,7$ (forte), $\mathrm{r}=-0,4$ (fraca) e $\mathrm{r}=-0,4$ (fraca), respectivamente.

Na correlação negativa os picos possuem sinais opostos, ou seja, podemos supor que em $10^{\circ} \mathrm{S}$, quando ocorre um aumento de transporte da CCOP, também acontece um aumento de transporte da AMOC, isto porque as velocidades dos transportes da CCOP e da AMOC são 
opostas. Nas demais latitudes, como os resultados de correlação foram pequenos, podemos aferir que não existe relação em a CCOP nessas latitudes e a AMOC. Este trabalho foi importante porque serviu como um primeiro passo para estudar a essa relação tão complexa entre a CCOP e a AMOC. Pesquisas futuras podem se aprofundar na questão de que somente a latitude $10^{\circ} \mathrm{S}$ apresentou correlação substancial com a AMOC. Foi de imensa importância constatar que tanto o HYCOM como e ECCO são capazes de reproduzir as características da CCOP no Atlântico Sul, e isto pode servir como base para estudos futuros. 


\section{Referências}

[Aguirre 2013] Aguirre, Antonio. 2013. "Uma introdução à análise espectral de séries temporais econômicas." Nova Economia 5, no. 1.

[Biló et al. 2014] Biló, Tiago C, I Silveira, César B Rocha, and Wellington Ceccopieri. 2014. “On the Brazil Current thickening in Santos Basin (23-28 S).” OSM, ID, vol. 14707.

[Bleck 2002] Bleck, Rainer. 2002. "An oceanic general circulation model framed in hybrid isopycnic-Cartesian coordinates." Ocean modelling 4 (1): 55-88.

[Boebel et al. 1999] Boebel, Olaf, Claudia Schmid, Guillermo Podestá, and Walter Zenk. 1999. "Intermediate water in the Brazil-Malvinas Confluence Zone: A Lagrangian view." Journal of Geophysical Research: Oceans 104 (C9): 21063-21082.

[Bower and Hunt 2000] Bower, Amy S, and Heather D Hunt. 2000. "Lagrangian observations of the deep western boundary current in the North Atlantic Ocean. Part I: Large-scale pathways and spreading rates.” Journal of Physical Oceanography 30 (5): 764-783.

[Boyer 2018] Boyer, T.P.; Baranova, O.K.; Coleman C.; Garcia H.E.; Grodsky A.; Locarnini R.A.; Mishonov A.V.; O’Brien T.D.; Paver C.R.; Reagan J.R.; et al. 2018. "World Ocean Database 2018."

[Broecker 1979] Broecker, Wallace S. 1979. "A revised estimate for the radiocarbon age of North Atlantic Deep Water." Journal of Geophysical Research: Oceans 84 (C6): 3218-3226.

[Bryden, King, and McCarthy 2011] Bryden, Harry L, Brian A King, and Gerard D McCarthy. 2011. "South Atlantic overturning circulation at 24 S." Journal of Marine Research 69 (1): $38-55$.

[Caesar et al. 2018] Caesar, Levke, Stefan Rahmstorf, Alexander Robinson, G Feulner, and V Saba. 2018. "Observed fingerprint of a weakening Atlantic Ocean overturning circulation." Nature 556 (7700): 191.

[Cirano et al. 2006] Cirano, Mauro, Mauricio M Mata, Edmo JD Campos, and Núbia FR Deiró. 2006. "A circulação oceânica de larga-escala na região oeste do Atlântico Sul com base no modelo de circulação global OCCAM." Revista Brasileira de Geofísica 24 (2): 209-230.

[Commission et al. 2010] Commission, Intergovernmental Oceanographic, et al. 2010. "The International thermodynamic equation of seawater-2010: calculation and use of thermodynamic properties."

[Csanady 1967] Csanady, GT. 1967. "On the "resistance law" of a turbulent Ekman layer." journal of the Atmospheric Sciences 24 (5): 467-471. 
[da Silveira, de Miranda, and Brown 1994] da Silveira, Ilson CA, Luiz B de Miranda, and Wendell S Brown. 1994. "On the origins of the North Brazil Current." Journal of Geophysical Research: Oceans 99 (C11): 22501-22512.

[Delworth, Manabe, and Stouffer 1993] Delworth, T, S Manabe, and RJ Stouffer. 1993. "Interdecadal variations of the thermohaline circulation in a coupled ocean-atmosphere model." Journal of Climate 6 (11): 1993-2011.

[Dengler et al. 2004] Dengler, Marcus, FA Schott, Carsten Eden, Peter Brandt, Jürgen Fischer, and Rainer J Zantopp. 2004. "Break-up of the Atlantic deep western boundary current into eddies at 8 S." Nature 432 (7020): 1018.

[Diz and Barker 2015] Diz, Paula, and Stephen Barker. 2015. "Linkages between rapid climate variability and deep-sea benthic foraminifera in the deep Subantarctic South Atlantic during the last 95 kyr." Paleoceanography and Paleoclimatology 30 (6): 601-611.

[Doney and Jenkins 1994] Doney, Scott C, and William J Jenkins. 1994. "Ventilation of the deep western boundary current and abyssal western North Atlantic: Estimates from tritium and 3He distributions." Journal of Physical Oceanography 24 (3): 638-659.

[Donohoe et al. 2013] Donohoe, Aaron, John Marshall, David Ferreira, and David Mcgee. 2013. "The relationship between ITCZ location and cross-equatorial atmospheric heat transport: From the seasonal cycle to the Last Glacial Maximum." Journal of Climate 26 (11): $3597-3618$.

[Emery 2001] Emery, WJ. 2001. "Water types and water masses." Encyclopedia of ocean sciences 6:3179-3187.

[Frajka-Williams et al. 2016] Frajka-Williams, E, CS Meinen, WE Johns, DA Smeed, A Duchez, AJ Lawrence, DA Cuthbertson, GD McCarthy, HL Bryden, MO Baringer, et al. 2016. "Compensation between meridional flow components of the Atlantic MOC at 26-N." Ocean Science 12 (2): 481.

[Fukumori 2002] Fukumori, Ichiro. 2002. “A partitioned Kalman filter and smoother.” Monthly Weather Review 130 (5): 1370-1383.

[Garzoli and Baringer 2007] Garzoli, Silvia L, and Molly O Baringer. 2007. "Meridional heat transport determined with expandable bathythermographs - Part II: South Atlantic transport." Deep Sea Research Part I: Oceanographic Research Papers 54 (8): 1402-1420.

[Garzoli et al. 2013] Garzoli, Silvia L, Molly O Baringer, Shenfu Dong, Renellys C Perez, and Qi Yao. 2013. "South Atlantic meridional fluxes." Deep Sea Research Part I: Oceanographic Research Papers 71:21-32. 
[Garzoli et al. 2015] Garzoli, Silvia L, Shenfu Dong, Rana Fine, Christopher S Meinen, Renellys C Perez, Claudia Schmid, Erik Van Sebille, and Qi Yao. 2015. "The fate of the deep western boundary current in the South Atlantic.” Deep Sea Research Part I: Oceanographic Research Papers 103:125-136.

[Giresse 2007] Giresse, Pierre. 2007. Tropical and sub-Tropical West Africa-marine and continental changes during the Late Quaternary. Volume 10. Elsevier.

[Gordon 1986] Gordon, Arnold L. 1986. “Interocean exchange of thermocline water.” Journal of Geophysical Research: Oceans 91 (C4): 5037-5046.

[Hummels et al. 2015] Hummels, Rebecca, Peter Brandt, Marcus Dengler, Jürgen Fischer, Moacyr Araujo, Doris Veleda, and Jonathan V Durgadoo. 2015. "Interannual to decadal changes in the western boundary circulation in the Atlantic at 11 S." Geophysical Research Letters 42 (18): 7615-7622.

[Johnson and Chambers 2013] Johnson, Gregory C, and Don P Chambers. 2013. "Ocean bottom pressure seasonal cycles and decadal trends from GRACE Release-05: Ocean circulation implications." Journal of Geophysical Research: Oceans 118 (9): 4228-4240.

[Kalnay et al. 1996] Kalnay, Eugenia, Masao Kanamitsu, Robert Kistler, William Collins, Dennis Deaven, Lev Gandin, Mark Iredell, Suranjana Saha, Glenn White, John Woollen, et al. 1996. "The NCEP/NCAR 40-year reanalysis project." Bulletin of the American meteorological Society 77 (3): 437-472.

[Kanzow, Send, and McCartney 2008] Kanzow, Torsten, Uwe Send, and M McCartney. 2008. "On the variability of the deep meridional transports in the tropical North Atlantic." Deep Sea Research Part I: Oceanographic Research Papers 55 (12): 1601-1623.

[Kim, Lee, and Fukumori 2007] Kim, Seung-Bum, Tong Lee, and Ichiro Fukumori. 2007. "Mechanisms controlling the interannual variation of mixed layer temperature averaged over the Niño-3 region." Journal of climate 20 (15): 3822-3843.

[Kistler et al. 2001] Kistler, Robert, Eugenia Kalnay, William Collins, Suranjana Saha, Glenn White, John Woollen, Muthuvel Chelliah, Wesley Ebisuzaki, Masao Kanamitsu, Vernon Kousky, et al. 2001. "The NCEP-NCAR 50-year reanalysis: monthly means CD-ROM and documentation.” Bulletin of the American Meteorological society 82 (2): 247-268.

[Kuhlbrodt et al. 2007] Kuhlbrodt, Till, Alexa Griesel, Marisa Montoya, Anders Levermann, Matthias Hofmann, and Stefan Rahmstorf. 2007. "On the driving processes of the Atlantic meridional overturning circulation." Reviews of Geophysics 45, no. 2.

[Latif et al. 2007] Latif, Mojib, Claus W Böning, Jürgen Willebrand, Arne Biastoch, 
F Alvarez-Garcia, Noel Keenlyside, and H Pohlmann. 2007. "Decadal to multidecadal variability of the Atlantic MOC: mechanisms and predictability." Washington DC American Geophysical Union Geophysical Monograph Series 173:149-166.

[Lee et al. 1990] Lee, Thomas N, William Johns, Rainer Zantopp, and Friedrich Schott. 1990. "Western boundary current structure and variability east of Abaco, Bahamas at 26.5 N." Journal of Physical Oceanography 20 (3): 446-466.

[Levermann et al. 2005] Levermann, Anders, Alexa Griesel, Matthias Hofmann, Marisa Montoya, and Stefan Rahmstorf. 2005. "Dynamic sea level changes following changes in the thermohaline circulation." Climate Dynamics 24 (4): 347-354.

[Levitus, Burgett, and Boyer 1994] Levitus, Sydney, Russell Burgett, and Timothy P Boyer. 1994. "World Ocean Atlas 1994. Volume 3. Salinity." Technical Report, National Environmental Satellite, Data, and Information Service, Washington, DC (United States).

[Liu et al. 2017] Liu, Wei, Shang-Ping Xie, Zhengyu Liu, and Jiang Zhu. 2017. "Overlooked possibility of a collapsed Atlantic Meridional Overturning Circulation in warming climate." Science Advances 3 (1): e1601666.

[Lynch-Stieglitz et al. 2007] Lynch-Stieglitz, Jean, Jess F Adkins, William B Curry, Trond Dokken, Ian R Hall, Juan Carlos Herguera, Joël J-M Hirschi, Elena V Ivanova, Catherine Kissel, Olivier Marchal, et al. 2007. "Atlantic meridional overturning circulation during the Last Glacial Maximum.” science 316 (5821): 66-69.

[Manabe and Stouffer 1988] Manabe, Syukuro, and RJ Stouffer. 1988. “Two stable equilibria of a coupled ocean-atmosphere model." Journal of Climate 1 (9): 841-866.

[Marshall et al. 1997] Marshall, John, Alistair Adcroft, Chris Hill, Lev Perelman, and Curt Heisey. 1997. "A finite-volume, incompressible Navier Stokes model for studies of the ocean on parallel computers." Journal of Geophysical Research: Oceans 102 (C3): 5753-5766.

[Marshall and Speer 2012] Marshall, John, and Kevin Speer. 2012. "Closure of the meridional overturning circulation through Southern Ocean upwelling." Nature Geoscience 5 (3): 171.

[Meinen et al. 2004] Meinen, Christopher S, Silvia L Garzoli, William E Johns, and Molly O Baringer. 2004. "Transport variability of the deep western boundary current and the Antilles Current off Abaco Island, Bahamas.” Deep Sea Research Part I: Oceanographic Research Papers 51 (11): 1397-1415.

[Meinen et al. 2017] Meinen, Christopher S, Silvia L Garzoli, Renellys C Perez, Edmo Campos, Alberto R Piola, Maria Paz Chidichimo, Shenfu Dong, and Olga T Sato. 2017. "Charac- 
teristics and causes of Deep Western Boundary Current transport variability at $34.5 \mathrm{~S}$ during 2009-2014.” Ocean Science 13 (1): 175.

[Meinen et al. 2013] Meinen, Christopher S, William E Johns, Silvia L Garzoli, Erik van Sebille, Darren Rayner, Torsten Kanzow, and Molly O Baringer. 2013. "Variability of the deep western boundary current at 26.5 N during 2004-2009.” Deep Sea Research Part II: Topical Studies in Oceanography 85:154-168.

[Meinen et al. 2012] Meinen, CS, AR Piola, RC Perez, and SL Garzoli. 2012. "Deep Western Boundary Current transport variability in the South Atlantic: preliminary results from a pilot array at 34.5 S." Ocean Science 8 (6): 1041-1054.

[Molinari et al. 1998] Molinari, Robert L, Rana A Fine, W Douglas Wilson, Ruth G Curry, Jeff Abell, and Michael S McCartney. 1998. "The arrival of recently formed Labrador Sea Water in the deep western boundary current at 26.5 N." Geophysical Research Letters 25 (13): 2249-2252.

[Morozov et al. 2010] Morozov, Eugene G, Alexander N Demidov, Roman Y Tarakanov, and Walter Zenk. 2010. Abyssal channels in the Atlantic Ocean: Water structure and flows. Springer Science \& Business Media.

[Muller, Zangenberg, and Nonato 1998] Muller, Ikeda, Y, N Zangenberg, and L Nonato. 1998. "Direct measurements of western boundary currents off Brazil between 20øS and 28øS." $J$. Geophys. Res 103:5429-5437.

[Murphy and Katz 1997] Murphy, Allan H, and Richard W Katz. 1997. Forecast verification. Economic Value of Weather and Climate Forecasts. Cambridge University Press.

[Orsi, Johnson, and Bullister 1999] Orsi, AH, GC Johnson, and JL Bullister. 1999. "Circulation, mixing, and production of Antarctic Bottom Water." Progress in Oceanography 43 (1): 55-109.

[Peterson and Stramma 1991] Peterson, Ray G, and Lothar Stramma. 1991. "Upper-level circulation in the South Atlantic Ocean.” Progress in oceanography 26 (1): 1-73.

[Piola and Matano 2001] Piola, AR, and RP Matano. 2001. "Brazil and Falklands (Malvinas) currents." Ocean currents: a derivative of the encyclopedia of ocean sciences, pp. 35-43.

[Preu et al. 2013] Preu, Benedict, F Javier Hernández-Molina, Roberto Violante, Alberto R Piola, C Marcelo Paterlini, Tilmann Schwenk, Ines Voigt, Sebastian Krastel, and Volkhard Spiess. 2013. "Morphosedimentary and hydrographic features of the northern Argentine margin: the interplay between erosive, depositional and gravitational processes and its con- 
ceptual implications." Deep Sea Research Part I: Oceanographic Research Papers 75:157174.

[Rahmstorf 1994] Rahmstorf, Stefan. 1994. "Rapid climate transitions in a coupled oceanatmosphere model." Nature 372 (6501): 82.

[Rahmstorf 2002] — 2002. "Ocean circulation and climate during the past 120,000 years." Nature 419 (6903): 207.

[Reid 1989] Reid, Joseph L. 1989. “On the total geostrophic circulation of the South Atlantic Ocean: Flow patterns, tracers, and transports." Progress in Oceanography 23 (3): 149-244.

[Reid 1994] — 1994. "On the total geostrophic circulation of the North Atlantic Ocean: Flow patterns, tracers, and transports." Progress in Oceanography 33 (1): 1-92.

[Rhein et al. 1996] Rhein, M, Friedrich Schott, Jürgen Fischer, Uwe Send, and Lothar Stramma. 1996. "The deep water regime in the Equatorial Atlantic." In The South Atlantic, 261-271. Springer.

[Richardson 1977] Richardson, Philip L. 1977. "On the crossover between the Gulf Stream and the Western Boundary Undercurrent.” Deep Sea Research 24 (2): 139-159.

[SATANTON and Galton 2001] SATANTON, JM, and Pearson Galton. 2001. "the peas: A brief history of linear regression for statistics instructors." Journal of Statistical Education 9, no. 3 .

[Sato 2005] Sato, O. T. 2005. "Fluxos de calor oceânico medido por meio de satélites." In Oceanografia por satélites, edited by Ronald B Sousa, 1, 148-165. São Paulo: Oficina de Textos.

[Schmittner 2005] Schmittner, Andreas. 2005. "Decline of the marine ecosystem caused by a reduction in the Atlantic overturning circulation." Nature 434 (7033): 628.

[Schott et al. 1993] Schott, Friedrich, Jürgen Fischer, Jörg Reppin, and Uwe Send. 1993. “On mean and seasonal currents and transports at the western boundary of the equatorial Atlantic.” Journal of Geophysical Research: Oceans 98 (C8): 14353-14368.

[Schott et al. 2005] Schott, Friedrich A, Marcus Dengler, Rainer Zantopp, Lothar Stramma, Jürgen Fischer, and Peter Brandt. 2005. "The shallow and deep western boundary circulation of the South Atlantic at 5-11 S." Journal of Physical Oceanography 35 (11): 2031-2053.

[Schott et al. 2004] Schott, Friedrich A, Rainer Zantopp, Lothar Stramma, Marcus Dengler, Jürgen Fischer, and Mathieu Wibaux. 2004. "Circulation and deep-water export at the western exit of the subpolar North Atlantic." Journal of Physical Oceanography 34 (4): 817-843. 
[Silveira et al. 2000] Silveira, Ilson Carlos Almeida, André Campos Kersten Schmidt, Edmo José Dias Campos, Sueli Susana de Godoi, and Yoshimine Ikeda. 2000. “A corrente do Brasil ao largo da costa leste brasileira.” Revista Brasileira de Oceanografia 48 (2): 171183.

[Smethie et al. 2000] Smethie, William M, Rana A Fine, Alfred Putzka, and E Peter Jones. 2000. "Tracing the flow of North Atlantic Deep Water using chlorofluorocarbons." Journal of Geophysical Research: Oceans 105 (C6): 14297-14323.

[Stommel, Arons, and Faller 1958] Stommel, Henry, AB Arons, and AJ Faller. 1958. "Some examples of stationary planetary flow patterns in bounded basins." Tellus 10 (2): 179-187.

[Stommel and Arons 1960] Stommel, Henry, and Arnold B Arons. 1960. "On the abyssal circulation of the world ocean-II. An idealized model of the circulation pattern and amplitude in oceanic basins." Deep Sea Research (1953) 6:217-233.

[Stramma 1991] Stramma, Lothar. 1991. "Geostrophic transport of the South Equatorial Current in the Atlantic.” Journal of Marine Research 49 (2): 281-294.

[Stramma and England 1999] Stramma, Lothar, and Matthew England. 1999. “On the water masses and mean circulation of the South Atlantic Ocean.” Journal of Geophysical Research: Oceans 104 (C9): 20863-20883.

[Swallow and Worthington 1961] Swallow, John C, and LV Worthington. 1961. "An observation of a deep countercurrent in the western North Atlantic.” Deep Sea Research (1953) 8 (1): 1-IN3.

[Talley 2003] Talley, Lynne D. 2003. “Shallow, intermediate, and deep overturning components of the global heat budget." Journal of Physical oceanography 33 (3): 530-560.

[Talley et al. 2011] Talley, Lynne D, George L Pickard, William J Emery, and James H Swift. 2011. Descriptive physical oceanography: an introduction. Academic press.

[Thornalley et al. 2018] Thornalley, David JR, Delia W Oppo, Pablo Ortega, Jon I Robson, Chris M Brierley, Renee Davis, Ian R Hall, Paola Moffa-Sanchez, Neil L Rose, Peter T Spooner, et al. 2018. "Anomalously weak Labrador Sea convection and Atlantic overturning during the past 150 years." Nature 556 (7700): 227.

[Timmermann et al. 2005] Timmermann, Axel, SI An, Uta Krebs, and Hugues Goosse. 2005. "ENSO suppression due to weakening of the North Atlantic thermohaline circulation." Journal of Climate 18 (16): 3122-3139.

[Toggweiler and Samuels 1998] Toggweiler, JR, and B Samuels. 1998. “On the ocean's large- 
scale circulation near the limit of no vertical mixing." Journal of Physical Oceanography 28 (9): 1832-1852.

[Tomczak and Large 1989] Tomczak, Matthias, and Daniel GB Large. 1989. "Optimum multiparameter analysis of mixing in the thermocline of the eastern Indian Ocean." Journal of Geophysical Research: Oceans 94 (C11): 16141-16149.

[Tomczak 2000] Tomczak, Mntthias. 2000. An introduction to online physical oceanography. Oceanography Society.

[Trenberth and Caron 2001] Trenberth, Kevin E, and Julie M Caron. 2001. "Estimates of meridional atmosphere and ocean heat transports." Journal of Climate 14 (16): 3433-3443.

[Vellinga and Wood 2002] Vellinga, Michael, and Richard A Wood. 2002. "Global climatic impacts of a collapse of the Atlantic thermohaline circulation." Climatic change 54 (3): $251-267$.

[Warren 1981] Warren, Bruce A. 1981. "The shallow oxygen minimum of the South Indian Ocean.” Deep Sea Research Part A. Oceanographic Research Papers 28 (8): 859-864.

[Weijer et al. 2002] Weijer, Wilbert, Wilhelmus PM De Ruijter, Andreas Sterl, and Sybren S Drijfhout. 2002. "Response of the Atlantic overturning circulation to South Atlantic sources of buoyancy." Global and Planetary Change 34 (3-4): 293-311.

[Welch 1967] Welch, Peter. 1967. "The use of fast Fourier transform for the estimation of power spectra: a method based on time averaging over short, modified periodograms." IEEE Transactions on audio and electroacoustics 15 (2): 70-73.

[Wilks 1995] Wilks, Daniel S. 1995. "Statistical methods in the atmospheric sciences, 1995." Library of Cataloging-in-publication, Academic Press: San Diego, CA, p. 465.

[Wunsch and Heimbach 2007] Wunsch, Carl, and Patrick Heimbach. 2007. "Practical global oceanic state estimation.” Physica D: Nonlinear Phenomena 230 (1-2): 197-208.

[Zangenberg and Siedler 1998] Zangenberg, Norbert, and Gerold Siedler. 1998. "Path of the North Atlantic deep water in the Brazil Basin.” Journal of Geophysical Research: Oceans 103 (C3): 5419-5428. 